\title{
VERIFICAÇÃO SIMULTÂNEA DOS ESTADOS LIMITES ÚLTIMOS E DE SERVIÇO EM ANÁLISES NÃO-LINEARES DE PEÇAS DE CONCRETO ARMADO SUBMETIDAS À FLEXÃO PURA
}

Geilson Márcio Albuquerque de Vasconcelos

Dissertação apresentada à Escola de Engenharia de São Carlos da Universidade de São Paulo, como parte dos requisitos para obtenção do título de Mestre em Engenharia de Estruturas.

Orientador: Prof. Associado Márcio Roberto Silva Corrêa 
Ficha catalográfica preparada pela Seção de Tratamento da Informação do Serviço de Biblioteca - EESC/USP

Vasconcelos, Geilson Márcio Albuquerque de

Verificação simultânea dos estados limites últimos e de serviço em análises não-lineares de peças de concreto

armado submetidas à flexão pura / Geilson Márcio

Albuquerque de Vasconcelos. -- São Carlos, 2005.

Dissertação (Mestrado) -- Escola de Engenharia de São Carlos-Universidade de São Paulo, 2005.

Área: Engenharia de Estruturas.

Orientador: Prof. Assoc. Márcio Roberto Silva Corrêa.

1. Análise não-linear física. 2. Segurança das

estruturas 3. Estruturas de concreto armado. 4. Estados limites. I. Título. 
Candidato: Engenheiro GEILSON MÁRCIO ALBUQUERQUE DE VASCONCELOS

Dissertação defendida e julgada em 06-05-2005 perante a Comissão Julgadora:

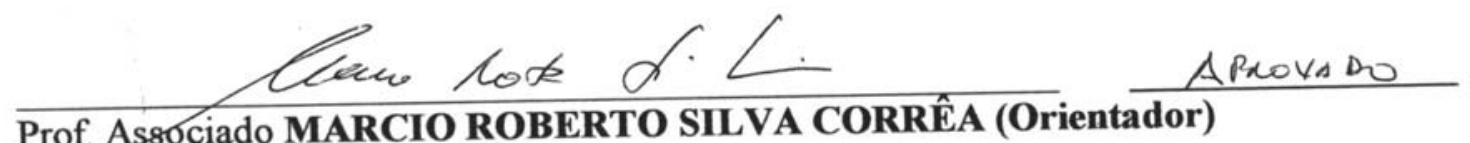
(Escola de Engenharia de São Carlos/USP)

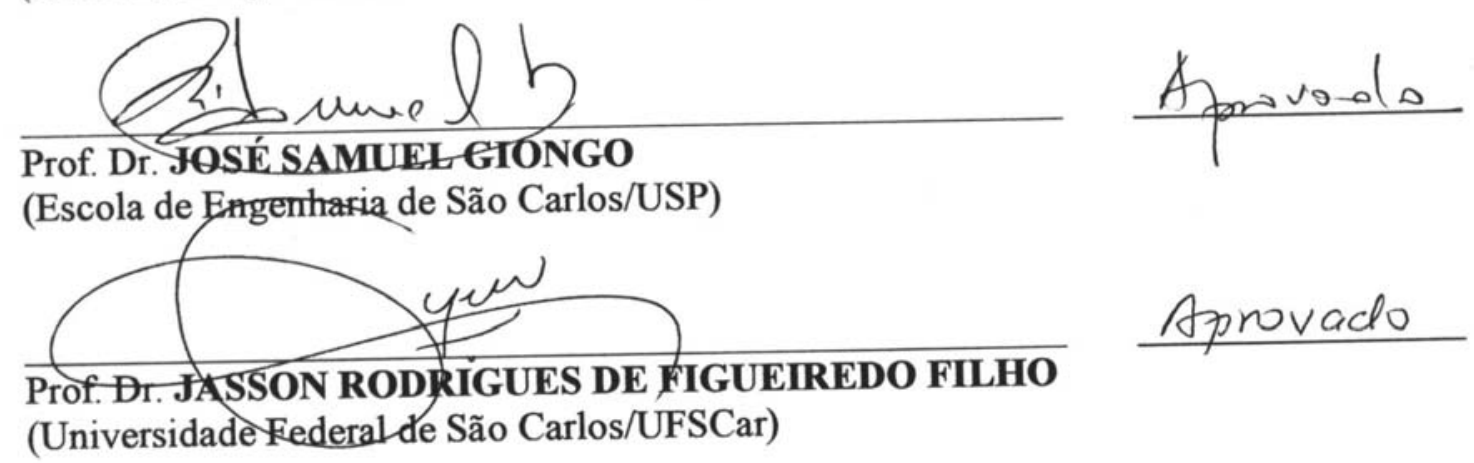

(Universidade Federalde São Carlos/UFSCar)

Prof. Associado MARCIO ROBERTO SILVA CORRÊA

Coordenador do Programa de Pós-Graduação em Engenharia

Civil (Engenharia de Estruturas)

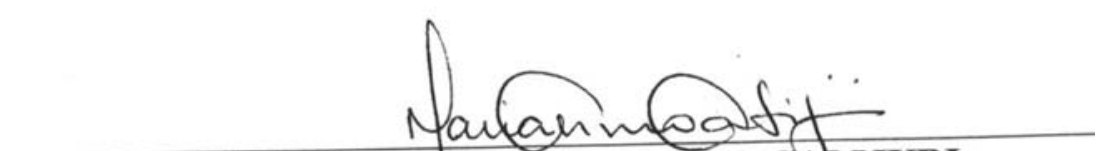

Profa. Titular MARIA DO CARMO CALIJURI

Presidente da Comissão de Pós-Graduação 


\section{DEDICATÓRIA}

Ao Senhor meu Deus pela força que me proporciona a cada dia e a minha Mãezinha do Céu pelo amor, carinho e entusiasmo durante toda minha vida.

Aos meus familiares que contribuíram para minha formação pessoal e profissional. Pelo carinho e amor em mim depositado durante todo esse tempo e que se motivam e se orgulham das minhas vitórias.

À minha esposa Lena Betânia Teixeira A. de Vasconcelos, pela imensa compreensão, carinho, confiança e amor nestes dois anos de mestrado em que fiquei distante de casa. Muito obrigado amor!

À minha filha Laís Regina. Amo-te demais filha. Pelas alegrias e satisfações passadas nos períodos de retorno à família. Foram momentos que me fortaleceram a continuar o mestrado, mesmo com a sofrida distância.

Aos meus pais Gilberto Teixeira de Vasconcelos e Margarida Maria de Albuquerque Vasconcelos; em especial à minha mamãe pelo amor, carinho, garra e dedicação na criação da nossa família e em minha formação. Muito obrigado Mamãe por tudo que tens feito por mim.

Aos meus irmãos Gilverlan e Gilciran pelo carinho e afeto.

À minha tia Maria Regina, que me proporcionou tantos ensinamentos. Obrigado por ter contribuído para minha formação profissional e pessoal. Amo-te muito titia. 


\section{AGRADECIMENTOS}

Ao professor e orientador Márcio Roberto Silva Corrêa, pelos ensinamentos e amizade desfrutados durante este período; pelo empenho e satisfação em transmitir seus conhecimentos.

Aos professores que compõem o Departamento de Engenharia de Estrutura da EESC/USP: gostaria de firmar meus sinceros agradecimentos ao professor José Samuel Giongo pelas sugestões e contribuições dadas durante o desenvolvimento deste trabalho e por sua amizade.

Ao professor Jasson Rodrigues de Figueiredo Filho da Universidade Federal de São Carlos - UFSCar pelas contribuições prestadas no exame de qualificação e na defesa do mestrado.

À professora Ruth de Gouvêa Duarte pelas sugestões e correções no texto do presente trabalho.

Aos funcionários do Departamento de Engenharia de Estruturas, em especial a Rosi Jordão, Maria Nadir Minatel e “Toninho" pela presteza em servir.

À CAPES - Coordenação de Aperfeiçoamento de Pessoal de Ensino Superior, pela bolsa que propiciou minha formação no mestrado.

Ao conterrâneo e amigo Edson Costa de Assis Júnior pelo convívio nestes dois anos. Sou bastante grato pelas contribuições dadas ao trabalho e pela amizade e conversas compartilhadas neste período tão importante para nós dois. Ao amigo alagoano Jefferson Lins da Silva pela companhia e amizade neste último ano.

Aos demais alagoanos que fizeram ou fazem parte do convívio neste período: Alexandre "Topó", André Dória, Eduardo Toledo, Fábio Lopes, Gustavo Codá, Jerônymo Pereira, Márcio Felix, Rafael Piatti, Saulo Almeida, Valber Pedrosa e Walter Oliveira. 
Aos amigos da turma e do Departamento de Engenharia de Estruturas, não irei agradecer individualmente, porque poderia deixar de citar alguém. Obrigado a todos pelo convívio e amizade conquistada.

Ao Projeto Universidades Renovadas (PUR) e aos amigos do Grupo de Perseverança e Partilha GPP - São Carlos, que durante o convívio deste a graduação ajudaram em minha formação como profissional do Reino de Deus.

Aos professores e amigos da Universidade Federal de Alagoas - UFAL que contribuíram para minha formação profissional e pessoal; em especial ao professor João Carlos Cordeiro Barbirato pelo convívio durante a graduação e incentivo à pesquisa científica. Aos companheiros do Programa Especial de Capacitação de Discentes de Engenharia Civil - PEC/Eng. Civil durante o tempo de convívio. 
"Trabalha como se tudo dependesse de ti e confia como se tudo dependesse de Deus".

Santo Inácio de Loyola

(1491-1552) 


\section{RESUMO}

VASCONCELOS, G.M.A. (2005). Verificação simultânea dos estados limites últimos e de serviços em análises não-lineares de peças de concreto armado submetidas à flexão pura. Dissertação (Mestrado) - Escola de Engenharia de São Carlos, Universidade de São Paulo.

Neste trabalho foram discutidos os aspectos de dimensionamento e verificação da segurança de elementos estruturais de concreto armado considerando a nãolinearidade dos materiais. O estudo abordou uma nova proposta para a verificação simultânea dos estados limites últimos (ELU) e dos estados limites de serviço (ELS) para elementos de concreto armado submetidos à flexão, voltada especialmente para aplicações considerando a não-linearidade física utilizando o método dos elementos finitos. As propostas alternativas apresentadas na consideração de coeficientes minoradores das resistências dos materiais, trataram da utilização de valores médios para as relações tensão-deformação e para as resistências dos materiais; valores de referência que permitiram a composição de coeficientes globais de segurança, que independem da ruptura ser causada por esgotamento da capacidade resistente do concreto ou do aço e, finalmente, valores médios para as relações tensão-deformação no aço e no concreto, com limitação das resistências em seus valores de projeto. Foram analisadas seções transversais retangulares e do tipo " $T$ " submetidas à flexão pura, com o uso das propostas alternativas. Foram, também, estudadas vigas isostáticas e hiperestáticas incluindo a verificação das reservas da capacidade resistente da estrutura, sendo que foi considerada a redistribuição dos esforços internos no caso hiperestático. As análises realizadas serviram de base para assumir-se que a terceira proposta anteriormente citada, é a mais adequada e a que atendeu, simultaneamente, às verificações dos ELU e ELS; o que a torna viável para aplicações práticas.

Palavras-chave: Análise não-linear física, segurança das estruturas, estruturas de concreto armado, estados limites. 


\begin{abstract}
VASCONCELOS, G.M.A. (2005). Simultaneous verification of the ultimate limit states and of serviceability in nonlinear analysis of reinforced concrete beams subjected to pure bending. M.Sc. Dissertation - Engineering School at São Carlos, São Paulo University, São Carlos.
\end{abstract}

The present work deals with dimensioning and verification of the safety conditions of reinforced concrete structural elements, taking into account the material non-linearity. It includes a new proposal for the simultaneous verification of the ultimate limit states (ULS) and the serviceability limit states (SLS) for reinforced concrete bending elements, enhancing Finite Element applications with physical nonlinearities. The alternative proposals for the material safety factors include the use of mean values for the stress-strain relationships and the strength of materials; reference values that allow the composition of global safety coefficients that do not dependent on the type of failure, brittle in the concrete or ductile in the steel and, finally, means values for the concrete and steel stress-strain relationships, keeping the stresses always lower than the design strength values. Rectangular and T-type cross-sectional areas in pure bending were analyzed, using the alternative proposals. Statically determinate and hyperstatic beams were also studied to verify the safety conditions, including the redistribution of the internal forces in the hyperstatic cases. According to the analyses performed it is apparent that the third proposal is the most adequate and satisfies simultaneously the ULS and SLS verifications, being viable for practical applications.

Keywords: Physical non-linear analysis, safety of the structures, reinforced concrete structures, limit states. 


\section{LISTA DE FIGURAS}

Figura 2.1 - Elemento finito tridimensional de barra. 09

Figura 2.2 - Elemento finito de seção transversal retangular estratificada. 10

Figura 2.3 - Diagrama tensão-deformação para compressão axial do concreto, CEB-FIP MC90.

Figura 2.4 - Diagrama tensão-deformação para tração axial do concreto, Figueiras (1983)

Figura 2.5 - Diagrama tensão-deformação para o aço - elastoplástico perfeito.

Figura 2.6 - Diagrama tensão-deformação para o aço - elastoplástico com encruamento.

Figura 3.1 - Formação de fissuras: a) sistemática e b) assistemática, Mollica Júnior (1986) [adaptada].

Figura 3.2 - Diagrama tensão-deformação do aço. 33

Figura 3.3 - Diagrama tensão-deformação do concreto C30, CEB-FIP MC90. 33

Figura 3.4 - Razão ente os momentos resistentes com diferentes resistência dos materiais - König et al. (1997) e Ahner \& Tue (1997) [adaptada]. 38

Figura 3.5 - Razão ente os momentos resistentes da seção retangular submetida à flexão simples.

Figura 3.6 - Seção transversal submetida à flexão: a) retangular e b) do tipo "T".

Medidas em $\mathrm{cm}$.

Figura 3.7 - Seção retangular submetida à flexão: a) sem armadura de compressão e b) armadura de compressão $(2 \phi 6,30 \mathrm{~mm})$.

Figura 3.8 - Seção retangular submetida à flexão: a) taxa de armadura de compressão $\rho=0,25 \%$ e b) taxa de armadura de compressão $\rho=0,50 \%$.

Figura 3.9 - Seção do tipo “T” submetida à flexão: a) sem armadura de compressão e b) armadura de compressão $(2 \phi 6,30 \mathrm{~mm})$. 
Figura 3.10 - Seção do tipo "T" submetida à flexão: a) taxa de armadura de compressão $\rho=0,25 \%$ e b) taxa de armadura de compressão $\rho=0,50 \%$.

Figura 4.1 - Segurança da seção transversal - flexão simples.

Figura 4.2 - Placa biapoiada - Wittek e Meiswinkel (2000). 50

Figura 4.3 - Discretização da placa biapoiada e estratificação da seção transversal......51

Figura 4.4 - Fator de carga vs. deslocamento - análises com valores médios e de referência.

Figura 4.5 - Fator de carga vs. deslocamento: a) análise com valores médios e b) análise com valores de referência.

Figura 4.6 - Fator de carga vs. deslocamento - análises com valores médios e de referência realizadas no presente trabalho.

Figura 4.7 - Viga contínua com dois vãos - Wittek e Meiswinkel (2000).

Figura 4.8 - Disposições das armaduras na viga contínua.

Figura 4.9 - Discretização da viga contínua e estratificação da seção transversal.

Figura 4.10 - Fator de carga vs. deslocamento - análises com valores médios e de referência.

Figura 4.11 - Fator de carga vs. deslocamento: a) análise com valores médios e b) análise com valores de referência.

Figura 4.12 - Fator de carga vs. deslocamento - análises com valores médios e de referência realizadas no presente trabalho.

Figura 4.13 - Viga biapoiada.

Figura 4.14 - Discretização da viga biapoiada e estratificação da seção transversal. ....61

Figura 4.15 - Fator de carga vs. deslocamento no meio do vão da viga biapoiada. 62

Figura 4.16 - Viga apoiada-engastada.

Figura 4.17 - Disposições das armaduras na viga apoiada-engastada.

Figura 4.18 - Discretização da viga apoiada-engastada e estratificação da seção transversal. 
Figura 4.19 - Fator de carga vs. deslocamento no vão da viga apoiada-engastada sem redistribuição. 66

Figura 4.20 - Fator de carga vs. deslocamento no vão da viga apoiada-engastada com redistribuição.

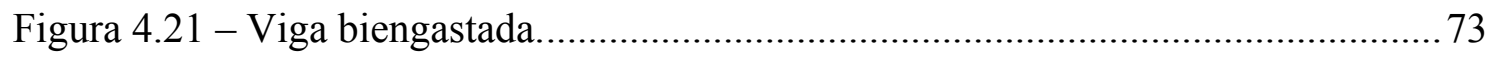

Figura 4.22 - Disposição das armaduras ao longo da viga biengastada. ........................ 74

Figura 4.23 - Discretização da viga biengastada e estratificação da seção transversal.. 74 Figura 4.24 - Fator de carga vs. deslocamento no vão da viga biengastada sem redistribuição 75

Figura 4.25 - Fator de carga $v s$. deslocamento no vão da viga biengastada: a) com redistribuição de $\delta=0,88$ e b) com redistribuição de $\delta=0,75$ .79

Figura 4.26 - Capacidade de rotação de rótulas plásticas, NBR 6118:2003 [adaptada].80 


\section{LISTA DE TABELAS}

Tabela 3.1 - Coeficientes ponderadores de ações variáveis, NBR 6118:2003. 23

Tabela 3.2 - Coeficientes $\gamma_{f}=\gamma_{f 1} \cdot \gamma_{f 3}$, NBR 8681:2003.

Tabela 3.3 - Valores do coeficientes de $\gamma_{c}$ e $\gamma_{s}$, NBR 6118:2003. .26

Tabela 3.4 - Limites de fissuração, NBR 6118:2003.

Tabela 3.5 - Limites para deslocamentos, NBR 6118:2003.

Tabela 4.1 - Segurança das seções transversais críticas da viga contínua. 54

Tabela 4.2-Resistência dos materiais.

Tabela 4.3 - Flechas da viga biapoiada.

Tabela 4.4 - Momentos fletores máximos na viga apoiada-engastada sem redistribuição para análise não-linear.

Tabela 4.5 -Flechas da viga apoiada-engastada. 68

Tabela 4.6 - Momentos fletores máximos na viga apoiada-engastada com redistribuição para análise não-linear.

Tabela 4.7 - Flechas da viga apoiada-engastada com redistribuição $(\delta=0,93)$.

Tabela 4.8 - Resultados das análises com ou sem redistribuição dos esforços solicitantes da viga apoiada-engastada.

Tabela 4.9 - Momentos fletores máximos na viga biengastada sem redistribuição para análise não-linear. .76

Tabela 4.10 - Flechas da viga biengastada. .76

Tabela 4.11 - Momentos fletores e armaduras da viga biengastada com redistribuição.

Tabela 4.12 - Limite da capacidade de rotação da rótula plástica para os apoios. .81

Tabela 4.13 - Rotações das rótulas plásticas para as análises não-lineares. .81

Tabela 4.14 - Aberturas de fissuras na viga biengastada. 82 


\section{SUMÁRIO}

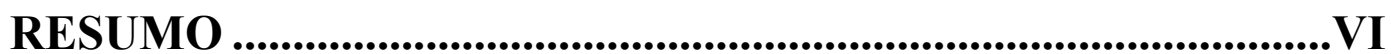

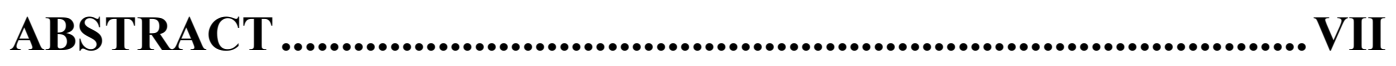

LISTA DE FIGURAS ......................................................... VIII

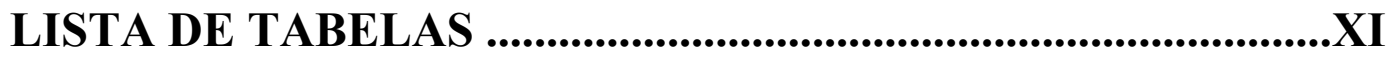

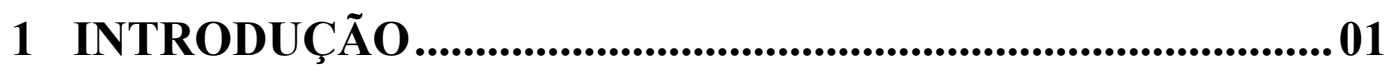

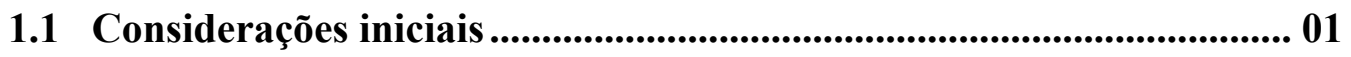

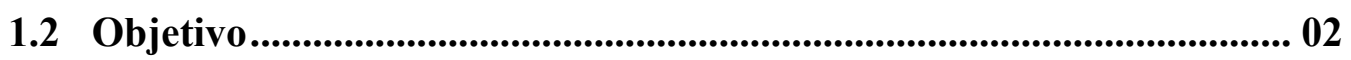

1.3 Justificativa ................................................................................. 03

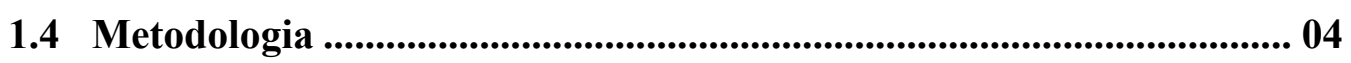

2 NÃO-LINEARIDADE FÍSICA ..............................................06

2.1 Considerações iniciais ............................................................................... 06

2.2 Breve histórico ................................................................................. 06

2.3 Método numérico utilizado ..................................................................... 08

2.4 Campo de aplicação ................................................................................... 11

2.5 Modelos constitutivos dos materiais ..................................................... 11

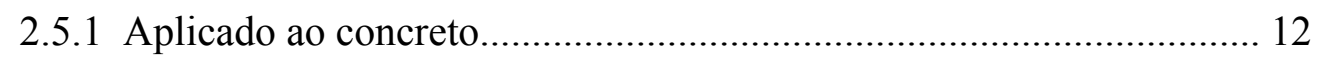

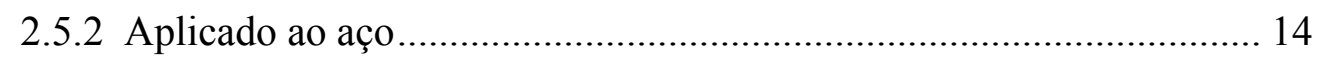

3 ABORDAGENS NORMATIVAS E NOVA CONSIDERAÇÃO DE SEGURANÇA ............................................................................................... 16

3.1 Considerações iniciais ................................................................... 16

3.2 Métodos de dimensionamento.......................................................... 16

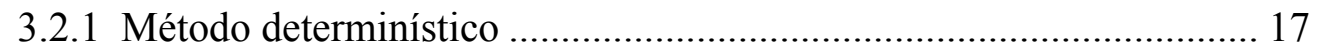

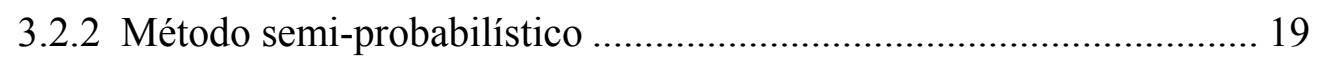

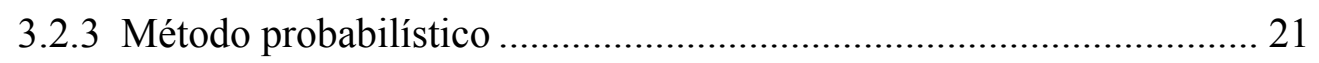

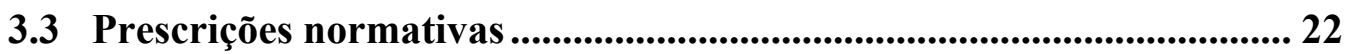

3.3.1 Coeficientes de ponderação das ações ............................................. 22

3.3.2 Ponderadores das resistências dos materiais ..................................... 26 
3.3.3 Verificação do estado limite de fissuração........................................ 26

3.3.4 Verificação do estado limite de deformação excessiva....................... 29

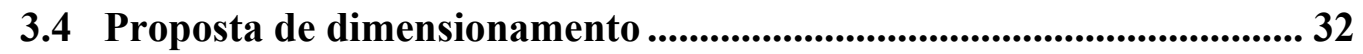

3.5 Proposta para uma nova consideração de segurança .......................... 34

4 EXEMPLOS E APLICAÇÕES ..................................................46

4.1 Considerações gerais.............................................................................. 46

4.2 Comparação entre resultados - aferição do programa ......................... 47

4.2.1 Seção transversal........................................................................... 48

4.2.2 Placa biapoiada - Wittek e Meiswinkel (2000) ................................ 49

4.2.3 Viga contínua com dois vãos - Wittek e Meiswinkel (2000)............. 53

4.3 Exemplos aplicados à NBR 6118:2003 ..................................................... 58

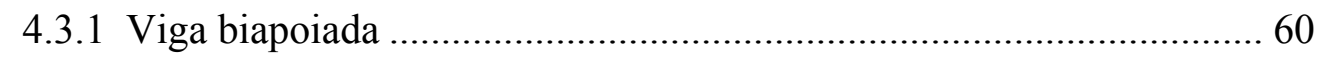

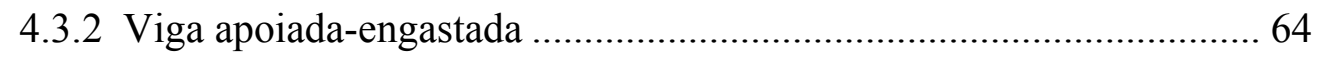

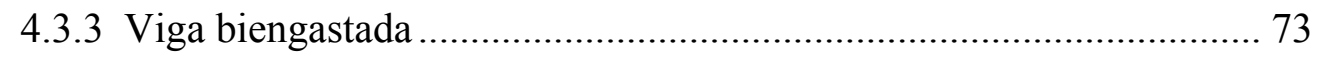

5 CONCLUSÃO E SUGESTÃ̃ ...........................................83

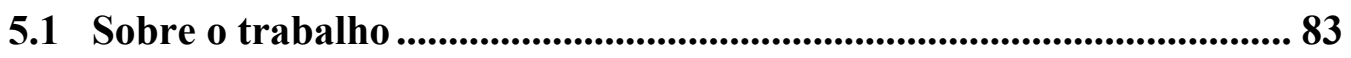

5.2 Sugestão para trabalhos futuros ....................................................... 84

REFERÊNCIAS ............................................................................... 85

APÊEDICE $A$ A

APÊNCIDE B 


\section{INTRODUÇÃO}

\subsection{Considerações iniciais}

Nos últimos anos, o meio científico tem desenvolvido importantes avanços na análise não-linear de estruturas de concreto, particularmente aquelas ligadas diretamente ao concreto armado, material largamente empregado na construção civil. Porém, tal avanço ainda não foi incorporado ao meio técnico, em especial no que se refere à análise estrutural - em virtude das dificuldades inerentes ao processo - e, também, ao descompasso ainda existente entre os procedimentos de análise estrutural e os de dimensionamento, principalmente no que tange aos coeficientes de ponderação de ações e de resistências.

Sabe-se que o modelo elástico-linear normalmente é utilizado para representar o comportamento dos materiais, em virtude da relativa simplicidade em sua formulação e, conseqüentemente, em seu equacionamento, quando comparado a modelos de cálculo mais refinados, como é o caso da análise estrutural considerando a não-linearidade dos materiais.

As formulações do comportamento não-linear conduzem a problemas matemáticos mais complexos, com soluções praticamente impossíveis sem o auxílio de computadores com configuração que proporcione boa capacidade de trabalho. Por este motivo, o emprego da não-lineariadade, como ferramenta usual de projeto, foi adiado por algum tempo, como também o foram os métodos numéricos, dentre eles, Método 
das Diferenças Finitas (MDF), Método dos Elementos Finitos (MEF) e Método dos Elementos de Contorno (MEC).

O estudo da não-linearidade física tem evoluído bastante, tanto no aspecto das formulações teóricas quanto na melhoria da qualidade das implementações computacionais. Melhorias nos modelos não-lineares, como otimizações nas rotinas de cálculo, agilizam o processamento de estruturas usuais de concreto, cujas rotinas de cálculo podem se tornar viáveis para uso nos escritórios de projeto de estruturas, sob a forma de programas computacionais.

\subsection{Objetivo}

O objetivo deste trabalho é fazer análises de elementos de concreto armado submetidas a solicitações normais de flexão pura empregando o comportamento nãolinear físico. Nestas análises foram considerados os valores médios para as relações tensão-deformação no aço e no concreto, limitando suas resistências nos valores de cálculo, para que se possa satisfazer tanto aos estados limites últimos quanto aos estados limites de serviço.

O presente trabalho irá avaliar também a formulação de uma nova proposta para verificação dos estados limites que, independente do critério de ruptura do elemento se dar por esgotamento da resistência do aço ou do concreto, tenha um mesmo coeficiente global de segurança.

O presente estudo compreendeu as atividades listadas a seguir.

Verificação do comportamento de vigas de concreto armado submetidas à flexão pura, dimensionadas para resistir a esforços solicitantes, empregando a análise elástico-linear e não-linear física.

Avaliação de propostas alternativas de dimensionamento para o regime nãolinear físico considerando valores médios, valores de cálculo ou valores de referência das resistências dos materiais, aço e concreto.

Elaboração de rotinas no software MathCad para dimensionamento de peças de concreto armado, verificação da capacidade resistente de seção transversal, formação de abertura máxima de fissuras e deformações excessivas, para proporcionar maior rapidez em tais verificações. 
Análise das propostas apresentadas, aplicadas aos estados limites últimos e de serviço de elementos de concreto armado que proporcionem peças seguras de acordo com as recomendações da NBR 6118:2003.

\subsection{Justificativa}

A consideração de soluções estruturais cada vez mais audaciosas e ao mesmo tempo mais econômicas, envolvendo técnicas mais complexas, conduzem à necessidade de utilizar modelos que descrevam o mais real possível comportamento da estrutura durante as várias fases da construção dando, assim, fornecendo ao projetista, de forma rápida e viável, um valor adequado da segurança revelado pela estrutura em estudo, (HENRIQUES, 1991).

$\mathrm{Na}$ análise e no dimensionamento de estruturas de concreto armado são conhecidas algumas limitações exibidas pelos métodos clássicos, baseados no modelo de comportamento elástico-linear dos materiais. Desta forma, a freqüente consideração de simplificações pode conduzir a acréscimos no custo da edificação, sobretudo quando se lida com casos poucos correntes.

Normalmente, as normas regulamentadoras de estruturas de concreto recomendam o emprego de análises não-lineares físicas por serem mais consistentes, mesmo que de forma simplificada, pois, em alguns casos, a análise não-linear torna-se inviável em virtude de fatores como necessidade de computadores com maior capacidade de processamento, tempo computacional elevado, entre outros.

No dimensionamento dos elementos de concreto armado são determinados os esforços solicitantes considerando a teoria da elasticidade independentemente do comportamento do material. Posteriormente, dimensiona-se o elemento para as seções mais solicitadas, majorando-se os esforços e minorando-se as resistências dos materiais por meio dos coeficientes ponderadores estabelecidos por normas regulamentadoras.

Segundo Henriques (1998), esta metodologia pode ser considerada aceitável para análises lineares; entretanto, deixa de ser válida quando a capacidade resistente das estruturas é verificada com técnicas não-lineares incrementais e iterativas. Neste caso, as relações constitutivas consideradas nas análises e na verificação da segurança não podem ser consideradas independentes.

De acordo com a NBR 6118:2003 e o CEB-FIP MC90, os métodos de análise não-lineares podem ser empregados tanto para os estados limites últimos (ELU) quanto 
para os estados limites de serviço (ELS), desde que satisfaçam às condições de equilíbrio e de compatibilidade.

O CEB-FIP MC90 propõe que verificada a segurança considerando a nãolinearidade, seja empregado o valor médio da resistência dos materiais na estrutura. Dessa forma, a segurança da estrutura ou da seção crítica dependeria do critério de ruptura a que estivesse submetida, seja ela frágil (esgotamento da capacidade resistente do concreto) ou dúctil (esgotamento da capacidade resistente do aço), podendo resultar em margens de segurança diferentes, como relatado nos trabalhos de Lourenço et al. (1992), Camara et al. (1994) e Eibl et al. (1995).

Entretanto, König et al. (1997) propõem alterações na consideração dos valores médios das resistências dos materiais ao empregar a análise não-linear, proporcionando a mesma margem de segurança da estrutura, independentemente do critério de ruptura do elemento. Vários trabalhos foram realizados nesta linha e proporcionaram resultados satisfatórios; Tue (1996), König et al. (1997) e Ahner e Tue (1997).

As mudanças e adaptações propostas por König et al. (1997) foram também estudas por Oliveira (2001), empregando os parâmetros da NBR 6118:2003 apenas na avaliação da segurança de seções transversais de concreto armado. No presente trabalho serão avaliados, além de seções transversais de concreto armado, elementos de viga isostáticas e hiperestáticas submetidas à flexão pura.

\subsection{Metodologia}

Estudar as alternativas de verificação da segurança das estruturas de concreto armado considerando coeficientes de segurança para a seção transversal crítica e para a estrutura, propostas pelo CEB-FIP MC90 ao empregar a não-linearidade física quando se utilizam os valores das resistências médias e de referência para o concreto e para o aço. Fazer as necessárias adaptações destas propostas à NBR 6118:2003, em virtude da diferença entre o coeficiente de minoração da resistência característica à compressão do concreto utilizado pela NBR 6118:2003 e pelo CEB-FIP MC90, analisando e verificando os fatores favoráveis e desfavoráveis.

Considerar vigas de concreto armado para fundamentar a idéia da proposta em que considera o valor médio das resistências dos materiais, limitando-as aos seus valores de projeto. Aplicar os conceitos às vigas isostáticas e hiperestáticas, variando 
parâmetros tais como geometria, carregamento, taxas de armaduras e resistência dos materiais.

O dimensionamento dos elementos de concreto é feito para o ELU utilizando programa desenvolvido pelo autor no software MathCad disponível no Departamento de Estrutura da EESC/USP. Além deste, foram desenvolvidos programas para verificação das seções resistentes e dos ELS - estado de formação de fissuração e de deformação excessiva.

Analisar as vigas submetidas à flexão pura, para verificação das propostas do coeficiente global de segurança e da consideração dos valores médios da resistência dos materiais, limitando-as no valor de cálculo, e comparar seus resultados com análises desenvolvidas por autores que trabalharam nesta mesma linha de pesquisa. As análises não-lineares físicas são realizadas utilizando o programa ANPAV, desenvolvido por Oliveira (2001), sendo feitas algumas adaptações no código original.

Comparar os resultados obtidos, sob o ponto de vista dos critérios de segurança estabelecidos pela NBR 6118:2003. 


\section{NÃO-LINEARIDADE FÍSICA}

\subsection{Considerações iniciais}

Nos últimos anos, os centros de pesquisa acadêmica vêem desenvolvendo importantes avanços nos estudos do comportamento não-linear das estruturas de concreto armado. Apesar desses avanços serem pouco empregados no meio técnico, em virtude da complexidade de sua fundamentação teórica e da necessidade de uso de recursos computacionais em suas aplicações, os códigos normativos buscam tratar, mesmo que de forma simplificada, os aspectos da não-linearidade.

Esses procedimentos são muito utilizados em projetos de pesquisa, na busca de formas simplificadas que possam ser empregadas na prática, reproduzindo o comportamento não-linear físico e geométrico das estruturas de concreto armado.

Neste capítulo mostra-se o avanço das pesquisas quanto à não-linearidade física, bem como, alguns conceitos e aproximações empregadas no presente trabalho.

\subsection{Breve histórico}

Vários pesquisadores trabalharam com o intuito de obter e aprimorar os modelos representativos do comportamento não-linear físico em diferentes áreas do conhecimento. 
Na década de 60 ocorreu substancial desenvolvimento de computadores de grande porte e grandes avanços nas linguagens e programas computacionais. Em virtude desse crescimento, os métodos numéricos passaram a ser aplicados na Engenharia e em demais áreas do conhecimento.

Ngo e Scordelis (1967) e Nilson (1968) utilizaram o Método dos Elementos Finitos (MEF) em estudos das estruturas de concreto armado. A partir dessa época intensificou-se o uso de análises não-lineares aplicadas a esse material. Zienckiewicz (1969), fez várias generalizações das relações constitutivas, aplicando o método dos elementos finitos a problemas elastoplásticos. Cervenka (1970) ${ }^{1}$ apud Proença (1988), fez uma proposta para aplicação da teoria da plasticidade tendo em vista a nãolinearidade do concreto à compressão, utilizando critérios semelhantes aos usualmente empregados às estruturas metálicas.

Vários trabalhos foram desenvolvidos no âmbito das formulações numéricas para o procedimento computacional. Entretanto, alguns pesquisadores conduziram trabalhos para o campo das relações constitutivas do concreto. Dentre eles podem ser destacados os trabalhos de Chen e Chen (1975), Bazant e Bhat (1976) e Cedolin e Deipoli (1977). Segundo Owen e Hinton (1980), outros pesquisadores proporcionaram grandes contribuições não apenas aos modelos constitutivos, como também ao desenvolvimento de técnicas numéricas mais acuradas, buscando a melhoria da eficiência do MEF.

Owen e Hinton (1980) desenvolveram modelos constitutivos com aplicação computacional, baseados no MEF para análise de estruturas de concreto. Proença (1988) desenvolveu estudos acerca dos principais modelos matemáticos normalmente empregados na análise do concreto armado para compreensão do comportamento global não-linear das estruturas.

El Matwally et al. (1990) fizeram estudos de pilares de concreto armado considerando a não-linearidade física e geométrica, com o emprego da técnica do MEF e compararam suas análises com ensaios laboratoriais de Abel-Sayed (1975), Goyal e Jackson (1971) e Drysdale e Huggins (1971) e as análises numéricas de Cranston (1982), obtendo resultados bastante semelhantes. Sathurappan et al. (1992) desenvolveram um modelo com componente de integral discreta utilizando o MEF

\footnotetext{
${ }^{1}$ CERVENKA, V. (1970) Inelastic finite element analysis of reinforced concrete panels under in plane loads. Ph. D. thesis, University of Colorado.
} 
aplicado às placas e cascas de concreto armado e protendido, empregando a nãolinearidade dos materiais. Os autores aferiram seu programa com ensaios experimentais de lajes de concreto armado submetida a carregamento monotônico crescente uniformemente distribuídos onde avaliaram as deformações e deslocamentos provocados pela aplicação das cargas, alcançando resultados próximos aos dos ensaios realizados.

No Departamento de Engenharia de Estrutura da EESC/USP, vários trabalhos foram desenvolvidos nesta linha de pesquisa; Ballarotti (1981) analisou o comportamento elastoplástico em pórticos planos retangulares submetidos a carregamento monotônico crescente. Proença (1988) desenvolveu estudos acerca dos modelos representativos da não-linearidade física do concreto. Corrêa (1991) desenvolveu um sistema computacional para análise de pavimentos de edifício considerando lajes e vigas integradas ao mesmo modelo, com tratamento não-linear físico. Oliveira (1997), apresentou uma proposta à análise de pavimentos de edifícios de concreto armado empregando a não-linearidade dos materiais, com base na relação momento-curvatura. Sanches Júnior (1998) estudou o comportamento de pavimentos de concreto armado de edifícios utilizando modelos não-lineares para os materiais. Oliveira (2001) em estudo mais detalhado aprimorou a modelagem desenvolvida em 1997, com proposta de metodologia para a aplicação a projetos. Propôs, também, uma nova forma de dimensionamento e verificação da segurança de estruturas de concreto armado, considerando o coeficiente global de segurança, motivado por trabalhos desenvolvidos por pesquisadores alemães, com destaque para G. König, N. V. Tue, C. Ahner e J. Eibl.

\subsection{Método numérico utilizado}

O método numérico utilizado para fazer as análises considerando o comportamento não-linear dos materiais foi o Método dos Elementos Finitos (MEF), empregado no programa utilizado nas análises.

O sistema ANSER (ANálise de Sistemas Estruturais Reticulados), desenvolvido por Ramalho (1990) e Corrêa (1991) e implementado por Oliveira (2001), inclui, em sua biblioteca um elemento de barra tridimensional, com nós em suas extremidades e seis graus de liberdade por nó, conforme Figura 2.1. Essa nova versão do sistema computacional, desenvolvida por Oliveira para a análise não-linear de 
pavimentos de concreto armado, será designada por ANPAV, sendo que os elementos utilizados no presente estudo são a seguir descritos.

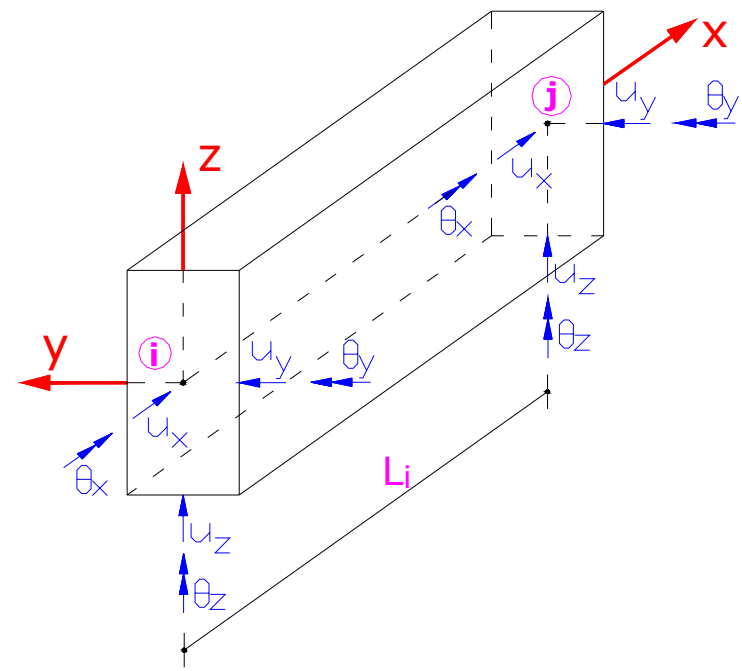

Figura 2.1 - Elemento finito tridimensional de barra.

sendo:
$u_{x} \quad$ translação segundo o eixo local $\mathrm{x}$;
$u_{y} \quad$ translação segundo o eixo local y;
$u_{z} \quad$ translação segundo o eixo local z;
$\theta_{x} \quad$ Rotação em torno do eixo local x;
$\theta_{y} \quad$ Rotação em torno do eixo local y;
$\theta_{z} \quad$ Rotação em torno do eixo local z;
$L_{i} \quad$ comprimento do elemento finito.

A seção transversal do elemento pode ser considerada estratificada. Para os elementos não-estratificados, a seção transversal apresenta geometria constante ao longo do elemento, composta por um único material. Considerar a seção transversal estratificada implica na extensão do domínio de integração também sobre essa seção. Assim, a integração sobre a seção transversal é obtida pelo somatório discreto da contribuição de cada uma das camadas que a compõe.

Novotny et al. (1994) realizaram uma investigação sobre métodos de integração mais empregados na previsão dos deslocamentos de elementos estruturais, considerando um comportamento elastoplástico. Os autores concluíram que a integração por camadas pode ser considerada suficiente no emprego da análise não-linear. Os autores fizeram estudos variando o número de camadas e/ou pontos de integração de 
Gauss. Concluíram que empregando um número de camadas superior a oito (8), o erro de integração torna-se praticamente desprezível.

Nos exemplos analisados, foram utilizadas dez (10) camadas nas seções transversais estratificadas. A Figura 2.2 mostra um elemento de seção retangular com estratificação da seção transversal.

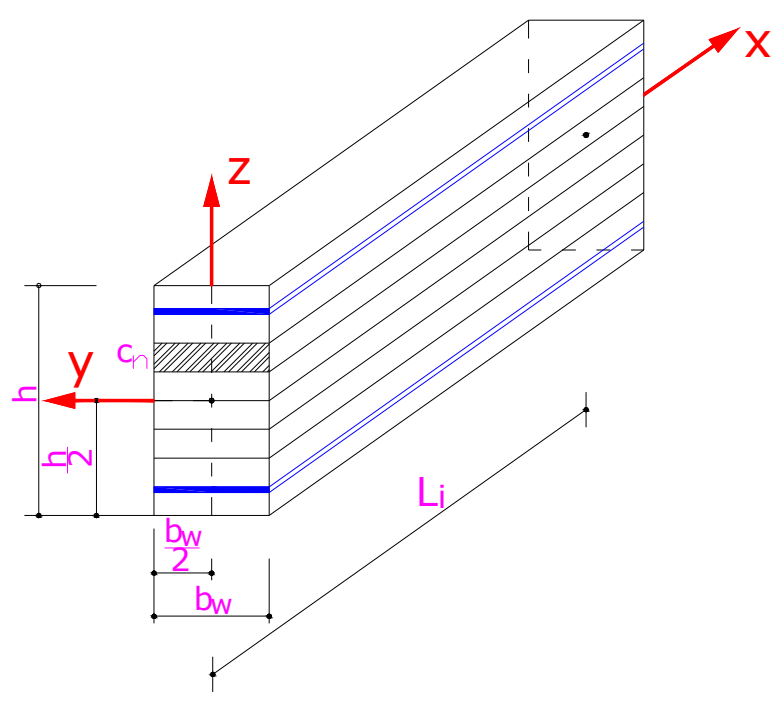

Figura 2.2 - Elemento finito de seção transversal retangular estratificada.

De acordo com Oliveira (2001), a seção transversal estratificada, além de permitir a aplicação dos modelos constitutivos dos materiais aço e concreto, abre espaço à implementação consistente da relação de interação entre as camadas compostas por diferentes materiais.

A não-linearidade do modelo constitutivo decorre do fato de, genericamente, a cada instante o material poder sofrer um carregamento plástico ou um descarregamento elástico, dificultando o cálculo da deformação plástica total. Assim, a não-linearidade é resolvida numericamente por um procedimento incremental-iterativo. Vários são os procedimentos incremental-iterativo utilizados, dentre eles pode-se citar: NewtonRaphson Pleno, Newton-Raphson Modificado (KTO, KT1, KT2) e Método da Matriz Secante. O procedimento incremental-iterativo utilizado neste trabalho foi o método Newton-Raphson Pleno, que considera a atualização da matriz de rigidez do sistema a cada iteração de todo incremento de carga. 


\subsection{Campo de aplicação}

Teoricamente, não há restrições no campo de aplicação da análise não-linear física às estruturas, com exceção de algumas estruturas esbeltas, nas quais a capacidade resistente é reduzida pelos efeitos de segunda ordem. Neste caso, a não-linearidade geométrica é determinante na redistribuição dos momentos e forças internas antes de ser atingido o ELU, conforme Bulletin d Information 227 do CEB (1995).

Uma das limitações da não-linearidade é não possibilitar o uso do princípio da superposição de efeitos, o que pode limitar o emprego deste procedimento para grandes estruturas submetidas a múltiplas condições de carregamento.

A análise não-linear é um procedimento que descreve melhor o comportamento da resposta estrutural. Deste modo, deve ser considerado, sempre que possível, como método de referência para aferir resultados obtidos com outras aproximações, como o cálculo linear com ou sem redistribuição e o modelo plástico.

Uma das vantagens importantes do emprego da não-linearidade física é o uso na redistribuição dos esforços solicitantes, o que torna possível explorar as eventuais reservas de resistência da estrutura, este fato ocorre, exclusivamente, em estruturas hiperestáticas.

Os centros de pesquisas têm empregado cada vez mais a não-linearidade em seus trabalhos para melhor representar o comportamento dos materiais, bem como dos sistemas estruturais.

\subsection{Modelos constitutivos dos materiais}

Os modelos constitutivos para os materiais empregados neste trabalho foram considerados de forma a representar os parâmetros mais importantes envolvidos nos problemas em questão.

Será apresentado apenas o estado uniaxial para ambos os materiais empregados no concreto armado. Para a aplicação das relações constitutivas na análise de elementos finitos uniaxiais, como é o caso das vigas (elemento utilizado nas análises), exige-se a utilização uniaxial para a representação do comportamento mecânico dos materiais. 


\subsubsection{Aplicado ao concreto}

O concreto apresenta propriedades mecânicas dependentes da intensidade de solicitação. Comporta-se como material frágil quando submetido a tensões de tração. Por outro lado, apresenta comportamento que pode ser admitido como plástico sob compressão.

A literatura técnica apresenta várias possibilidades para esses comportamentos; porém neste trabalho foram abordadas as propostas apresentadas pelo Código Modelo do CEB-FIP MC90 para o concreto à compressão e o modelo de Figueiras (1983) para a tração.

O CEB-FIP MC90 apresenta diagrama tensão-deformação tanto para a compressão quanto para a tração sob solicitações uniaxiais do concreto, porém no presente estudo será mostrado apenas o comportamento à compressão, pois o modelo para o comportamento à tração do concreto considerado no trabalho é o proposto por Figueiras (1983). Percebe-se no diagrama, relacionado à compressão do concreto, Figura 2.3, o comportamento não-linear; observa-se que o segundo trecho estende-se além do ponto correspondente à deformação última do concreto $\left(\varepsilon_{c u}\right)$, representando o comportamento do concreto pós-esmagamento. Estas curvas são propostas para carregamento de curta duração.

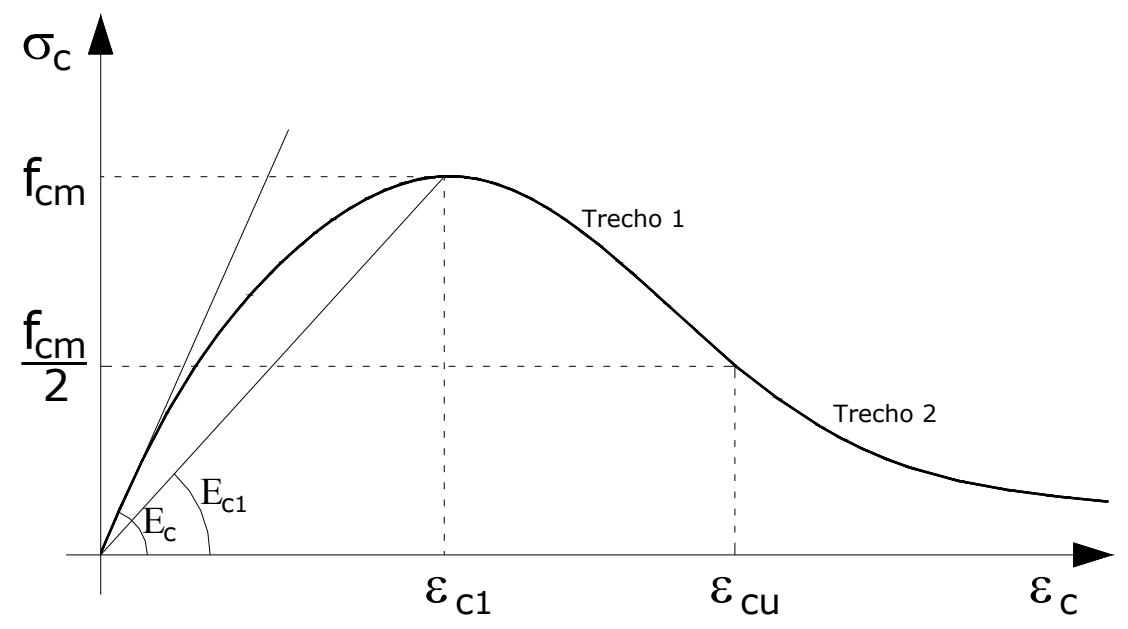

Figura 2.3 - Diagrama tensão-deformação para compressão axial do concreto, CEB-FIP MC90.

As equações que regem a relação entre tensão de compressão e deformação do concreto são expressas a seguir. 


$$
\begin{gathered}
\sigma_{c}=-\frac{\frac{E_{c}}{E_{c 1}} \cdot \frac{\varepsilon_{c}}{\varepsilon_{c 1}}-\left(\frac{\varepsilon_{c}}{\varepsilon_{c 1}}\right)^{2}}{1+\left(\frac{E_{c}}{E_{c 1}}-2\right) \cdot \frac{\varepsilon_{c}}{\varepsilon_{c 1}}} \cdot f_{c m} \text { para }\left|\varepsilon_{c}\right|<\left|\varepsilon_{c u}\right| \\
\sigma_{c}=-\left[\left(\frac{1}{\left.\left.\frac{\varepsilon_{c u}}{\varepsilon_{c 1}} \cdot \xi-\frac{2}{\left(\frac{\varepsilon_{c u}}{\varepsilon_{c 1}}\right)^{2}}\right) \cdot\left(\frac{\varepsilon_{c}}{\varepsilon_{c 1}}\right)^{2}+\left(\frac{4}{\frac{\varepsilon_{c u}}{\varepsilon_{c 1}}}-\xi\right) \cdot \frac{\varepsilon_{c}}{\varepsilon_{c 1}}\right]^{-1} \cdot f_{c m} \text { para }\left|\varepsilon_{c}\right|>\left|\varepsilon_{c u}\right|}\right.\right.
\end{gathered}
$$

Com a razão entre as deformações e o parâmetro adimensional dados na eq. (2.3) e eq.(2.4), respectivamente.

$$
\begin{aligned}
& \frac{\varepsilon_{c u}}{\varepsilon_{c 1}}=\frac{1}{2}\left(\frac{1}{2} \cdot \frac{E_{c}}{E_{c 1}}+1\right)+\sqrt{\left[\frac{1}{4} \cdot\left(\frac{1}{2} \cdot \frac{E_{c}}{E_{c 1}}+1\right)^{2}-\frac{1}{2}\right]} \\
& \xi=\frac{4\left(\left(\frac{\varepsilon_{c u}}{\varepsilon_{c 1}}\right)^{2}\left(\frac{E_{c}}{E_{c 1}}-2\right)+2 \frac{\varepsilon_{c u}}{\varepsilon_{c 1}}-\frac{E_{c}}{E_{c 1}}\right)}{\left(\frac{\varepsilon_{c u}}{\varepsilon_{c 1}} \cdot\left(\frac{E_{c}}{E_{c 1}}-2\right)+1\right)^{2}}
\end{aligned}
$$

sendo:

$$
\begin{array}{ll}
\sigma_{c} & \text { tensão normal de compressão do concreto; } \\
f_{c m} & \text { resistência à compressão do concreto; } \\
E_{c} & \text { módulo tangente do concreto; } \\
E_{c 1} & \text { módulo secante da origem ao pico de compressão do concreto; } \\
\varepsilon_{c} & \text { deformação específica de compressão do concreto; } \\
\varepsilon_{c 1} & \text { deformação específica corresponde à } f_{c m} ; \\
\varepsilon_{c u} & \text { deformação última do concreto; } \\
\xi & \text { parâmetro adimensional. }
\end{array}
$$

Na região tracionada do concreto, Figura 2.4, observa-se que o comportamento sob tração é representado por dois segmentos de reta. O modelo considerado por 
Figueiras (1983) contempla o enrijecimento à tração ${ }^{2}$ do concreto. Desse modo, tem-se a contribuição do concreto íntegro entre duas fissuras, com isso tornando-se mais realístico na representação do comportamento do concreto submetido a esforços de tração.

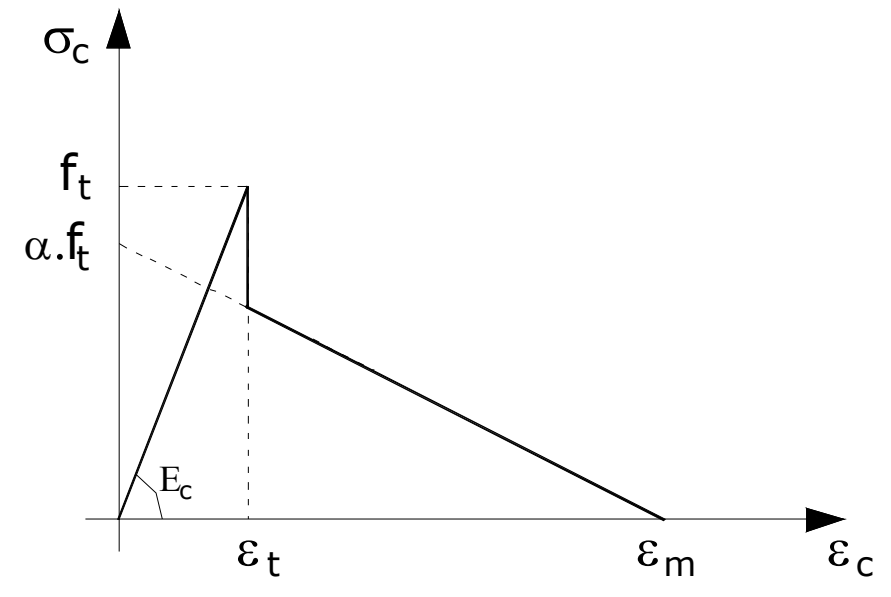

Figura 2.4 - Diagrama tensão-deformação para tração axial do concreto, Figueiras (1983).

sendo:
$f_{t} \quad$ resistência à tração no concreto;
$\varepsilon_{m} \quad$ deformação específica limite do concreto à tração $\left(\varepsilon_{m}=0,0020\right)$;
$\alpha \quad$ coeficiente que impõe o grau de enrijecimento $(0,5 \leq \alpha \leq 0,7)$.

\subsubsection{Aplicado ao aço}

O aço utilizado na construção civil tem comportamento dúctil, por apresentar um patamar de escoamento, sendo bastante semelhante quer na tração quer na compressão. Um modelo elastoplástico pode ser considerado para representação de seu comportamento mecânico. Sob a ação de esforços combinados, esse comportamento é bem representado pelo critério de escoamento de Von Mises.

O comportamento mecânico das barras de aço, empregado nos modelos dos elementos estruturais, foi representado por um modelo constitutivo uniaxial elastoplástico perfeito, ilustrado na Figura 2.5.

\footnotetext{
${ }^{2}$ Enrijecimento à tração, designa a contribuição do concreto íntegro, entre duas fissuras sucessivas, que exerce sobre a rigidez de um elemento de concreto armado fletido ou tracionado no estádio II.
} 


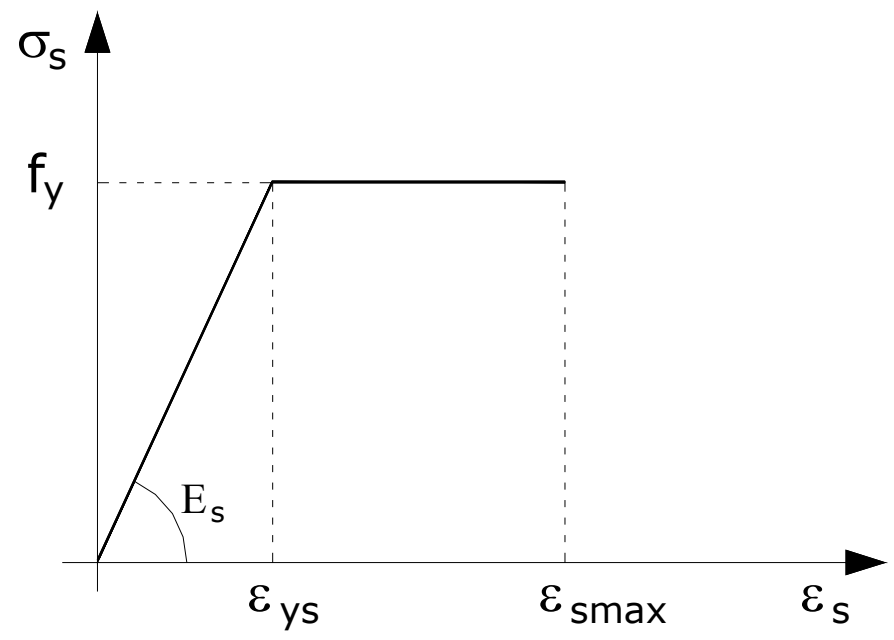

Figura 2.5 - Diagrama tensão-deformação para o aço - elastoplástico perfeito.

Alternativamente o modelo para o aço poderia ser considerado com o fez Pinto (2002) que admitiu diagrama bilinear, porém com possibilidade de encruamento positivo, conforme Figura 2.6.

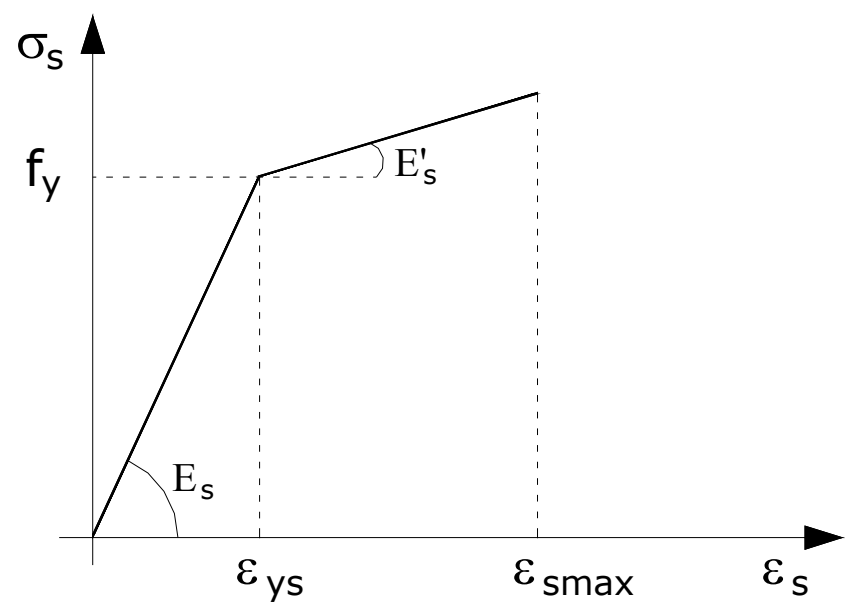

Figura 2.6 - Diagrama tensão-deformação para o aço - elastoplástico com encruamento.

sendo:

$\sigma_{s} \quad$ tensão normal de tração do aço;

$f_{y} \quad$ resistência de escoamento do aço $\left(E_{s}=210000 \mathrm{MPa}\right)$;

$E_{s} \quad$ módulo de elasticidade do aço;

$E_{s}^{\prime} \quad$ módulo de elasticidade do aço após escoamento;

$\varepsilon_{s} \quad$ deformação específica de tração do aço;

$\varepsilon_{y s} \quad$ deformação específica do aço correspondente à resistência de

escoamento;

$\varepsilon_{s \max }$ deformação específica máxima permitida para o aço $\left(\varepsilon_{y u}=10 \%\right)$. 


\section{ABORDAGENS NORMATIVAS E NOVA CONSIDERAÇÃO DE SEGURANÇA}

\subsection{Considerações iniciais}

Neste capítulo são abordados os métodos de dimensionamento e verificação da segurança utilizados nos projetos de cálculo das estruturas, bem como o método empregado na norma brasileira NBR 6118:2003 em vigor e uma possível proposta de dimensionamento e verificação da segurança das estruturas de concreto armado, considerando coeficiente global de segurança e valores médios da resistência dos materiais limitando-os aos valores de projeto.

\subsection{Métodos de dimensionamento}

Nas obras de engenharia, a principal preocupação é manter a integridade estrutural das construções. Porém, dois aspectos fundamentais devem ser considerados, o de segurança e da economia. Segurança que proporcione à estrutura capacidade de suportar as variadas ações que possam solicitá-las durante a vida útil, assim como as condições de funcionalidade a que foi destinada.

Para que a segurança e a economia das estruturas fossem asseguradas, vários métodos passaram a ser utilizados nos projetos estruturais, cujos estudos têm avançado constantemente, na busca de melhores resultados. 
Segundo Zagottis (1974), o primeiro método empregado poderia ser denominado método intuitivo, no qual a segurança das construções era obtida pelas concepções baseadas na intuição dos projetistas e construtores, que podia ser pura ou, mais comumente, condicionada por sucessos e insucessos de construções anteriores.

De acordo com o desenvolvimento da mecânica estrutural, foram criadas teorias quantitativas que progressivamente reproduziam melhor os diversos comportamentos estruturais. Essas melhorias ocorreram nas definições reológicas dos materiais, na determinação dos esforços solicitantes, deformações e deslocamentos provocados por determinado carregamento ou na definição de critérios de resistência dos materiais.

Os métodos considerados nos projetos estruturais podem ser o método empírico (comentado acima), o método determinístico, o semi-probabilístico e o probabilístico. Estes métodos serão brevemente comentados a seguir.

\subsubsection{Método determinístico}

De acordo com Zagottis (1974), o método determinístico significa que, para um mesmo corpo, com as mesmas vinculações, a aplicação de uma solicitação, de acordo com determinada lei de variação ao longo do tempo, se pudesse ser repetida diversas vezes, produziria em todas elas os mesmos esforços internos, as mesmas deformações e os mesmos deslocamentos.

Um método determinístico bastante conhecido é o método das tensões admissíveis, cujo dimensionamento estrutural, para garantir a segurança exige que, em estado de serviço, a máxima tensão atuante não ultrapasse determinado valor, considerado como admissível, (FUSCO, 1985).

Assim, para o caso de solicitações normais, como em flexão de vigas, a condição descrita acima, pode ser representada da seguinte forma:

$$
\sigma_{\max } \leq \sigma_{a d m}
$$

Sabe-se que os primeiros valores atribuídos às tensões admissíveis dos materiais foram normalizados em função de experiências práticas dos projetos realizados na época. O método das tensões admissíveis foi um pequeno avanço do método intuitivo, até então empregado. 
Ao longo do tempo, procurou-se introduzir um critério mais racional na definição das tensões admissíveis. Para tanto, considerou-se o coeficiente de segurança interno impondo-se que a maior tensão proveniente da utilização da estrutura não ultrapassasse o valor correspondente às tensões de ruptura ou escoamento dos materiais, dividida por $\gamma_{i}$, (ZAGOTTIS, 1974). Desse modo a eq.(3.1) passa a ser:

$$
\sigma_{\max } \leq \sigma_{a d m}=\frac{f}{\gamma_{i}}
$$

sendo:

$\begin{array}{ll}f & \text { resistência obtida em ensaio padronizado; } \\ \gamma_{i} & \text { coeficiente de segurança. }\end{array}$

Os coeficientes de segurança internos também eram determinados empiricamente e os valores atribuídos conforme o sucesso das estruturas em uso. Os coeficientes poderiam ser alterados, permitindo um progresso gradativo e seguro nos critérios de projeto, de forma a atender aspectos econômicos e de segurança.

Segundo Zagottis (1974), o método das tensões admissíveis procura estabelecer uma medida da segurança das estruturas e uma sistemática para introdução da segurança nos projetos estruturais; porém, esta medida pode ser bastante deficiente. De acordo com o autor, o coeficiente de segurança deve justificar, além de outros fatores, a variabilidade das resistências dos materiais, que são maiores com o crescimento das dispersões correspondentes.

Com relação à sistemática na introdução da segurança nos projetos estruturais, podem ser feitas algumas críticas do emprego deste método. Primeiramente, o aspecto de haver apenas uma preocupação com o estabelecimento da "distância" conveniente entre a situação de uso e aquela correspondente à ruína (desagregação do material) ou colapso (perda da capacidade portante) da estrutura. Assim, o método das tensões admissíveis não considera a verificação de outras condições que possam invalidar a utilização da estrutura como, por exemplo, a sua deformação excessiva.

Entretanto, o método das tensões admissíveis foi o primeiro a ser incorporado à normalização brasileira, no ano de 1940 com a primeira versão da NB-1, dando origem à ABNT (Associação Brasileira de Normas Técnicas). Em 1960 foi editada a NB-1, considerando o método dos coeficientes de segurança internos e externos, sendo os internos referentes à resistência dos materiais e o externo às solicitações na estrutura. 
Apenas em 1978 a NB-1, denominada NBR 6118:1978, passou a utilizar o método dos estados limites, que será comentado posteriormente.

Castro et al. (1997), salientam que a transposição de uma norma inicialmente baseada em tensões admissíveis para estados limites é feita de maneira a não afetar de forma significativa os resultados globais. Assim, apesar da mudança brusca na parte conceitual embutida nos métodos, os resultados não devem divergir significativamente quando o projetista dimensiona a estrutura utilizando uma ou outra versão.

\subsubsection{Método semi-probabilístico}

O método semi-probabilístico é fundamentado em análise estatística com coeficientes ponderadores aplicados tanto às ações quanto às resistências dos materiais, porém admitindo o comportamento estrutural como determinístico. Por esse fato é chamado semi-probabilístico. O método mais utilizado nas estruturas de concreto é o dos estados limites, que é um método semi-probabilístico.

Este método, semelhante aos demais, considera que a segurança da estrutura deve ser verificada em relação às situações que possam trazer riscos à integridade da própria estrutura ou para uso normal da construção.

As normas brasileiras em vigor, que tratam dos critérios de segurança a serem verificados no projeto estrutural são: a NBR 6118:2003 - Projeto de estruturas de concreto e a NBR 8681:2003 - Ações e segurança nas estruturas, que atribuem os requisitos exigíveis na verificação da segurança das estruturas de concreto usuais da construção civil. A Norma de Ações e Segurança faz distinção entre os estados limites últimos e os estados limites de serviço.

Estados Limites Últimos (ELU) são aqueles correspondentes ao esgotamento da capacidade portante da estrutura, estando relacionados ao colapso ou outra forma de ruína parcial ou total da estrutura, que paralise o uso da mesma.

Estados Limites de Utilização ou de Serviço (ELS) são aqueles correspondentes às exigências funcionais, aparências, conforto dos usuários e durabilidade da estrutura. Os ELS decorrem de ações cujas combinações podem ter diferentes tempos de permanência na estrutura, como: combinações quase permanentes, combinações freqüentes e combinações raras. As expressões que regem tais combinações serão mostradas posteriormente. 
Apesar de avanços nas pesquisas, ainda não se dispõe de uma metodologia totalmente fundamentada, que possa ser usada nas normas de projetos considerando o comportamento não-linear que verifique simultaneamente o ELU e o ELS. Portanto, duas metodologias procuram preencher essa lacuna. A primeira, liderada pelo pesquisador Macchi (1995) defende a permanência do método semi-probabilístico, porém sem descartar a necessidade de algumas adaptações. A segunda, conduzida por Eibl (1995) e König (1997) defende o conceito de um único coeficiente de segurança global relativo à resistência dos materiais, que será comentada no item 3.5 deste trabalho.

No Bulettin d'Information no 229 do CEB (1995), Macchi (1995) defende a permanência do método semi-probabilístico, pelo largo conhecimento adquirido até então; não descartando a possibilidade de algumas alterações que poderiam ser feitas para atender às novas necessidades e contemplar os novos conhecimentos. $\mathrm{O}$ autor acrescenta que os novos métodos de dimensionamento necessitariam ser calibrados por análise de confiabilidade e, ainda, ser aplicados em casos de estruturas reais, considerando as variáveis que influenciam a segurança. $\mathrm{O}$ pesquisador tece críticas ao método dos coeficientes globais de segurança, proposto por König et al. (1997), com relação à real capacidade de modelagem de ruína, principalmente de estruturas complexas.

Conforme Macchi (1995), a probabilidade de falha (ruína) de uma estrutura é mais bem avaliada pelos estudos das funções de distribuição aleatórias das variáveis envolvidas, tais como carregamento, geometria, resistências dos materiais, de acordo com a análise de confiabilidade. Porém, esta análise ainda inviabiliza sua utilização corrente, favorecendo a adoção usual de uma metodologia determinística.

Segundo o Bulettin d'Information $\mathrm{n}^{\mathrm{o}} 229$ do CEB (1995), os membros do comitê afirmam que o modelo não-linear é o mais apropriado a ser considerado nas análises, de modo que este deveria ser utilizado na calibração dos novos procedimentos de dimensionamento e verificação da segurança dos elementos estruturais. Este trabalho considera a análise não-linear física para a nova proposta de dimensionamento e verificação de estruturas de concreto armado. 


\subsubsection{Método probabilístico}

A análise probabilística lida com as incertezas do problema em questão, tanto para as ações, as resistências e para o comportamento estrutural. Segundo Fusco (1976), as incertezas relacionadas aos problemas de engenharia decorrem da variabilidade inerente aos fenômenos naturais, da falta de dados suficientes ou da falta de entendimento completo de todas as causas e de todos os efeitos relacionados aos sistemas materiais.

Os métodos probabilísticos de avaliação da segurança de estruturas consistem na determinação da probabilidade de falha da estrutura, em condições reais de funcionamento, utilizando técnicas baseadas na teoria da confiabilidade estrutural.

De acordo com Henriques (1998), a utilização de métodos probabilísticos na prática corrente de projetos de engenharia civil, tem sido mais empregada no ramo da engenharia marítima e hidráulica; especificamente utilizada na avaliação de chuvas de bacias hidrográficas, ou na avaliação dos picos máximos de redes de água no saneamento. Segundo o referido autor, na engenharia de estruturas a aplicação deste método encontra-se restrito a situações bastante particulares, como plataformas off shore, ações do vento e do tráfego em pontes de grandes vãos e em outros poucos casos.

No dimensionamento de qualquer elemento estrutural é necessário que a resistência $(\mathrm{R})$ seja maior que os esforços solicitantes $(\mathrm{S})$, atuantes durante toda a vida útil da estrutura. No entanto, durante as análises surgem incertezas ligadas à resistência ou ao carregamento. Assim, sempre irá existir uma probabilidade de ruína associada a um elemento ou à estrutura como um todo. Deste modo, a confiabilidade de uma estrutura ou elemento pode ser avaliada quanto à probabilidade de falha $(P(R<S))$ ou quanto à probabilidade de sobrevivência $(P(R>S))$, (ANG e TANG, 1984).

O problema básico da confiabilidade estrutural considera a resistência $\mathrm{R}$ e a solicitação S, cada uma descrita pelas respectivas funções de densidade de probabilidade $f_{R}$ e $f_{S}$, respectivamente. Portanto, a probabilidade de ruptura $p_{f}$ pode ser definida conforme as equações abaixo.

$$
p_{f}=P(R \leq S)=P(R-S \leq 0)=P\left(\frac{R}{S} \leq 1\right)
$$


$p_{f}=\iint_{D} f_{R . S}(r, s) d r d s$

Vários pesquisadores têm se dedicado aos estudos do método probabilístico por ser um procedimento que trata das variáveis aleatórias envolvidas nos problemas, assim, representando melhor o sistema estrutural como um todo. Porém, as aplicações ao meio técnico ocorrerão em futuro não muito próximo.

Algumas pesquisas foram desenvolvidas no Departamento de Engenharia de Estruturas - EESC/USP empregando o procedimento do método probabilístico, para verificar a confiabilidade estrutural, assim como, a otimização de estruturas de concreto armado; pode-se citar os trabalhos de Bernardo (1999) em que avaliou a segurança e confiabilidade em pavimentos de edifícios, introduzindo conceitos probabilísticos e estatísticos aplicados a um modelo de comportamento não-linear para o concreto armado, Chaves (2004), desenvolveu um programa computacional para a determinação da seção transversal de pilares de concreto armado com o custo mínimo e a determinação do índice de confiabilidade desta estrutura para um estado limite e Neves (2004), desenvolveu novas técnicas aproximadas de análise de confiabilidade para grelhas de concreto armado levando-se em consideração os vários modos importantes de probabilidades de falha.

\subsection{Prescrições normativas}

A seguir são apresentadas as prescrições adotadas pela normalização brasileira, empregadas no presente trabalho.

\subsubsection{Coeficientes de ponderação das ações}

Os coeficientes de ponderação aqui relacionados estão de acordo com as recomendações das normas NBR 6118:2003 e NBR 8681:2003. O valor de cálculo das ações é obtido a partir dos respectivos valores característicos, multiplicando-os pelo coeficiente de ponderação $\gamma_{f}$, que se desdobra em três outros coeficientes, como mostra a eq.(3.5).

$\gamma_{f}=\gamma_{f 1} \cdot \gamma_{f 2} \cdot \gamma_{f 3}$ 
O coeficiente $\gamma_{f 1}$ leva em consideração a variabilidade das ações, $\gamma_{f 3}$ considera os possíveis erros de avaliação dos efeitos das ações, seja por problemas construtivos, seja por deficiência do método de cálculo empregado. Por fim, o coeficiente $\gamma_{f 2}$ leva em conta a ocorrência simultânea das ações, sendo substituído por fatores de combinação ou de redução $\left(\psi_{i}\right)$, como mostra a Tabela 3.1, de acordo com a combinação de ações empregada ou o estado limite analisado, segundo a NBR 6118:2003.

Tabela 3.1 - Coeficientes ponderadores de ações variáveis, NBR 6118:2003.

\begin{tabular}{l|ccc}
\hline \multicolumn{1}{c|}{ Cargas acidentais de edifícios } & \multicolumn{3}{c}{$\gamma_{f 2}$} \\
\cline { 2 - 5 } & $\psi_{0}$ & $\psi_{1}$ & $\psi_{2}$ \\
\hline $\begin{array}{l}\text { Locais em que não há predominância de pesos de } \\
\text { equipamentos que permanecem fixos por longos períodos }\end{array}$ & 0,5 & 0,4 & 0,3 \\
$\begin{array}{l}\text { de tempo, nem de elevadas concentrações de pessoas. } \\
\text { Locais em que não há predominância de pesos de }\end{array}$ & 0,7 & 0,6 & 0,4 \\
$\begin{array}{l}\text { equipamentos que permanecem fixos por longos períodos } \\
\text { de tempo, ou de elevada concentração de pessoas. }\end{array}$ & & & \\
\hline Biblioteca, arquivos, oficinas e garagens. & & & \\
\hline
\end{tabular}

O fator ponderador $\gamma_{f}$, considerando-se a análise linear, pode ser aplicado tanto na majoração das ações quanto nos seus efeitos, pois o resultado não será alterado. De acordo com a NBR 8681:2003, se os cálculos dos esforços solicitantes atuantes forem feitos em regime elástico linear, o coeficiente $\gamma_{f}$ pode ser multiplicado tanto no carregamento característico quanto diretamente ao esforço característico, pois independe da ordem de aplicação do coeficiente, conforme as expressões abaixo.

$$
\begin{aligned}
& S_{d}=S\left(\gamma_{f} \cdot F_{k}\right) \\
& S_{d}=\gamma_{f} \cdot S_{k}=\gamma_{f} \cdot S\left(F_{k}\right)
\end{aligned}
$$

sendo:
$F_{k}$
ação característica;
$S_{d, k} \quad$ esforço solicitante de cálculo ou característico. 
Entretanto, se o cálculo dos esforços solicitantes for feito por um processo nãolinear, o coeficiente $\gamma_{f}$ deverá ser aplicado à ação característica, conforme eq.(3.8), devido à inexistência de proporcionalidade entre causas e efeitos.

$S_{d}=S\left(\gamma_{f} \cdot F_{k}\right)$

A NBR 8681:2003 estabelece os coeficientes de ponderação das ações no ELU, para cargas permanentes e para a carga variável principal, como mostra a Tabela 3.2, que considerou-se o valor de $\gamma_{f 2}=1,0$, resultando $\gamma_{f}=\gamma_{f 1} \cdot \gamma_{f 3}$. Porém, para a combinação das demais cargas variáveis, toma-se $\gamma_{f 2}=\psi_{i}$, cujos respectivos valores foram mostrados na Tabela 3.1.

Tabela 3.2 - Coeficientes $\gamma_{f}=\gamma_{f 1} \cdot \gamma_{f 3}$, NBR 8681:2003.

\begin{tabular}{l|cccc}
\hline \multirow{2}{*}{$\begin{array}{c}\text { Combinações de } \\
\text { aços }\end{array}$} & \multicolumn{4}{|c}{ Ações } \\
\cline { 2 - 5 } & Permanentes $\left(\gamma_{g}=\gamma_{f}\right)$ & Variáveis $\left(\gamma_{q}=\gamma_{f}\right)$ \\
\cline { 2 - 5 } & Desfavorável & Favorável & Geral & Temporária \\
\hline $\begin{array}{l}\text { Normais } \\
\text { Especiais ou de } \\
\text { construção }\end{array}$ & 1,4 & 1,0 & 1,4 & 1,2 \\
Excepcionais & 1,3 & 1,0 & 1,2 & 1,0 \\
\hline
\end{tabular}

Neste trabalho serão analisadas as condições de projeto para elementos estruturais de concreto armado submetidos às condições usuais, empregando-se apenas as combinações normais na verificação do ELU, expressa pela eq.(3.9). Não foram consideradas as ações indiretas permanentes, como retração e variáveis térmicas.

$$
F_{d}=\gamma_{g} \cdot F_{g k}+\gamma_{q} \cdot\left(F_{q 1 k}+\sum_{j=2}^{n} \psi_{0 j} \cdot F_{q i k}\right)
$$

sendo:

$$
\begin{array}{ll}
F_{g k} & \text { valor característico das ações permanentes diretas; } \\
F_{q 1 k} & \text { valor característico da ação variável principal; }
\end{array}
$$


$\begin{array}{ll}F_{q j k} & \text { valor característico das demais ações variáveis; } \\ \psi_{0 j} & \text { fator de combinação das cargas variáveis. }\end{array}$

Na consideração dos estados limites de serviço, os coeficientes de ponderação das ações são tomados com valor $\gamma_{f 1} \cdot \gamma_{f 3}=1,0$, portanto $\gamma_{f}=\gamma_{f 2}$, em que o valor de $\gamma_{f 2}$ é variável de acordo com a análise que se deseja fazer, conforme Tabela 3.1.

$\psi_{f 2}=1,0$ para combinações raras;

$\psi_{f 2}=\psi_{1} \quad$ para combinações freqüentes;

$\psi_{f 2}=\psi_{2} \quad$ para combinações quase permanentes.

De acordo com a NBR 6118:2003, o estado limite de serviço (ELS) deve ser verificado com uma das combinações mostradas abaixo. Nos exemplos apresentados no capítulo 4 deste trabalho, foram utilizadas as combinações quase-permanentes e combinações freqüentes.

\section{\$ Combinações Quase Permanentes (CQP)}

Nestas combinações as ações podem atuar durante grande parte do período de vida da estrutura e sua consideração é necessária na verificação do estado limite de deformações excessivas, segundo a eq.(3.10).

$F_{d, s e r}=\sum F_{g i, k}+\sum \psi_{2 j} F_{q j, k}$

\section{$\oplus \quad$ Combinações Freqüentes $(C F)$}

Nestas combinações, as ações se repetem várias vezes durante o período de vida da estrutura e sua consideração é necessária para verificar o estado limite de formação de fissuras, de abertura de fissuras e vibrações, conforme a eq.(3.11).

$F_{d, s e r}=\sum F_{g i, k}+\psi_{1} F_{q 1, k}+\sum \psi_{2 j} F_{q j, k}$

\section{† Combinações Raras (CR)}

Nestas combinações as ações algumas vezes ocorrem durante o período de vida da estrutura e sua consideração é necessária na verificação do estado limite de formação de fissuras, de acordo com a eq.(3.12). 


$$
F_{d, s e r}=\sum F_{g i, k}+F_{q 1, k}+\sum \psi_{1 j} F_{q j, k}
$$

\subsubsection{Ponderadores das resistências dos materiais}

Os coeficientes ponderadores aplicados aos materiais que fazem parte da estrutura têm suas resistências características minoradas pelo parâmetro $\gamma_{m}$, segundo o método semi-probabilístico. De acordo com a NBR 6118:2003, os valores dos coeficientes das resistências nos estados limites últimos são indicados na Tabela 3.3

Tabela 3.3 - Valores do coeficientes de $\gamma_{c}$ e $\gamma_{s}$, NBR 6118:2003.

\begin{tabular}{lcc}
\hline \multicolumn{1}{c}{ Combinações } & Concreto & Aço \\
& $\gamma_{c}$ & $\gamma_{s}$ \\
\hline Normais & 1,4 & 1,15 \\
Especiais ou de construção & 1,2 & 1,15 \\
Excepcionais & 1,2 & 1,0 \\
\hline
\end{tabular}

Para os coeficientes de ponderação das resistências nos estados limites de serviço, a NBR 6118:2003 indica a não necessidade de minoração, portanto, $\gamma_{m}=1,0$ para os materiais que compõem a estrutura. Assim, emprega-se a própria resistência característica dos materiais.

\subsubsection{Verificação do estado limite de fissuração}

Em estruturas de concreto armado, a fissuração ocorre quando as tensões de tração excedem a resistência dos elementos. Nestes elementos, as fissuras são inevitáveis, em virtude da baixa resistência do concreto à tração, devendo-se limitar as suas aberturas. Sabe-se que a fissuração permite a entrada de agentes agressivos capazes de desencadear a maioria de seus mecanismos de degradação, comprometendo a utilização dos elementos tanto na redução da durabilidade quanto no prejuízo que pode trazer ao seu funcionamento e à sua estética.

A verificação de aberturas de fissuras é feita para o estado limite de serviço sob ação das combinações freqüentes. No ELS as estruturas trabalham parcialmente nos 
Estádios I e II. A separação entre esses dois estádios em peças fletidas é definida pelo momento de fissuração.

A NBR 6118:2003 estabelece valores de abertura máxima característica das fissuras em função da classe de agressividade ambiental, conforme apresentado na Tabela 3.4, apenas para elementos estruturais de concreto armado.

Tabela 3.4 - Limites de fissuração, NBR 6118:2003.

\begin{tabular}{ccc}
\hline $\begin{array}{c}\text { Classe de Agressividade } \\
\text { Ambiental (CAA) }\end{array}$ & Exigência à fissuração & $\begin{array}{c}\text { Combinação de ação em } \\
\text { serviço }\end{array}$ \\
\hline CAA I & $w_{k} \leq 0,4 \mathrm{~mm}$ & \\
CAA II a CAA III & $w_{k} \leq 0,3 \mathrm{~mm}$ & Combinação freqüente \\
CAA IV & $w_{k} \leq 0,2 \mathrm{~mm}$ & \\
\hline
\end{tabular}

A NBR 6118:2003 apresenta duas expressões que determinam a abertura característica das fissuras em elementos de concreto, eq.(3.13) e eq.(3.14), para formação sistemática e assistemática das fissuras, respectivamente.

$$
\begin{aligned}
& w_{k}=\frac{\phi}{12,5 \cdot \eta_{i}} \cdot \frac{\sigma_{s}}{E_{s}} \cdot\left(\frac{4}{\rho_{r}}+45\right) \\
& w_{k}=\frac{\phi}{12,5 \cdot \eta_{i}} \cdot \frac{\sigma_{s}}{E_{s}} \cdot \frac{3 \cdot \sigma_{s}}{f_{c t m}}
\end{aligned}
$$

sendo:

$$
\begin{array}{ll}
\phi & \text { diâmetro da barra ou do conjunto de barras tracionadas; } \\
\eta_{i} & \begin{array}{l}
\text { coeficiente de conformação superficial da armadura considerada, para } \\
\text { barra com alta aderência } \eta_{1}=2,25 ;
\end{array} \\
E_{s} & \begin{array}{l}
\text { módulo de elasticidade do aço; } \\
\text { tensão de tração no centro de gravidade da armadura, calculada no }
\end{array} \\
\sigma_{s} & \begin{array}{l}
\text { estádio II; } \\
\rho_{r}
\end{array} \\
\quad \text { taxa geométrica de armadura, sendo } \rho_{r}=\frac{A_{s}}{A_{c r}}-\text { taxa de área das } \\
f_{c t m} & \text { resistência média à tração do concreto. }
\end{array}
$$


O limite para aberturas de fissuras $\left(w_{k}\right)$ determinadas com as expressões acima deve ser o menor valor entre eles.

Segundo Mollica Júnior (1986), a formação sistemática de fissuras ocorre quando a resultante de tração na barra de aço for maior ou igual à resultante de tração no concreto; elas são caracterizadas pela uniformidade de espaçamento e de abertura. A formação assistemática de fissuras ocorre quando a taxa geométrica de armadura é menor que a razão entre a resistência à tração do concreto e a tensão na armadura na seção fissurada. Assim, a fissuração assistemática ocorre nas peças com baixas taxas de armadura, apresentando falta de uniformidade no espaçamento e na abertura das fissuras. As referidas formações são ilustradas na Figura 3.1.

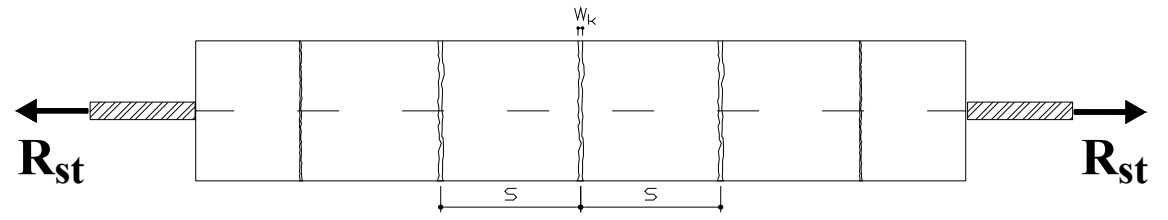

(a)

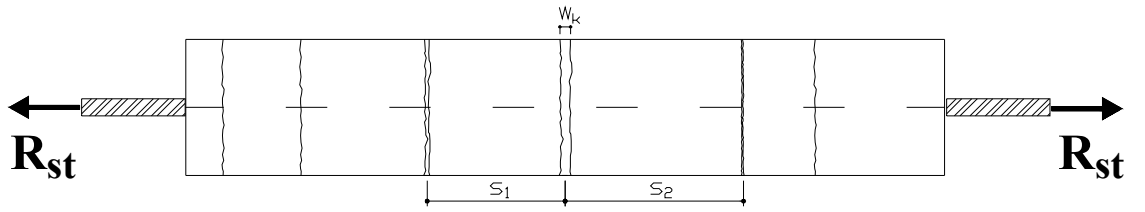

(b)

Figura 3.1 - Formação de fissuras: a) sistemática e b) assistemática, Mollica Júnior (1986) [adaptada].

Leggerini e Campos Filho (2004) desenvolveram um programa com interface gráfica para automatizar os procedimentos de verificação do estado limite de serviço de abertura das fissuras em seções retangulares e do tipo "T" para peças de concreto armado submetidas à flexão simples, de acordo com as recomendações da NBR 6118:2003.

No presente estudo foi desenvolvido um programa no software MathCad para a verificação de abertura de fissuras em elementos de concreto armado, baseado nestas expressões. 


\subsubsection{Verificação do estado limite de deformação excessiva}

De acordo com NBR 6118:2003, o estado limite de deformações excessivas é o estado em que as deformações atingem os limites estabelecidos para uso normal da edificação.

De acordo com Carvalho e Figueiredo Filho (2004), na verificação dos estados limites de deformações excessivas devem ser analisadas, além das combinações de ações a que os elementos estão submetidos, as propriedades geométricas das seções, os efeitos da fissuração e da fluência do concreto e as flechas-limite, sendo estas últimas diretamente ligadas ao tipo ou à destinação do elemento estrutural.

A verificação dos valores limites estabelecidos pela NBR 6118:2003 para a deformação da estrutura, mais apropriadamente rotações e deslocamentos em elementos lineares, analisados isoladamente e submetidos a combinações de ações, deve ser realizada por modelos que considerem a rigidez efetiva das seções da peça estrutural. Com isso, leva-se em consideração a presença das armaduras, a existência de fisssuras no concreto e as deformações diferidas no tempo.

Os deslocamentos limites são valores práticos utilizados para verificações em serviço do estado limite de deformações excessivas da estrutura, definidos pela NBR 6118:2003. Os limites da Tabela 3.5 são alguns limites para deslocamentos estabelecidos pela NBR 6118:2003. Neste caso apresentam-se apenas os relacionados à aceitabilidade sensorial, por este ser o tipo de efeito tratado neste trabalho.

Tabela 3.5 - Limites para deslocamentos, NBR 6118:2003.

\begin{tabular}{|c|c|c|c|}
\hline $\begin{array}{l}\text { Razão da } \\
\text { limitação }\end{array}$ & Exemplo & $\begin{array}{l}\text { Deslocamento } \\
\text { a considerar }\end{array}$ & $\begin{array}{c}\text { Deslocamento } \\
\text { limite }\end{array}$ \\
\hline Visual & $\begin{array}{c}\text { Deslocamentos visíveis em } \\
\text { elementos estruturais }\end{array}$ & Total & $\ell / 250$ \\
\hline Outro & Vibrações sentidas no piso & $\begin{array}{c}\text { Devido a cargas } \\
\text { acidentais }\end{array}$ & $\ell / 350$ \\
\hline \multicolumn{4}{|c|}{ Observações: ${ }^{*}$ Todos os valores limites de deslocamentos supõem elementos de vão $\ell$ suportados en } \\
\hline
\end{tabular}


Nos elementos de concreto armado, o cálculo da rigidez e, conseqüentemente dos deslocamentos, torna-se mais complexo, pois além da existência da armadura, acentuando a heterogeneidade do material, existe a possibilidade de regiões dos elementos terem parte do concreto fissurado, o que diminui a rigidez das seções nessas regiões.

Sabe-se que as seções de uma viga de concreto armado trabalham nos estádios I e II, quando solicitadas pelas ações de serviço e sua rigidez é substancialmente afetada pelo momento e pelo grau de fissuração atuante no concreto. Desse modo, para não introduzir a variação da inércia na peça de concreto, é necessário utilizar uma inércia equivalente que contemple tal situação de maneira aproximada.

O modelo proposto por Branson (1968), na avaliação de flechas em elementos de concreto armado, admite para todo o elemento uma única inércia que representa os trechos fissurados e não fissurados.

Para a avaliação aproximada da flecha imediata em vigas de concreto a NBR 6118:2003 considera a expressão proposta por Branson (1968), para o cálculo da rigidez equivalente, como mostra a eq.(3.15)

$(E I)_{e q}=E_{c s}\left\{\left(\frac{M_{r}}{M_{a}}\right)^{3} \cdot I_{c}+\left[1-\left(\frac{M_{r}}{M_{a}}\right)^{3}\right] \cdot I_{I I}\right\} \leq E_{c s} \cdot I_{c}$

sendo:

$I_{c} \quad$ momento de inércia da seção bruta de concreto; momento de inércia da seção fissurada de concreto no estádio II,

$I_{I I} \quad$ calculada com $\alpha_{e}=\frac{E_{s}}{E_{c s}}$; momento fletor na seção crítica do vão considerado, momento $M_{a} \quad$ máximo no vão para vigas biapoiadas ou contínuas e no apoio para balanços, para a combinação de ações considerada nessa avaliação;

$M_{r} \quad$ momento de fissuração do elemento estrutural;

$E_{c s} \quad$ módulo de elasticidade secante do concreto.

O momento de fissuração é definido como o momento fletor que a seção transversal é capaz de resistir sem a colaboração das barras das armaduras, sendo determinado pela eq.(3.16), considerando as hipóteses das seções homogêneas da Resistência dos Materiais. 


$$
M_{r}=\alpha \cdot \frac{f_{c t m} \cdot I_{c}}{y_{t}}
$$

sendo:

$$
\begin{aligned}
& \text { Fator que correlaciona aproximadamente a resistência à tração na } \\
& \alpha \text { flexão com a resistência à tração direta, sendo 1,2 para seções do tipo } \\
& \text { " } T \text { " ou duplo " } T \text { " e 1,5 para seções retangulares; } \\
& y_{t} \quad \text { distância do centro de gravidade da seção à fibra mais tracionada; } \\
& f_{c t m} \quad \text { resistência à tração direta do concreto }-f_{c t m}=0,30 \cdot f_{c k}^{2 / 3} \text { em MPa . }
\end{aligned}
$$

O deslocamento imediato ou instantâneo (sem considerar a fluência) em vigas de concreto armado é determinado pelas expressões da Mecânica Clássica, que depende do tipo de condição estática do sistema e do tipo de ações atuantes, utilizando-se a rigidez equivalente conforme a eq.(3.15).

Considera-se que as deformações provenientes da fluência sejam oriundas das ações permanentes. Porém, para calculá-las utiliza-se a combinação quase permanente, pois parte da carga acidental atua durante grande parcela do período de vida da estrutura, conforme sugere a NBR 6118:2003.

$\mathrm{Na}$ verificação do comportamento dos elementos estruturais considerando a não-linearidade física para o efeito de fluência $(\varphi)$, o programa desenvolvido por Oliveira (2001) - ANPAV, emprega a metodologia utilizada por Fusco (1981), que considera a decalagem do diagrama tensão-deformação para o concreto entre os instantes $t_{0}$ e $t$, na qual esta translação do diagrama tem razão $\varphi$ paralelamente ao eixo de $\varepsilon_{c}$.

Segundo a NBR 6118:2003, a flecha adicional diferida no tempo para vigas de concreto armado pode ser calculada de maneira aproximada pela multiplicação da flecha imediata pelo fator $\alpha_{f}$ dado pela eq.(3.17).

$$
\alpha_{f}=\frac{\Delta \xi}{1+50 \cdot \rho^{\prime}}
$$

sendo:

$$
\rho^{\prime} \quad \text { taxa geométrica de armadura de compressão }\left(\rho^{\prime}=\frac{A_{s}^{\prime}}{b \cdot d}\right)
$$




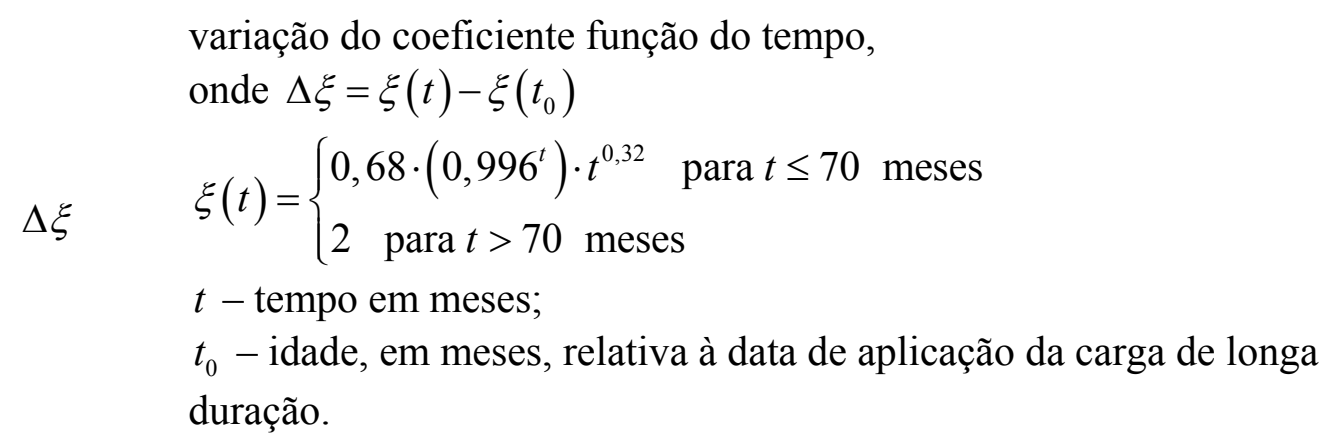

Portanto, o valor da flecha total no tempo infinito, segundo a NBR 6118:2003, para uma viga de concreto armado é determinado conforme a eq.(3.18)

$a_{\infty}=a_{0} \cdot\left(1+\alpha_{f}\right)$

sendo:

$a_{\infty} \quad$ flecha final no tempo infinito;

$a_{0} \quad$ flecha imediata em virtude das cargas permanentes.

No presente estudo foi desenvolvido um programa no software MathCad para o cálculo de flechas em elementos de concreto armado, baseado nestas expressões.

\subsection{Proposta de dimensionamento}

Neste estudo é apresentada uma proposta de dimensionamento considerando os valores médios para as relações tensão-deformação no aço e no concreto, limitando-se as suas resistências aos valores de cálculo $\left(f_{d}\right)$. Esta proposta apesar de denominada proposta de dimensionamento ela vem contemplar a verificação simultânea dos estados limites últimos e de serviços de peças de concreto armado.

A definição de uma relação constitutiva para o aço é mais simples, em virtude da invariabilidade do seu módulo de deformação longitudinal, como mostra a Figura 3.2 . 


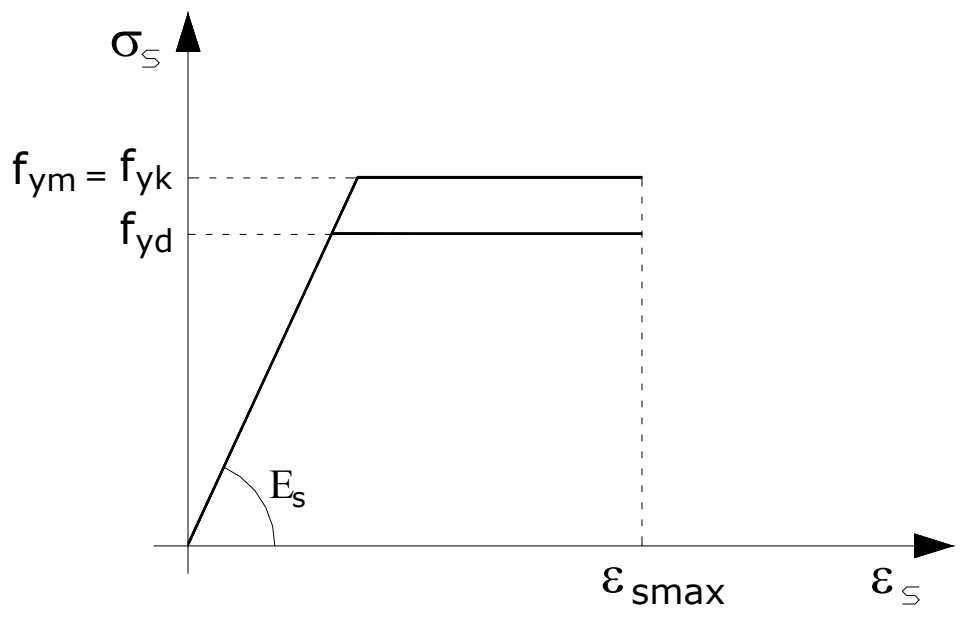

Figura 3.2 - Diagrama tensão-deformação do aço.

A definição de uma relação constitutiva para o concreto torna-se mais complexa, dada a variabilidade do seu módulo de deformação longitudinal. Ao limitar a tensão ao valor da resistência de projeto alteram-se, além da capacidade resistente teórica, as relações constitutivas do material. A curva tensão-deformação correspondente aos valores médios é substituída por uma relação elastoplástica perfeita até que seja atingida a deformação última do concreto a partir do que volta a considerar a relação média, na fase final do amolecimento, como mostra a Figura 3.3. A curva tensão-deformação do concreto à compressão considerada corresponde à proposta pelo CEB-FIP MC90.

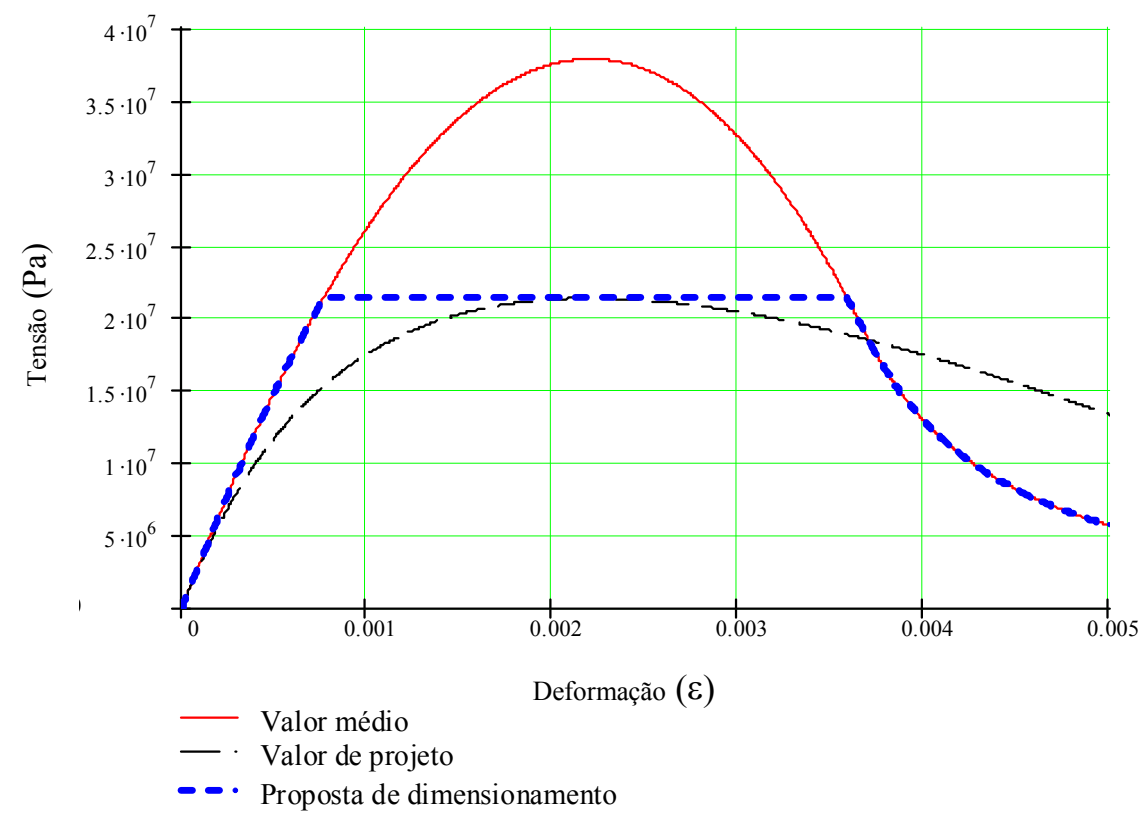

Figura 3.3 - Diagrama tensão-deformação do concreto C30, CEB-FIP MC90. 


\subsection{Proposta para uma nova consideração de segurança}

O cálculo de estruturas de concreto armado e protendido, considerando o ELU, deve satisfazer em cada seção transversal a condição de os esforços solicitantes serem menores ou iguais à capacidade resistente nesta região, conforme a eq.(3.19).

$$
S_{d} \leq R_{d}
$$

Sabe-se que a determinação dos esforços internos e externos de cálculo atuantes na seção transversal usualmente é feita de forma independente. Porém, esta separação é inconsistente para estruturas hiperestáticas do ponto de vista mecânico, em virtude da redistribuição dos esforços solicitantes que depende da rigidez relativa dos componentes estruturais.

Em estruturas isostáticas, a distribuição dos esforços solicitantes é determinada apenas pelas condições de equilíbrio. Alcançada a capacidade resistente da seção transversal, um novo estado de equilíbrio da seção tornar-se-ia impossível. Portanto, acrescido o carregamento, é inadmissível aumentar a capacidade resistente em qualquer seção transversal da estrutura. Assim, a margem de segurança da seção transversal crítica é igual à margem de toda estrutura.

No caso de estruturas hiperestáticas, é possível um acréscimo no carregamento depois de alcançada a capacidade resistente em uma ou mais seções transversais, pois a distribuição dos esforços solicitantes é determinada simultaneamente pelas condições de equilíbrio e de compatibilidade, caso exista capacidade de deformação plástica de pelo menos uma seção transversal crítica. Portanto, as capacidades resistentes da seção transversal e da estrutura não são as mesmas.

Segundo Tue (1996), König et al. (1997), a margem de segurança da seção transversal de concreto armado pode ser descrita pela razão entre a capacidade resistente teórica determinada com os valores médios e os valores de projeto das resistências dos materiais.

O tratamento da margem de segurança das estruturas de concreto novamente está em sendo abordado no âmbito acadêmico, pela larga utilização de procedimentos não-lineares. De acordo com o Bulettin d'Information n ${ }^{\mathrm{o}} 229$ do CEB (1995), a proposta 
dos membros do CEB-Commission 1 é criar um conceito de segurança consistente, utilizando a não-linearidade física para todos os tipos de modelos de estruturas. Porém, os membros do grupo deixam claro que a probabilidade de ruína pode ser avaliada pela abordagem probabilística, em virtude da variabilidade das resistências dos materiais e das ações. Entretanto, a avaliação probabilística aplicada às estruturas ainda não é viável para o uso prático.

A nova proposta para dimensionamento de estruturas de concreto que pode ser implantada consiste no emprego do método dos coeficientes globais. Esta proposta, de acordo com o Bulettin d'Information n 239 do CEB (1997), tem como finalidade estabelecer uma metodologia consistente capaz de ser utilizada para qualquer tipo de modelo e de estrutura. A eq.(3.20) expressa o método dos coeficientes globais.

$$
S\left(\gamma_{q} \cdot Q+\gamma_{g} \cdot G\right) \leq \frac{R_{s y s}}{\gamma_{g l}}
$$

sendo:
$S \quad$ esforços solicitantes;
$\gamma_{q} \quad$ fator de segurança parcial para ações variáveis;
Q ações variáveis;
$\gamma_{g} \quad$ fator de segurança parcial para ações permanentes;
$G \quad$ ações permanentes;
$R_{s y s} \quad$ capacidade resiste da estrutura;
$\gamma_{g l} \quad$ fator de segurança global para resistência da estrutura.

A grande dificuldade está na definição do valor do coeficiente global a ser utilizado. O coeficiente pode variar de acordo com o mecanismo de ruína da estrutura, pelo concreto ou pelo aço. Definindo-se as resistências médias ${ }^{3}$ dos materiais de forma simplificada conforme a eq.(3.21):

$$
\begin{aligned}
& f_{c m}=1,10 \cdot f_{c k} \\
& f_{y m}=1,10 \cdot f_{y k}
\end{aligned}
$$

\footnotetext{
${ }^{3}$ As resistênciass médias descritas não são as médias obtidas por meio de análise estatística.
} 
De acordo com as resistências dos materiais definidas acima, o coeficiente global $\left(\gamma_{g l}\right)$ para uma seção transversal situa-se aproximadamente entre 1,65 , quando ocorre o esgotamento da capacidade resistente do concreto e 1,265 quando esgota a capacidade resistente do aço, ao serem utilizados coeficientes de minoração das resistência de $\gamma_{c}=1,5$ e $\gamma_{s}=1,15$ para o concreto e para o aço, respectivamente, conforme CEB-FIP MC90. Estes valores podem ser calculados de forma analítica apresentados por König et al. (1997), como mostra a eq.(3.22) e eq.(3.23) para o concreto e para o aço.

$$
\begin{aligned}
& f_{c d}=\frac{f_{c k}}{1,5} \quad \text { e } f_{c m}=1,10 \cdot f_{c k} \Rightarrow \frac{f_{c m}}{f_{c d}}=1,10 \cdot 1,5=1,650 \\
& f_{y d}=\frac{f_{y k}}{1,15} \quad \text { e } f_{y m}=1,10 \cdot f_{y k} \Rightarrow \frac{f_{y m}}{f_{y d}}=1,10 \cdot 1,15=1,265
\end{aligned}
$$

Os coeficientes de segurança são diferentes se a ruptura ocorrer no concreto ou no aço, como comentado no parágrafo anterior. Caso a ruptura seja mista, há uma lacuna no procedimento, não sendo determinado o coeficiente de segurança nesses casos, o que dificulta a definição de uma metodologia única para a verificação das estruturas. Sabe-se que, normalmente, as vigas são projetadas para um estado limite último definido para deformação excessiva das armaduras de flexão, enquanto os pilares, pelo esmagamento do concreto.

Segundo König et al. (1997), um possível caminho para uma investigação determinística do coeficiente global de segurança é a modificação na resistência média do concreto; sendo a solução encontrada pelo referido autor e pelos membros do CEBCommission 1 para adaptar o valor da resistência média do concreto, desse modo substituindo-a por um valor convencional de referência. Pesquisas realizadas por König et al. $(1997)^{4}$ apud. Bulettin d'Information $\mathrm{n}^{\mathrm{o}} 239$ do CEB (1997) afirmam que a resistência média do concreto, medida in-situ, é cerca de $85 \%$ do respectivo valor da resistência característica à compressão, podendo ser expresso conforme a eq.(3.24).

\footnotetext{
${ }^{4}$ König G., Soukov D., Jungwirth F. (1997) - Sichere Betonproduktion für Stahlbetontragwerke, intermediate report 2, March 1997.
} 


$$
\frac{f_{c m}}{f_{c k}}=0,85
$$

No entanto, as considerações feitas para o diagrama parabólico da tensãodeformação para o concreto e o diagrama bi-linear para o aço foram mantidas inalteradas.

Considerando válida a eq.(3.24), os valores médios da resistência do concreto e do aço para determinação do comportamento de estruturas de concreto armado, podem ser redefinidos conforme a eq.(3.25), sendo neste texto denominados valores de referência das resistências dos materiais, para não serem confundidos com valores médios anteriormente definidos.

$$
\begin{aligned}
& f_{c R}=0,85 \cdot f_{c k} \\
& f_{y R}=1,10 \cdot f_{y k}
\end{aligned}
$$

Portanto, aceita a validade da eq. (3.25), os coeficientes globais de segurança referidos aos dois tipos de ruptura (frágil ou dúctil) tornam-se bastante próximos, podendo ser considerados iguais a 1,27. Lembrando que os coeficientes ponderadores da resistência do concreto $\left(\gamma_{c}\right)$ e do aço $\left(\gamma_{s}\right)$, estão de acordo com CEB-FIP MC90. A verificação analítica do coeficiente para o concreto e o aço é mostrada abaixo.

$$
\begin{gathered}
f_{c d}=\frac{f_{c k}}{1,5} \quad \text { e } f_{c R}=0,85 \cdot f_{c k} \Rightarrow \frac{f_{c R}}{f_{c d}}=0,85 \cdot 1,5=1,275 \\
f_{y d}=\frac{f_{y k}}{1,15} \quad \text { e } f_{y R}=1,10 \cdot f_{y k} \Rightarrow \frac{f_{y R}}{f_{y d}}=1,10 \cdot 1,15=1,265
\end{gathered}
$$

Para comprovar as considerações acima, König et al. (1997) e Anher e Tue (1997) fizeram algumas análises para verificar a capacidade resistente de uma seção transversal de concreto armado submetida à flexão pura. A Figura 3.4 mostra os resultados das análises nos quais foram empregados valores diferentes para as resistência dos materiais, com valores médios e de referência conforme a eq.(3.21) e a eq.(3.25), respectivamente. 
A mudança na resistência média adotada para os materiais segundo a eq.(3.25) influencia na determinação da capacidade resistente da seção transversal, como pode-se perceber na Figura 3.4. Observa-se pequena variação do coeficiente global de segurança $\left(\gamma_{g l}\right)$ entre os momentos resistentes com o acréscimo da taxa de armadura, quando são utilizadas as resistências de referência, tornando-se praticamente constante. No entanto, empregando-se os valores médios da resistência dos materiais esta variação é bastante significativa. Assim, torna-se bastante favorável para o emprego do coeficiente global de segurança único em estruturas de concreto.

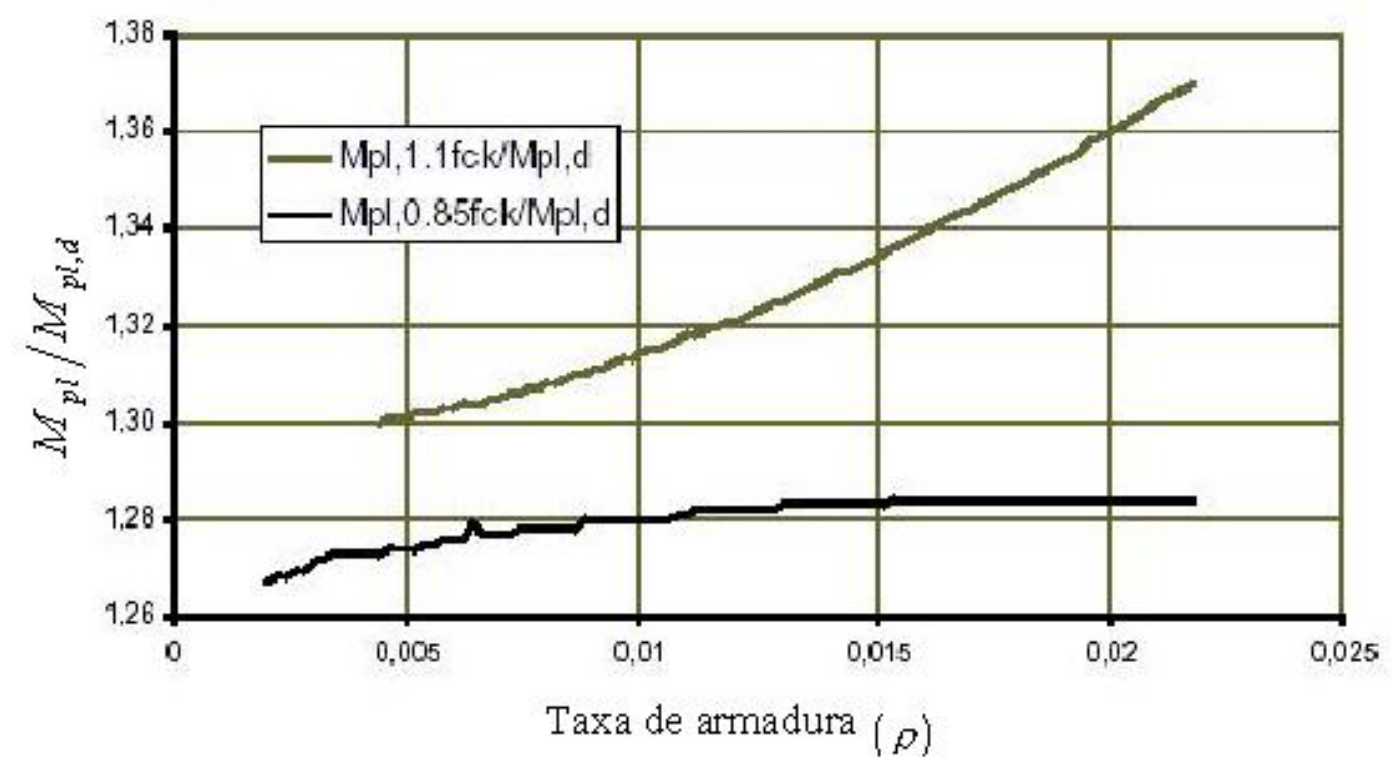

Figura 3.4 - Razão ente os momentos resistentes com diferentes resistência dos materiais - König et al. (1997) e Ahner \& Tue (1997) [adaptada].

sendo:

$M_{p l} \quad$ momento resistente obtido com as resistências médias e de referência,

$M_{p l, d} \quad$ momento resistente obtido com as resistências de cálculo.

Com o intuito de confirmar os resultados apresentados acima, foram feitas no presente trabalho algumas análises para uma seção transversal com largura de $15 \mathrm{~cm}$ e altura de $60 \mathrm{~cm}$, submetida à flexão pura considerando resistência característica à compressão do concreto de $25 \mathrm{MPa}$ e resistência característica à tração do aço de 500 $\mathrm{MPa}$, como mostra a Figura 3.5. Nestas análises foram empregados os valores dos coeficientes ponderadores segundo o CEB-FIP MC90 $\left(\gamma_{c}=1,5\right.$ e $\left.\gamma_{s}=1,15\right)$. 


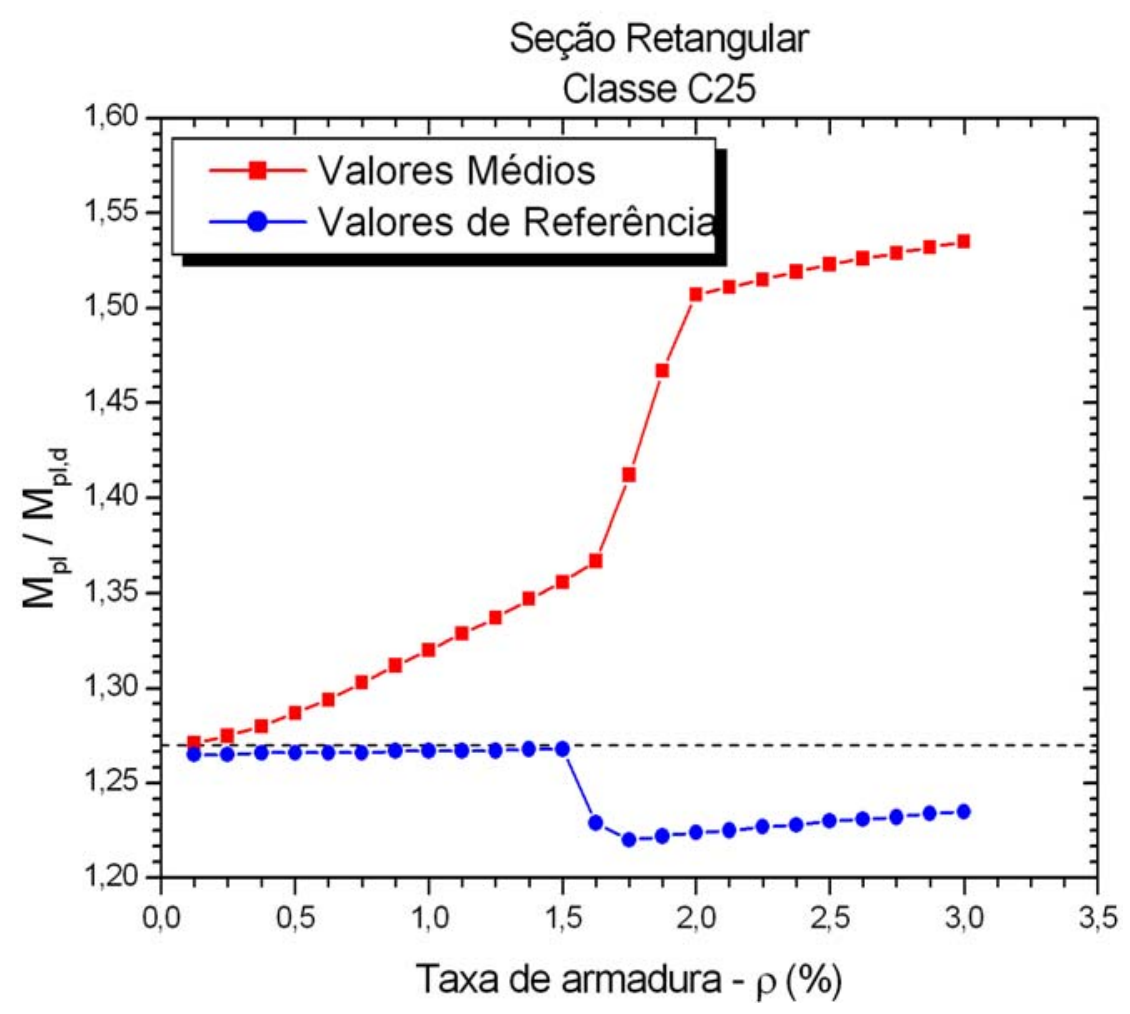

Figura 3.5 - Razão ente os momentos resistentes da seção retangular submetida à flexão simples.

Os valores da relação entre os momentos resistentes permaneceram praticamente constantes quando utilizados os valores de referência das resistências dos materiais, enquanto para os valores médios ocorreu grande variação à medida que se aumentava a taxa de armadura. A pequena mudança com os valores de referência ocorreu quando o elemento passou para o domínio 4, domínio este não recomendado para dimensionamento de peças de concreto armado, em virtude do subaproveitamento do aço e por ocorrer ruptura frágil dos materiais.

A Figura 3.5 confirma a pequena variabilidade do coeficiente global, tornadose bastante favorável para o emprego de um coeficiente de segurança praticamente constante.

Alguns trabalhos foram desenvolvidos com o intuito de verificar $o$ comportamento das estruturas de concreto, considerando a análise não-linear e as relações das resistências médias e de referência dos materiais, mostrados acima.

Ahner (1999), mostrou a expressiva vantagem dos métodos não-lineares, bem como a diferença do comportamento utilizando-se a resistência de cálculo, média e de referência, com um ganho na rigidez dos elementos quando utilizadas as resistências médias e de referência. $\mathrm{O}$ autor analisou um pórtico plano para verificar a influência do efeito de segunda ordem, cujos resultados foram satisfatórios empregando os valores de 
referência que proporcionam um coeficiente de segurança de 1,30, independente do critério de ruptura.

Ahner (2000) fez análise de pilares esbeltos submetidos à compressão excêntrica, tendo observado que o índice de confiabilidade $(\beta)$ utilizando-se a resistência de referência dos materiais em análise não-linear conduz a valor relativamente uniforme para diferentes situações de projeto. Na maioria das vezes o índice de confiabilidade encontrado era maior que 4,70, com uma probabilidade de ruptura de aproximadamente $10^{-6}$, valor este considerado satisfatório em elementos estruturais de vigas de concreto armado submetidos à flexão.

Wittek e Meiswinkel (2000) analisaram a carga última de projeto em peças fletidas e constataram que a segurança do sistema pode ser realizada com análise nãolinear física, admitindo-se valores de referência para o ELU.

Henriques et al. (2002) desenvolveram um método bastante semelhante ao proposto pelo Bulettin d'Information $\mathrm{n}^{\mathrm{o}} 239$ do CEB (1997), utilizando resistência média dos materiais, em que o coeficiente global varia de acordo com a posição da linha neutra e a resistência do concreto, praticamente constante para uma profundidade da linha neutra de $\frac{x}{d}=0,35$. Os dois métodos, König et al. (1997) e Henriques et al. (2002) proporcionaram resultados semelhantes, com pequena diferença quando se empregam maiores taxas de armaduras de tração.

Admitidas como válidas as considerações feitas quanto às resistências médias dos materiais propostas por König et al. (1997), cabe adaptá-las à normalização brasileira. Sabe-se que o coeficiente de minoração da resistência aplicado ao aço $\left(\gamma_{s}=1,15\right)$ é o mesmo tanto para CEB-FIB MC90 quanto para a NBR 6118:2003. Porém, o coeficiente aplicado ao concreto $\left(\gamma_{c}\right)$ é diferente, com o valor de $\gamma_{c}=1,4$ utilizado pela NBR 6118:2003. Assim, o coeficiente global de segurança pode ser determinado analiticamente conforme a eq.(3.28).

$$
f_{c m}=0,85 \cdot f_{c k} \Rightarrow \frac{f_{c m}}{f_{c d}}=0,85 \cdot 1,4=1,19
$$

Como a idéia é manter um mesmo coeficiente de segurança, independente do tipo de ruptura, seja por esmagamento do concreto ou por alongamento excessivo da 
armadura, deve-se determinar um valor para que a resistência do aço proporcione um coeficiente de segurança igual ao do concreto, conforme mostra a eq.(3.29).

$$
\frac{f_{y m}}{f_{y d}}=1,19 \Rightarrow f_{y m}=1,19 \cdot \frac{f_{y k}}{1,15} \Rightarrow f_{y m}=1,035 \cdot f_{y k}
$$

Percebe-se que, para obtenção da resistência média do aço, os coeficientes são diferentes. O Bulettin d'Information n ${ }^{o} 239$ do CEB (1997) não justifica a consideração do valor 1,10 para a resistência média e algumas pesquisas realizadas com objetivo de definir esse valor não obtiveram sucesso. Tem-se conhecimento que o critério de produção do aço é mais rigoroso que o do concreto, por isso, o valor de $10 \%$ da resistência característica para o aço parece estar excessivo.

Segundo Oliveira (2001), resultados obtidos no laboratório do Departamento de Engenharia de Estruturas da EESC/USP, não divulgados formalmente, sugerem resistências médias bem próximas do valor característico da resistência de escoamento do aço. Assim, a bem da consistência, parece razoável adotar a razão entre o valor médio e o valor característico da resistência do aço em 1,035, com acréscimo de 3,5\% . Portanto, a resistência média dos materiais, adaptada à normalização brasileira será dada pela eq.(3.30), também denominada resistência de referência.

$$
\begin{aligned}
& f_{c R}=0,85 \cdot f_{c k} \\
& f_{y R}=1,035 \cdot f_{y k}
\end{aligned}
$$

Com o intuito de verificar-se o comportamento do método do coeficiente global de segurança, foram realizadas algumas análises para a avaliação da capacidade resistente de seções transversais submetidas à flexão pura, conforme mostra a Figura 3.6. Nestas análises considerou-se o diagrama parábola-retângulo para o concreto e bilinear para o aço, verificando o estado limite último da seção. 


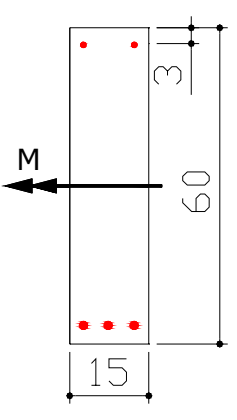

(a)

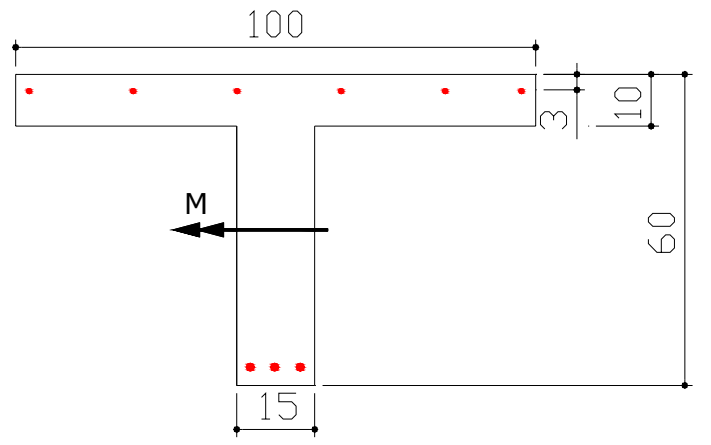

(b)

Figura 3.6 - Seção transversal submetida à flexão: a) retangular e b) do tipo "T". Medidas em cm.

Os resultados obtidos para a seção retangular à flexão simples em que se variou a taxa de armadura e a classe de concreto são mostrados na Figura 3.7 e Figura 3.8.

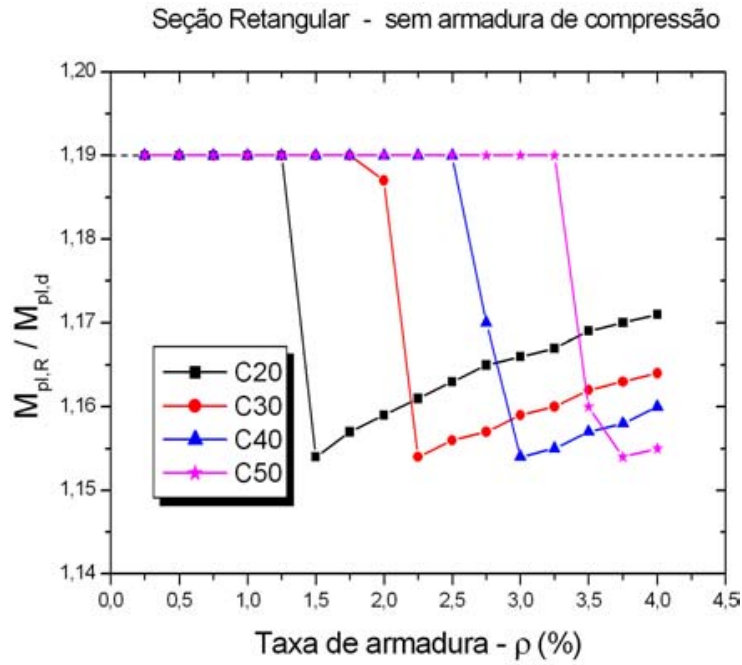

(a)

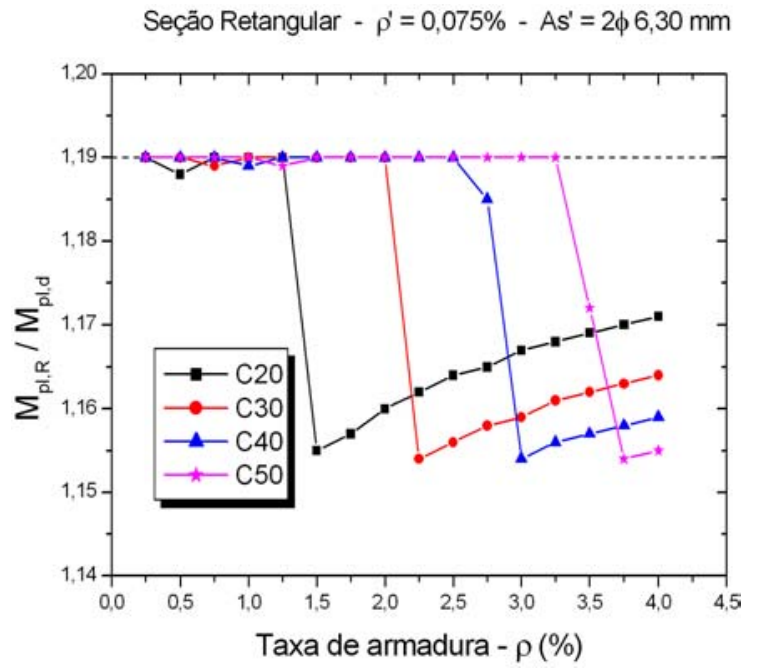

(b)

Figura 3.7 - Seção retangular submetida à flexão: a) sem armadura de compressão e b) armadura de compressão $(2 \phi 6,30 \mathrm{~mm})$. 


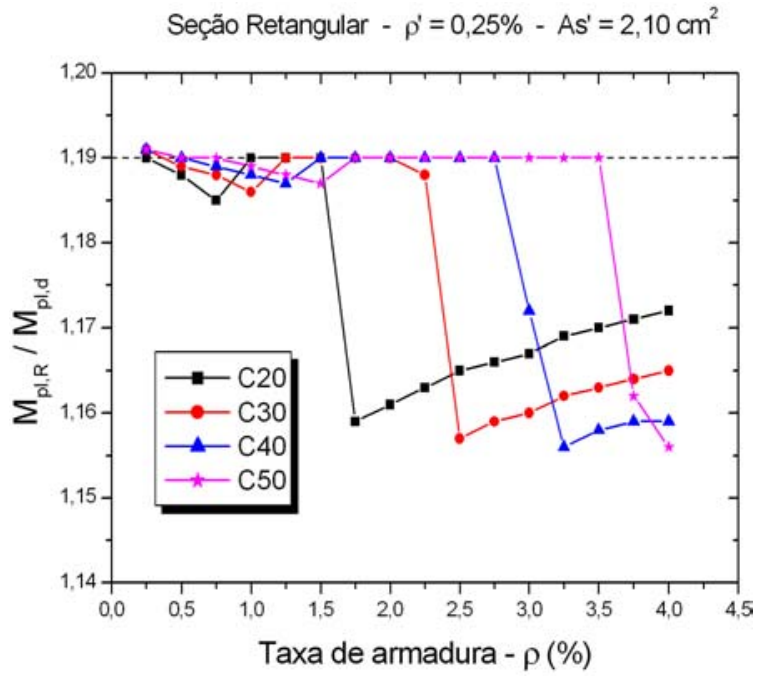

(a)

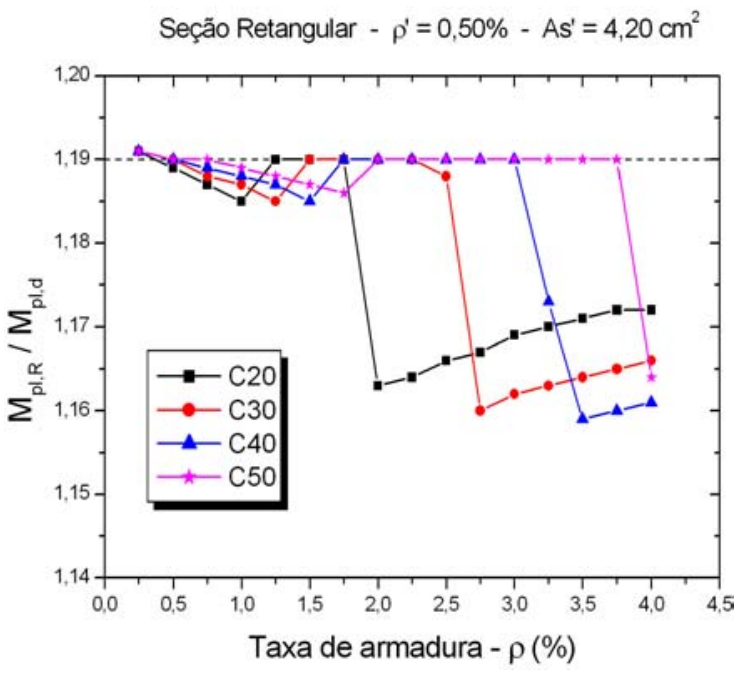

(b)

Figura 3.8 - Seção retangular submetida à flexão: a) taxa de armadura de compressão $\rho=0,25 \%$ e b) taxa de armadura de compressão $\rho=0,50 \%$.

Os resultados obtidos para a seção do tipo "T" são mostrados na Figura 3.9 e Figura 3.10.

Seção do tipo "T" - sem armadura de compressão

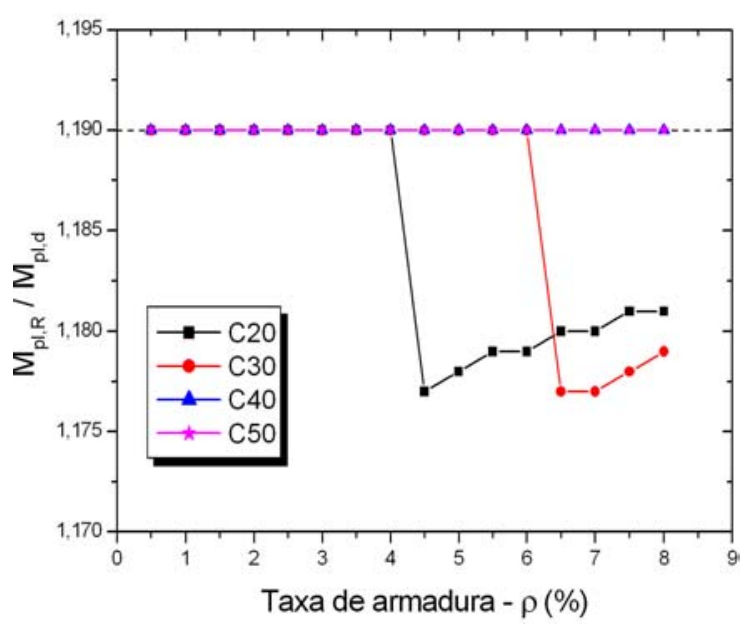

(a)
Seção do tipo "T" - $\rho^{\prime}=0,075 \%$ - As' $=2 \phi 6,30 \mathrm{~mm}$

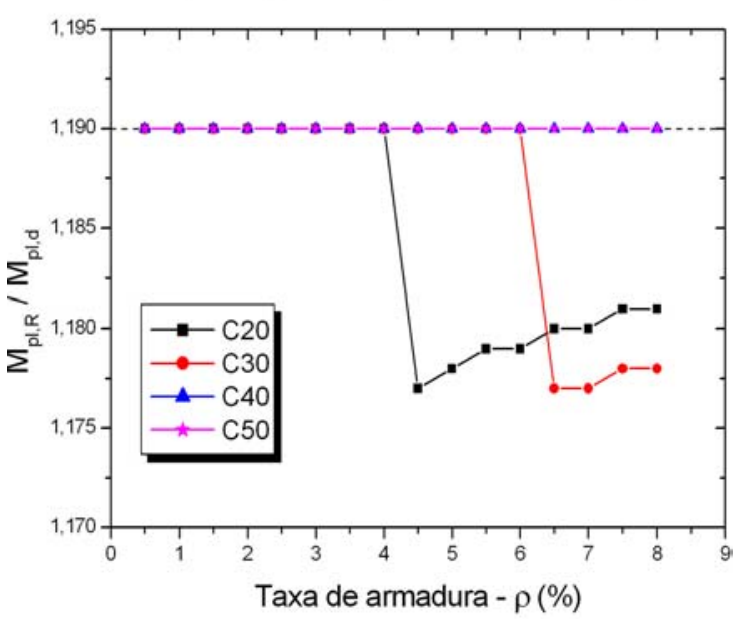

(b)

Figura 3.9 - Seção do tipo “T” submetida à flexão: a) sem armadura de compressão e b) armadura de compressão $(2 \phi 6,30 \mathrm{~mm})$. 


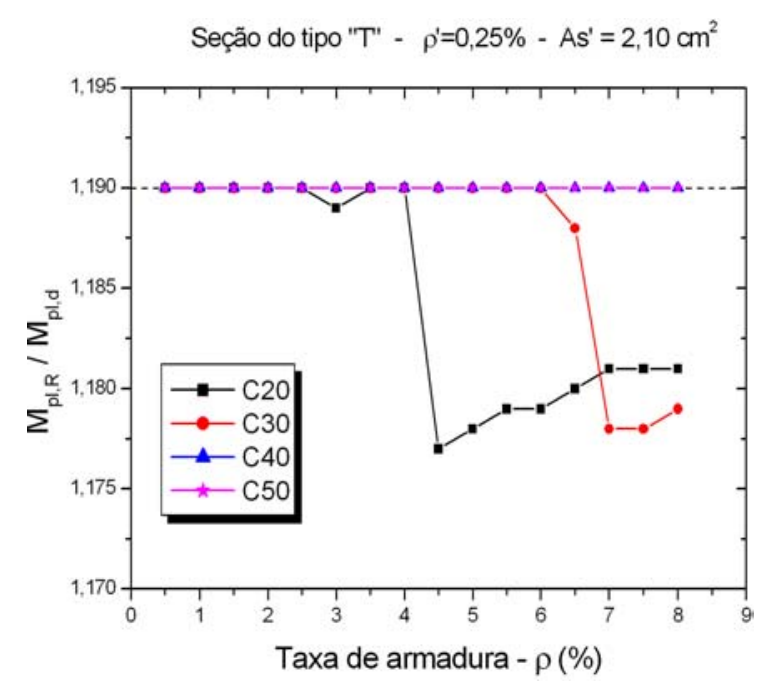

(a)

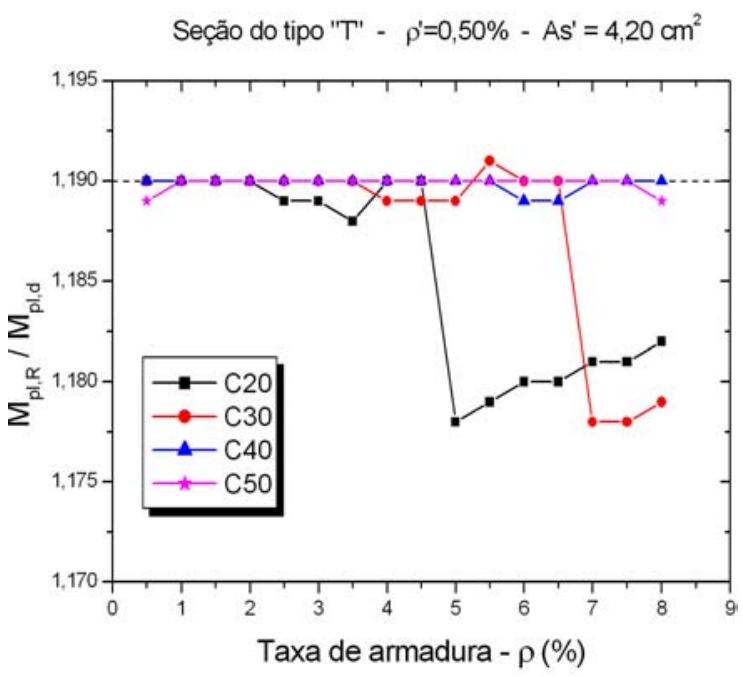

(b)

Figura 3.10 - Seção do tipo "T" submetida à flexão: a) taxa de armadura de compressão $\rho=0,25 \%$ e

b) taxa de armadura de compressão $\rho=0,50 \%$.

De forma geral, os diagramas mostraram boa uniformidade do coeficiente global de segurança, em torno do valor esperado $\left(\gamma_{g l}=1,19\right)$, indicando que o método pode ser empregado na verificação de estruturas de concreto. Entretanto, devem ser realizadas algumas análises e estudos mais minuciosos.

Nas seções transversais retangulares, o menor valor do coeficiente global de segurança foi de 1,154 para seção sem armadura de compressão. Quando considerada armadura de compressão, o coeficiente global teve pequenas variações com o menor valor em torno de 1,162 .

As seções do tipo "T" tiveram um melhor comportamento do coeficiente global em razão da contribuição da mesa comprimida de concreto. No entanto, seu menor valor em todos os casos, foi 1,177, com ou sem armadura de compressão.

Percebe-se que em todos os casos (seções retangulares e do tipo "T") houve menor variabilidade do coeficiente global quando empregadas classes de concreto maiores, o que é uma tendência natural. Em todas as análises, a mudança do coeficiente global de segurança ocorreu à medida que a profundidade da linha neutra passou para o domínio 4 (seção superarmada), usualmente evitado em virtude da possível ruptura frágil. 
Em resumo, o método dos coeficientes globais de segurança mostrou-se útil para o emprego na verificação de estruturas de concreto armado, considerada a nãolinearidade física, conforme será visto nos exemplos do capítulo seguinte.

Apesar desta proposta ser interessante por uniformizar os coeficientes parciais considerando um único coeficiente global de segurança, ela não contempla o dimensionamento de estruturas de concreto armado para o ELU. Tornando-se conveniente a introdução de uma nova proposta, neste caso a proposta de dimensionamento comentada no item 3.4 do presente trabalho, em que considera os valores médios das resistências dos materiais limitados aos valores de cálculo. 


\section{EXEMPLOS E APLICAÇÕES}

\subsection{Considerações gerais}

Neste capítulo são apresentados alguns exemplos com o intuito de fixar as idéias propostas ao dimensionamento e verificação da segurança de estruturas de concreto armado. Nas análises não-lineares físicas são empregadas as resistências médias e de referência dos materiais.

A verificação da segurança em regime não-linear é dependente das taxas de armaduras e da geometria das seções transversais pré-estabelecidas segundo um dimensionamento em regime elástico-linear. Portanto, nesse regime, a verificação é um processo iterativo de ajuste das dimensões e das taxas de armadura dos elementos. As plastificações às quais os elementos estão submetidos podem ser induzidas pelo projetista tanto na diminuição das taxas de armaduras longitudinais quanto nas dimensões das seções transversais (altura e largura) e, também, na combinação conjunta das soluções, desde que satisfaçam às exigências normativas.

Os dois primeiros exemplos foram comparados com o trabalho de Wittek e Meiswinkel (2000) para verificar e aferir o programa desenvolvido por Oliveira (2001) e adaptado no presente trabalho. Wittek e Meiswinkel consideram o diagrama tensãodeformação semelhante ao do CEB-FIP MC90 para o concreto e, para o aço, como um modelo elastoplástico com encruamento. Nestes exemplos foram considerados os coeficientes ponderadores das resistências, os módulos de deformações longitudinais 
tangente do aço e do concreto, de acordo com o CEB-FIP MC90, cujas expressões serão mostradas posteriormente.

$\mathrm{Na}$ análise do ELU foram consideradas diferentes propriedades mecânicas para os materiais, verificando-se o comportamento para as resistências de projeto, médias e de referência.

\subsection{Comparação entre resultados - aferição do programa}

Os exemplos realizados nesta seção foram estudados por Wittek e Meiswinkel (2000), nos quais foram considerados os mesmos parâmetros adotados pelos autores para melhor avaliar os resultados obtidos com o programa desenvolvido por Oliveira (2001) - ANPAV. No primeiro exemplo é verificada a segurança da seção transversal crítica com os valores médios e de referência da resistência dos materiais, utilizando o programa desenvolvido pelo autor no software MathCad. Cabe ressaltar que aferições do programa, reproduzindo a comparação entre resultados teóricos e experimentais foram apresentadas por Oliveira (2001).

Os dois exemplos seguintes, placa biapoiada e viga contínua, foram analisados considerando a não-linearidade dos materiais com o programa ANPAV. Foram escolhidos estes exemplos para aferir o programa com os resultados de Wittek e Meiswinkel. No entanto, foram feitas algumas modificações no programa ANPAV com relação à deformação última do aço, onde foi considerado o valor adotado pelo CEBFIP MC90 ( $\varepsilon_{y u}=25 \%$ ), e também o encruamento no aço. Desta forma, o modelo para o aço tornou-se elastoplástico com encruamento, ao invés de elastoplástico perfeito como adotado no programa original. Estas mudanças foram feitas para melhor representar os resultados. A resistência última do aço, considerando o encruamento, é representada pela eq.(4.1).

$f_{t u}=1,08 \cdot f_{y}$

sendo:

$f_{t u} \quad$ resistência última do aço;

$f_{y} \quad$ resistência de escoamento do aço. 
Os coeficientes ponderadores da resistência dos materiais aplicados aos exemplos foram os propostos pelo CEB-FIP MC90, ou seja, $\gamma_{c}=1,5$ para o concreto e $\gamma_{s}=1,15$ para o aço. Os valores da resistência média (índice ${ }_{\mathrm{m}}$ ) e de referência (índice R) do concreto e do aço estão mostrados na eq.(4.2).

$$
\begin{aligned}
& f_{c m}=f_{c k}+8 \text { em MPa } \\
& f_{y m}=f_{y k} \\
& f_{c R}=0,85 \cdot f_{c k} \\
& f_{y R}=1,10 \cdot f_{y k}
\end{aligned}
$$

Nas análises não-lineares os módulos de elasticidade longitudinais tangentes iniciais do concreto e do aço foram considerados segundo o CEB-FIP MC90, expressos pela eq.(4.3).

$$
\begin{aligned}
& E_{c}=\alpha_{e} \cdot\left(\frac{f_{c k}+\Delta f}{f_{c m o}}\right)^{1 / 3} \\
& E_{s}=210000 \mathrm{MPa}
\end{aligned}
$$

sendo:

$$
\begin{aligned}
& a_{e}=2,15 \times 10^{4} \mathrm{MPa} \\
& \Delta f=8 \mathrm{MPa} \\
& f_{c m o}=10 \mathrm{MPa}
\end{aligned}
$$

\subsubsection{Seção transversal}

Neste exemplo foi verificada a segurança da seção transversal submetida à flexão pura. A seção transversal tem medidas de $100 \mathrm{~cm}$ de largura e $18 \mathrm{~cm}$ de altura, com cobrimento da armadura de $2,5 \mathrm{~cm}$. Não foi considerada armadura de compressão na seção.

Os valores das resistências características dos materiais foram de $25 \mathrm{MPa}(\mathrm{C} 25)$ para o concreto à compressão e de $500 \mathrm{MPa}(\mathrm{CA}-50)$ para o aço. A segurança da seção transversal crítica é mostrada na Figura 4.1. 


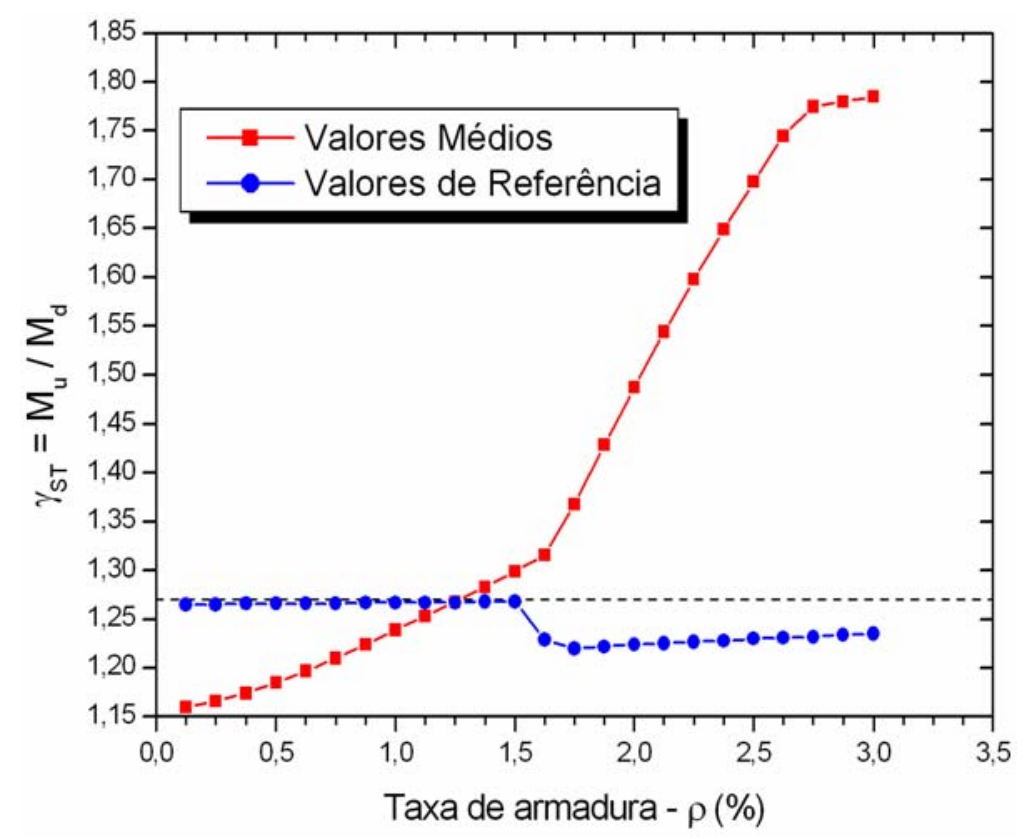

Figura 4.1 - Segurança da seção transversal - flexão simples.

Assumindo os valores médios para a resistência dos materiais, a influência da taxa de armadura é bastante considerável, de maneira que a segurança da seção transversal varia entre 1,15 e 1,30 para valores da profundidade da linha neutra (LN) entre os domínios 2 e 3 . A segurança da seção aumenta consideravelmente a partir da taxa de armadura de 1,5\%. Nos domínios 2 e 3, a segurança da seção transversal permanece praticamente constante e igual a 1,27 $\left(\gamma_{S T}=1,27\right)$ considerando os valores de referência para a resistência dos materiais, o que satisfaz a consideração do coeficiente global de segurança.

Percebe-se uma pequena variação na segurança da seção quando a profundidade da linha neutra passa para o domínio 4, domínio no qual não é recomendado para o dimensionamento de peças de concreto, por permitir a ocorrência de ruptura frágil dos materiais.

\subsubsection{Placa biapoiada - Wittek e Meiswinkel (2000)}

Neste exemplo foi analisada uma placa apoiada em duas extremidades, estudada por Wittek e Meiswinkel (2000). A placa biapoiada está submetida à carga uniformemente distribuída, sendo que sua seção transversal tem $100 \mathrm{~cm}$ de largura e $18 \mathrm{~cm}$ de altura, como mostra a Figura 4.2. 


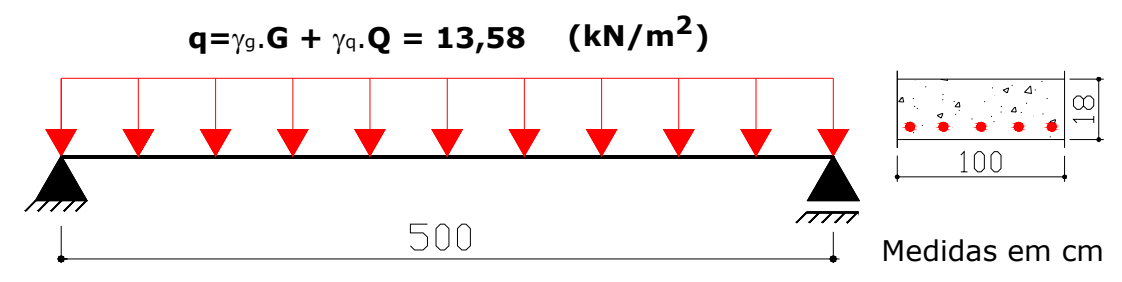

Figura 4.2 - Placa biapoiada - Wittek e Meiswinkel (2000).

Dimensionou-se a estrutura em regime elástico-linear atendendo ao ELU, utilizando a rotina de cálculo desenvolvida pelo autor no software MathCad. Foram considerados os valores dos coeficientes ponderadores das resistências dos materiais segundo o CEB-FIP MC90, sendo $\gamma_{c}=1,5$ (concreto) e $\gamma_{s}=1,15$ (aço). Os valores das resistências características à compressão do concreto de $25 \mathrm{MPa}$ e à tração do aço de $500 \mathrm{MPa}$.

\section{a) Regime elástico-linear}

$M_{d}=42,44 \mathrm{kNm} / \mathrm{m} ; \mathrm{h}=18 \mathrm{~cm} \rightarrow d=15 \mathrm{~cm}$

portanto, $A_{s}=7,05 \mathrm{~cm}^{2}$

O coeficiente de segurança da seção transversal $\left(\gamma_{S T}=M_{u} / M_{d}\right)$ foi de $\gamma_{S T}=1,18$ considerados os valores médios e $\gamma_{S T}=1,27$ para os valores de referência, praticamente os mesmos valores encontrados por Wittek e Meiswinkel (2000), que foram de 1,19 (valores médios) e 1,27 (valores de referência). Os valores médios e de referência da resistência dos materiais utilizados pelos referidos autores neste exemplo estão expressos na eq.(4.2).

\section{b) Regime não-linear físico}

Nesta análise foi considerada a armadura dimensionada com o regime elásticolinear, descrito acima. O elemento estrutural foi discretizado em 13 nós e 12 elementos, com maior discretização na região de momento máximo, com seção transversal estratificada em 10 camadas, como mostra a Figura 4.3. 


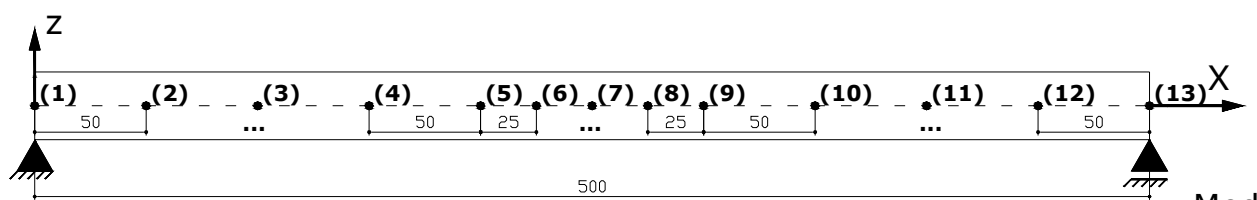

Medidas em $\mathrm{cm}$

Figura 4.3 - Discretização da placa biapoiada e estratificação da seção transversal.

Os resultados das análises são apresentados nas figuras seguintes considerando os valores médios e de referência das resistências dos materiais. A Figura 4.4 mostra as curvas do fator de carga $(\lambda \cdot q)$ versus deslocamento da estrutura no meio do vão, considerando os valores médios e de referência da resistência dos materiais. Os incrementos de carga atribuídos na análise não-linear foram definidos nos gráfícos como fator de carga $(\lambda)$. Quando for atribuído o carregamento total, para o qual a peça foi dimensionada, o fator de carga é igual a $1(\lambda=1,0)$; quando ultrapassar este valor, indica que a estrutura está suportando um maior carregamento do que o inicialmente projetado, tendo com isso uma reserva de carga.

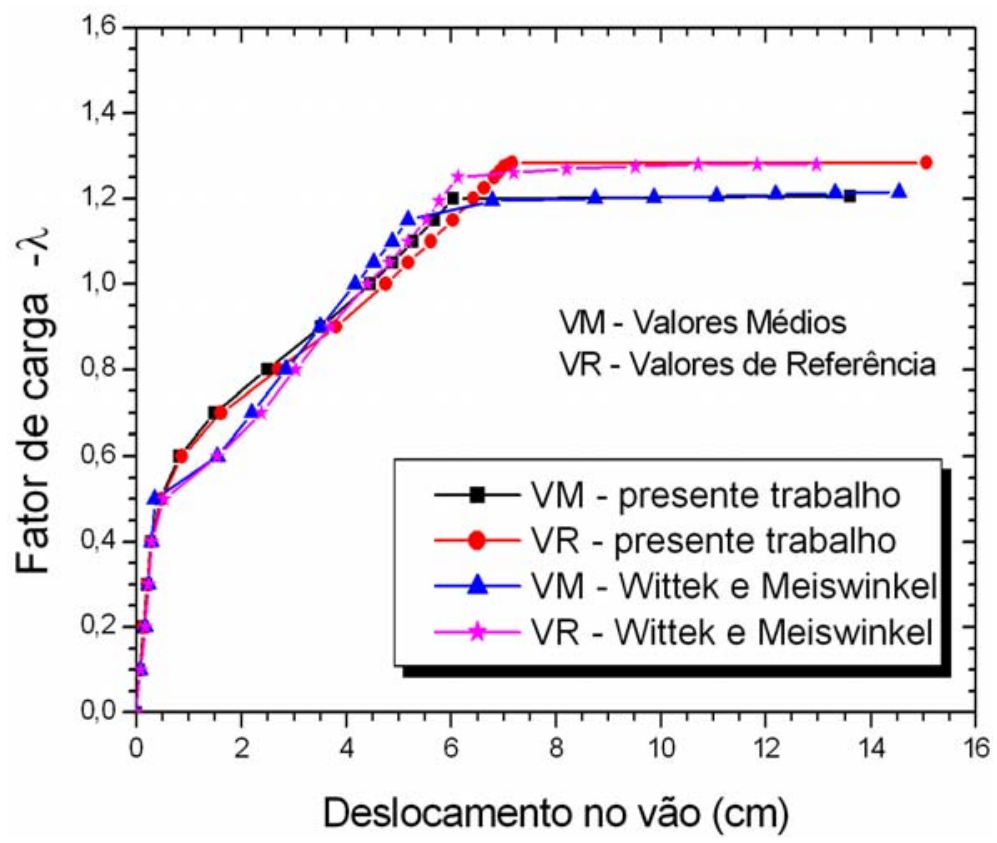

Figura 4.4 - Fator de carga vs. deslocamento - análises com valores médios e de referência.

Percebe-se que as análises com o programa ANPAV proporcionaram resultados semelhantes aos da referência utilizada, Wittek e Meiswinkel (2000), indicando que pode ser utilizado para análises de outros elementos. Porém, ocorreu uma pequena diferença após a fissuração da peça de concreto, com menores deslocamentos 
nas análises realizadas com o programa ANPAV, provavelmente em virtude do modelo considerado no programa contemplar a contribuição do concreto íntegro entre fissuras.

A Figura 4.5 mostra, em detalhes, os resultados das análises realizadas neste trabalho comparado-os com os de Wittek e Meiswinkel (2000). Os valores dos coeficientes globais da estrutura foram os mesmos encontrados pelos autores, sendo $\lambda_{u}=1,21$ para os valores médios e $\lambda_{u}=1,28$ com os valores de referência das propriedades dos materiais.

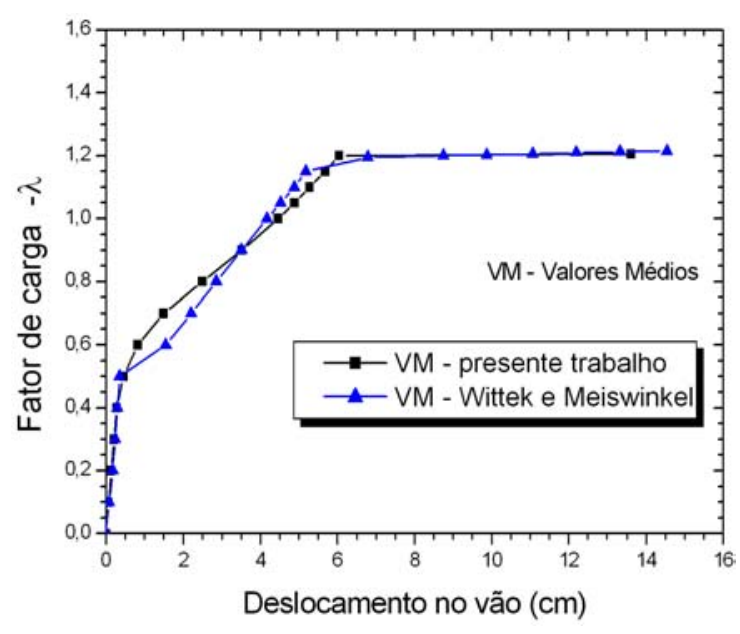

(a)

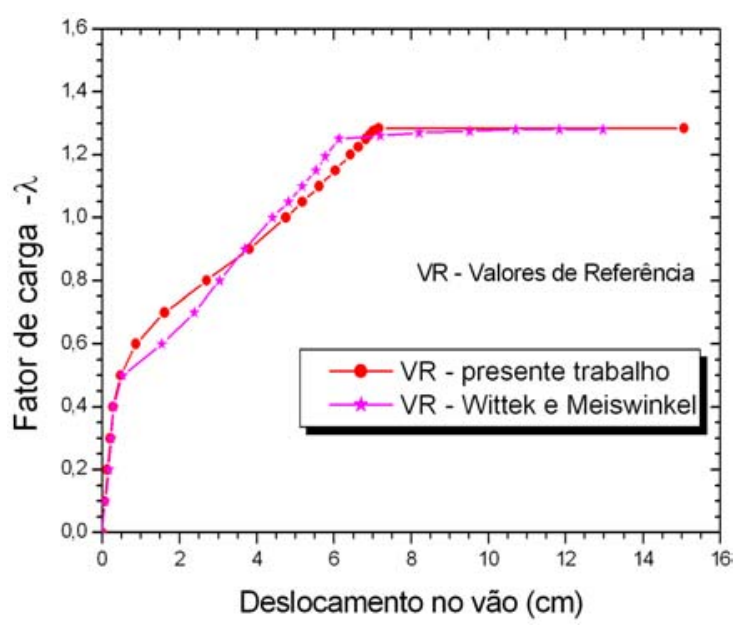

(b)

Figura 4.5 - Fator de carga vs. deslocamento: a) análise com valores médios e b) análise com valores de referência.

$\mathrm{Na}$ Figura 4.6 são mostrados apenas os resultados da análise desta investigação. O valor do fator de carga último considerando os valores médios foi de $\lambda_{u}=1,21$, enquanto para os valores de referência foi de $\lambda_{u}=1,28$, praticamente iguais aos das análises do coeficiente de segurança da seção transversal, que foram de $\gamma_{S T}=1,18$ e $\gamma_{S T}=1,27$, respectivamente. 


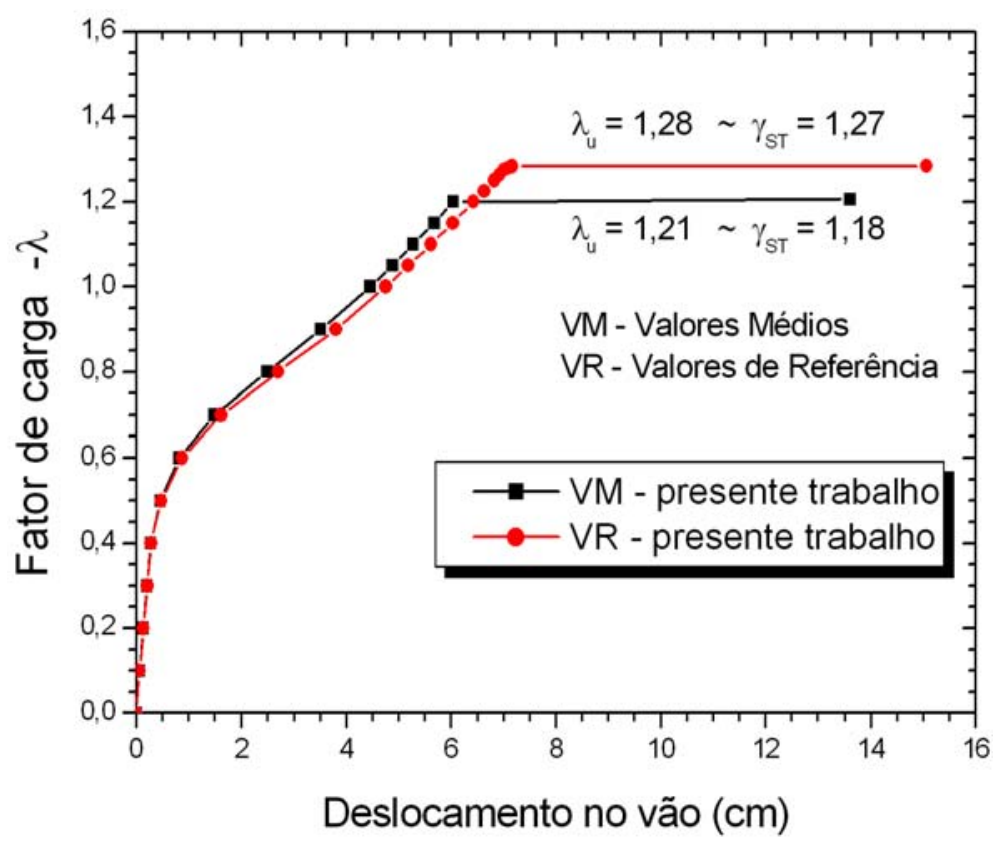

Figura 4.6 - Fator de carga vs. deslocamento - análises com valores médios e de referência realizadas no presente trabalho.

Como a placa biapoiada é uma estrutura isostática, resultando um único estado de equilíbrio, os valores dos coeficientes de segurança ficaram bastante próximos aos da análise não-linear física e da verificação da seção resistente, como era esperado.

\subsubsection{Viga contínua com dois vãos - Wittek e Meiswinkel (2000)}

Neste exemplo foi analisada a viga contínua com dois vãos estudada por Wittek e Meiswinkel (2000). A viga contínua está submetida à carga uniformemente distribuída, com seção transversal de $20 \mathrm{~cm}$ de largura e $70 \mathrm{~cm}$ de altura, como mostra a Figura 4.7.

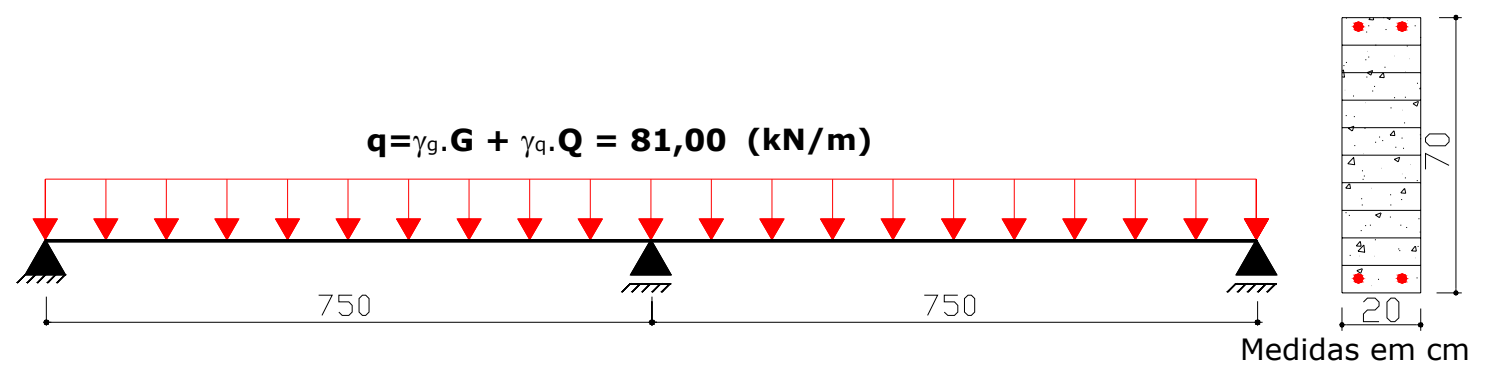

Figura 4.7 - Viga contínua com dois vãos - Wittek e Meiswinkel (2000). 
Foram utilizadas as mesmas armaduras empregadas pelos autores Wittek e Meiswinkel (2000). Nesta estrutura foi considerada a redistribuição dos esforços solicitantes. Dessa forma, ocorreu uma redução do momento fletor no apoio central e, conseqüentemente, um aumento dos momentos nos vão da estrutura para que ocorresse equilíbrio da estrutura.

As disposições das armaduras estão mostradas na Figura 4.8, sendo a armadura da face inferior disposta ao longo de todo o elemento e a armadura na face superior, junto ao apoio. As resistências características à compressão do concreto e à tração do aço foram de $25 \mathrm{MPa}(\mathrm{C} 25)$ e $500 \mathrm{MPa}(\mathrm{CA}-50)$, respectivamente.

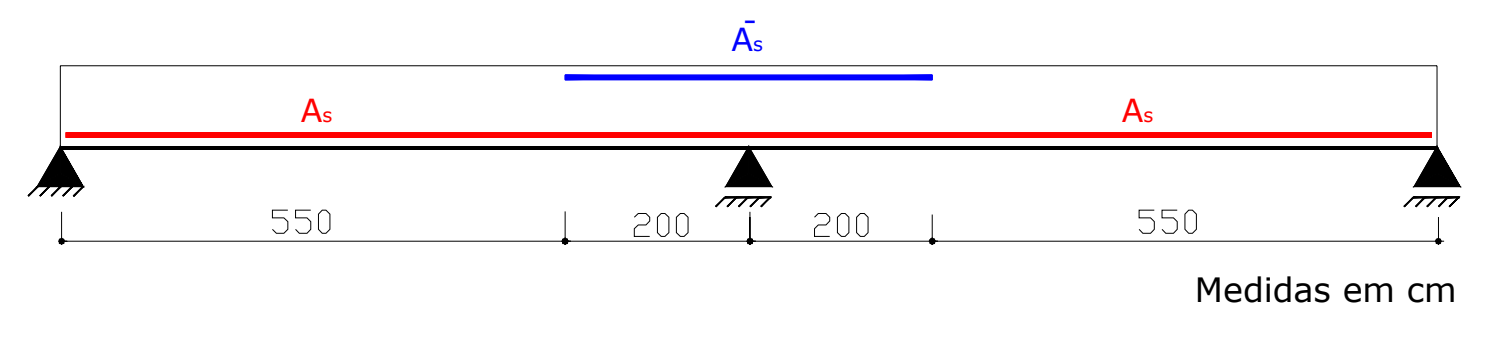

Figura 4.8 - Disposições das armaduras na viga contínua.

As armaduras das seções transversais têm área de $A_{s}^{-}=19,70 \mathrm{~cm}^{2}$ para o momento negativo - junto ao apoio e $A_{s}=16,60 \mathrm{~cm}^{2}$ nos vãos do elemento. Com os valores das áreas das armaduras longitudinais foram calculados os coeficientes de segurança das seções críticas transversais $\left(\gamma_{S T}\right)$ (vão e apoio) utilizando o programa de verificação de seção resistente desenvolvido pelo autor no software MathCad, cujos valores são mostrados na Tabela 4.1.

Tabela 4.1 - Segurança das seções transversais críticas da viga contínua.

\begin{tabular}{l|cccc}
\hline \multirow{2}{*}{ Caso } & \multicolumn{2}{|c}{ Apoio } & \multicolumn{2}{c}{ Vão } \\
\cline { 2 - 5 } & VM & VR & VM & VR \\
\hline Presente trabalho & 1,15 & 1,26 & 1,27 & 1,27 \\
Wittek e Meiswinkel (2000) & 1,17 & 1,25 & 1,25 & 1,27 \\
\hline \multicolumn{4}{c}{ VM - Valores médios } \\
& VR - Valores de referência
\end{tabular}


Os valores dos coeficientes de segurança das seções transversais críticas foram praticamente iguais aos valores encontrados pelos autores.

As análises, considerando a não-linearidade física, foram realizadas e comparadas com as da referência citada, alterando-se os valores da resistência dos materiais (médio e de referência). Os módulos de elasticidade longitudinal tangente do concreto e do aço foram calculados de acordo com a eq.(4.3).

A viga contínua foi discretizada em 31 nós e 30 elementos e a seção transversal estratificada em 10 camadas, Figura 4.9. Está sendo mostrado apenas um vão da viga, por ter sido utilizada a sua simetria, diminuindo com isso o tempo de processamento.

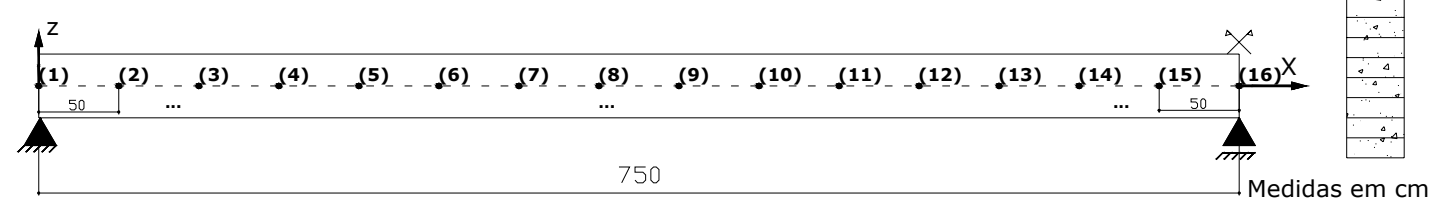

Figura 4.9 - Discretização da viga contínua e estratificação da seção transversal.

Os resultados das análises são apresentados nas figuras seguintes, considerando os valores médios e de referência das resistência dos materiais. As análises realizadas com o programa ANPAV (modificado) proporcionaram bons resultados para a viga hiperestática comparando-os com os de Wittek e Meiswinkel (2000), tanto para os valores médios quanto para os valores de referência da resistência dos materiais, como mostra a Figura 4.10. 


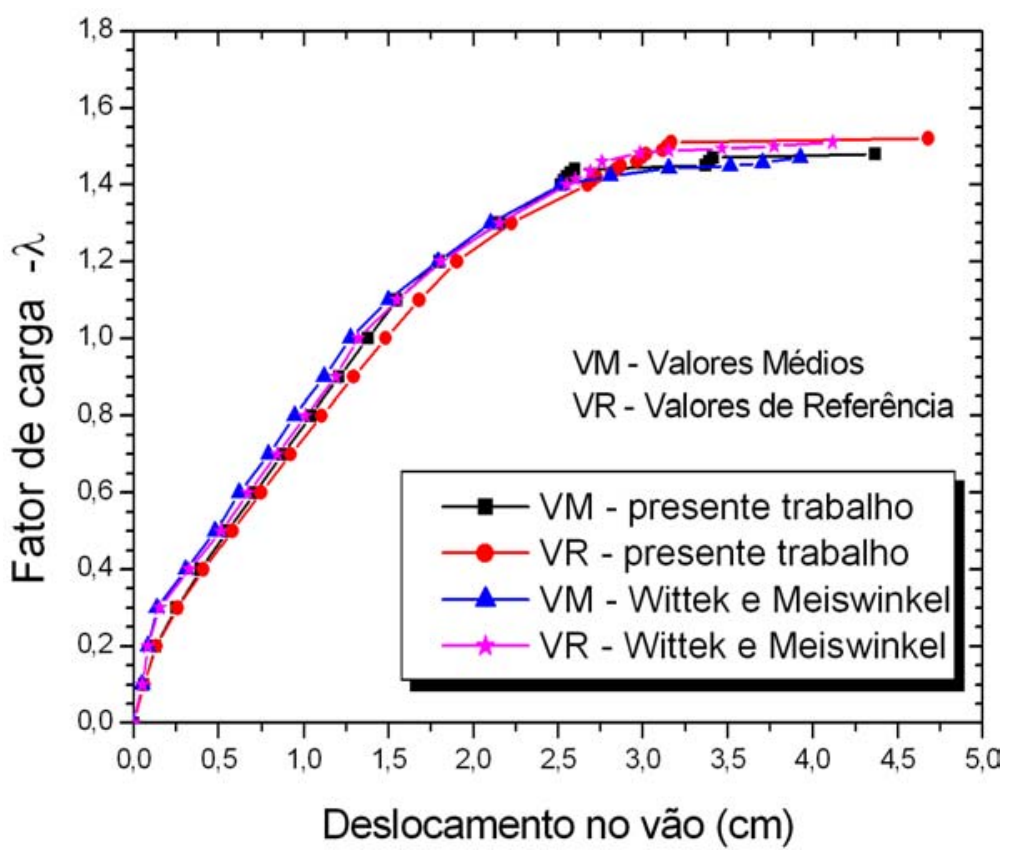

Figura 4.10 - Fator de carga vs. deslocamento - análises com valores médios e de referência.

Na Figura 4.11(a) e Figura 4.11(b) são mostrados em detalhe os resultados das análises, para melhor visualização, comparando-os com os da referência citada considerando os valores médios e de referência. Os resultados foram praticamente iguais ao longo de todos os incrementos de carga.

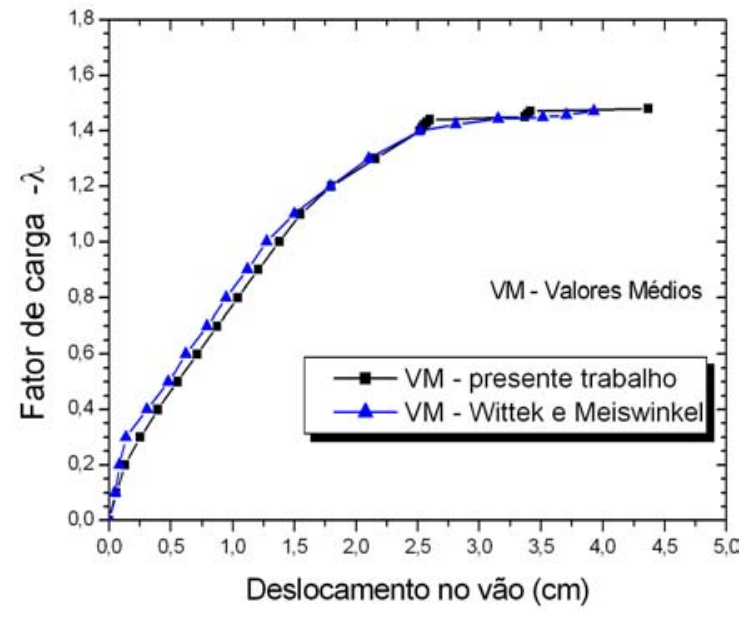

(a)

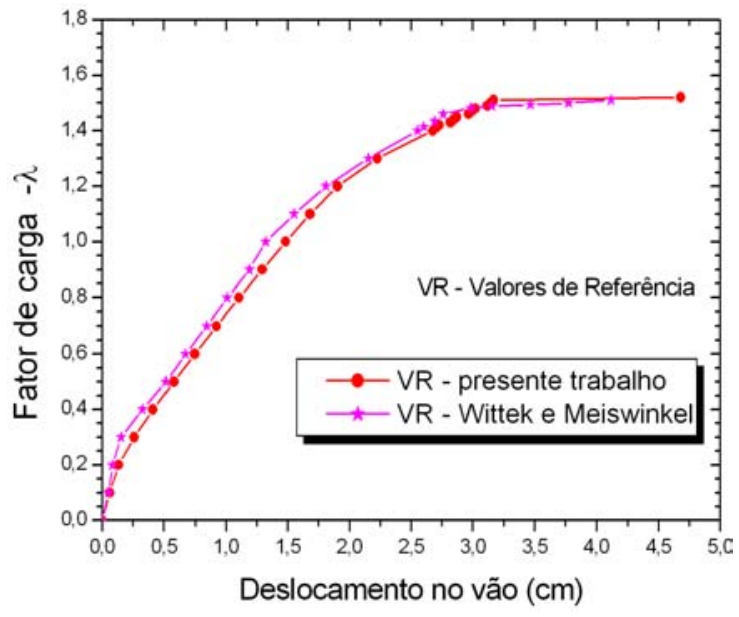

(b)

$\overline{\text { Figura } 4.11 \text { - Fator de carga } v s \text {. deslocamento: a) análise com valores médios e b) análise com valores de }}$ referência.

A Figura 4.12 mostra os resultados do presente trabalho. O fator de carga foi maior que o valor do coeficiente de segurança da seção transversal, tanto para valores 
médios $\left(\lambda_{u}=1,48>\gamma_{S T}=1,27\right)$ quanto para os valores de referência $\left(\lambda_{u}=1,52>\gamma_{S T}=1,27\right)$. As análises realizadas indicam a segurança da estrutura para a quantidade de armadura longitudinal considerada. Os esforços solicitantes no apoio ainda podem ser reduzidos empregando-se a redistribuição dos esforços e conseqüente redução da taxa de armadura neste apoio; entretanto, faz-se necessária a inclusão de verificações adicionais, tais como fissuração e capacidade máxima da rótula plástica, que serão mostradas nos exemplos seguintes.

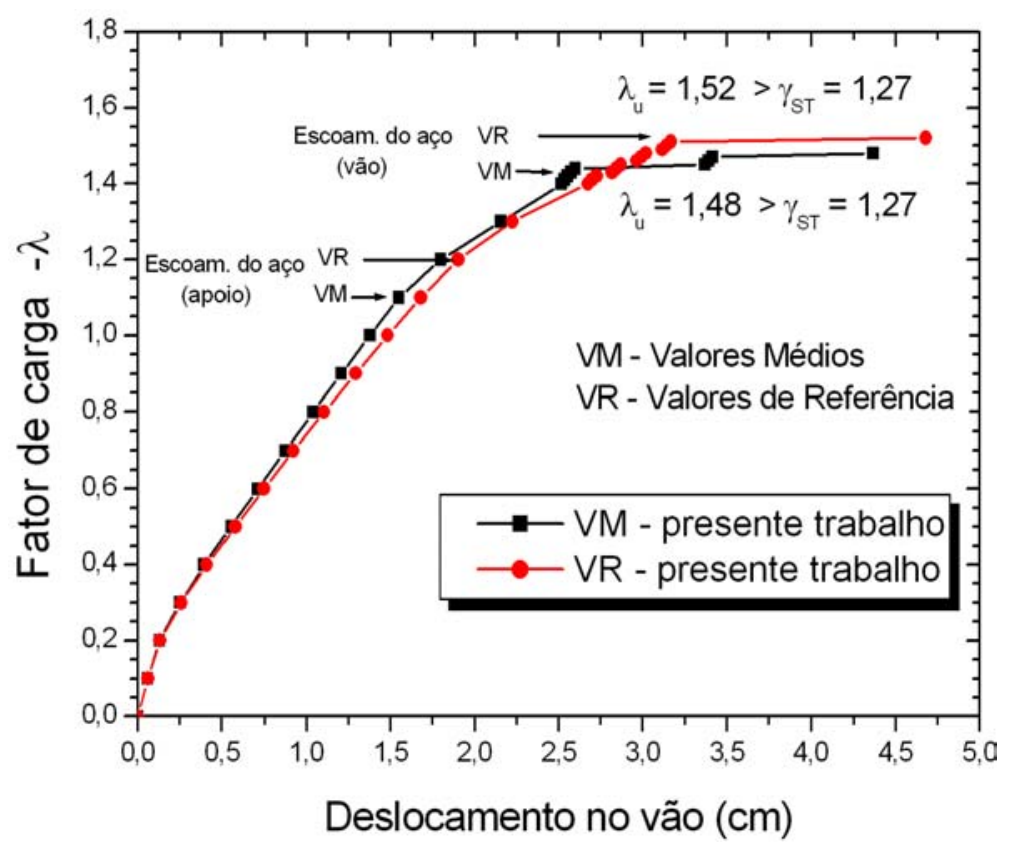

$\overline{\text { Figura } 4.12 \text { - Fator de carga } v s \text {. deslocamento - análises com valores médios e de referência realizadas no }}$ presente trabalho.

O escoamento da armadura ocorreu primeiro no apoio, Figura 4.12, em virtude da redistribuição do momento fletor (diminuindo o momento no apoio e aumentando no vão), como era de se esperar. Esta informação é obtida no arquivo de saída de resultados fornecida pelo programa ANPAV. Desta forma, ocorreu redução da taxa geométrica de armadura negativa e aumento da positiva. Aumentado-se o carregamento, ocorreu o escoamento da armadura no vão e, posteriormente, foi formada a segunda rótula plástica, agora no vão. Assim, a estrutura se tornou hipostática, chegando ao colapso com escoamento do aço e ruptura do concreto no apoio e no vão. 


\subsection{Exemplos aplicados à NBR 6118:2003}

Nos exemplos seguintes foram utilizados os parâmetros recomendados pela NBR 6118:2003, porém, com a consideração do diagrama tensão-deformação proposto pelo CEB-FIP MC90 para o concreto e o diagrama tensão-deformação para o aço, como um comportamento elastoplástico perfeito, com deformação última $\varepsilon_{s u}=10 \%$.

A NBR 6118:2003 considera a resistência característica inferior do concreto como aquele valor que tem apenas $5 \%$ de probabilidade de não ser atingindo. Assim, a NBR 12655:1996 sugere que o valor médio da resistência do concreto possa ser expresso pela eq.(4.4).

$f_{c m}=f_{c k}+1,65 \cdot s_{d}$

sendo:

$f_{c m} \quad$ resistência média à compressão;

$f_{c k}$ resistência característica à compressão;

$s_{d} \quad$ desvio-padrão.

Quando não for realizado ensaio laboratorial, o desvio padrão pode ser adotado em função da condição de preparo do concreto. De acordo com a NBR 12655:1996 para condição $\mathrm{A}^{*}$, o desvio padrão é de $4,0 \mathrm{MPa}$. Porém, não se tem recomendação alguma para o aço. No presente trabalho, será adotada a proposta de Oliveira (2001) que considera a resistência média do aço igual à resistência característica. Esta proposta torna-se condizente em virtude da invariabilidade do módulo de deformação longitudinal do aço e resistência com pequeno desvio-padrão. Oliveira (2004) em ensaios laboratoriais de barras $(\phi 5,0-\phi 12,5)$ encontrou resultados de resistência média de escoamento bem maiores que os valores das resistências características estabelecidas pelas NBR 6118:2003 e NBR 7480:1996.

O carregamento considerado nos exemplos é composto apenas por cargas uniformemente distribuídas, com parcela permanente de $25,00 \mathrm{kN} / m$ e variável de

\footnotetext{
* Condição A - aplicável às classes C10 até C80, o cimento e os agregados são medidos em massa, a água de amassamento é medida em massa ou volume com dispositivo dosador e corrigida em função da umidade dos agregados.
} 
$5,00 \mathrm{kN} / m$. A composição dos carregamentos de cálculo para as análises dos ELU e ELS, as combinações de ações e os fatores de combinação estão resumidos na Tabela 3.3 e Tabela 3.2, do capítulo anterior deste trabalho. Os valores para os respectivos estados de verificação são mostrados a seguir. Na eq.(4.6) utiliza-se a combinação quase-permanente e na eq.(4.7) a combinação freqüente, ambas para a verificação dos ELS.

ELU: $\quad F_{d, u}=1,4 \cdot 25+1,4 \cdot 5,0$

$$
F_{d, u}=42,00 \mathrm{kN} / m
$$

ELS (CQP): $\quad F_{d, s e r}=1,0 \cdot 25+0,3 \cdot 5,0$

$$
F_{d, u}=26,50 \mathrm{kN} / m
$$

ELS (CF): $\quad F_{d, s e r}=1,0 \cdot 25+0,4 \cdot 5,0$

$$
F_{d, u}=27,00 \mathrm{kN} / m
$$

Nas análises não-lineares, os módulos de elasticidade longitudinais dos materiais e a resistência à tração média do concreto considerada pela NBR 6118:2003, estão expressos na eq.(4.8).

Considerou-se, também, a armadura de porta estribos $(2 \phi 6,30 \mathrm{~mm})$ e cobrimento da armadura de $2,5 \mathrm{~cm}$, adequado para a classe de agressividade ambiental tipo I (CAA I).

$$
\begin{aligned}
& E_{c}=5600 \cdot f_{c k}^{1 / 2} \\
& E_{s}=210000 \mathrm{MPa} \\
& f_{c t, m}=0,3 \cdot f_{c k}^{2 / 3}
\end{aligned}
$$




\subsubsection{Viga biapoiada}

A viga biapoiada com seção transversal de $15 \mathrm{~cm}$ de largura e $50 \mathrm{~cm}$ de altura submetida a carga uniformemente distribuída é mostrada na Figura 4.13. Esse exemplo foi originalmente estudado por Oliveira (2001).

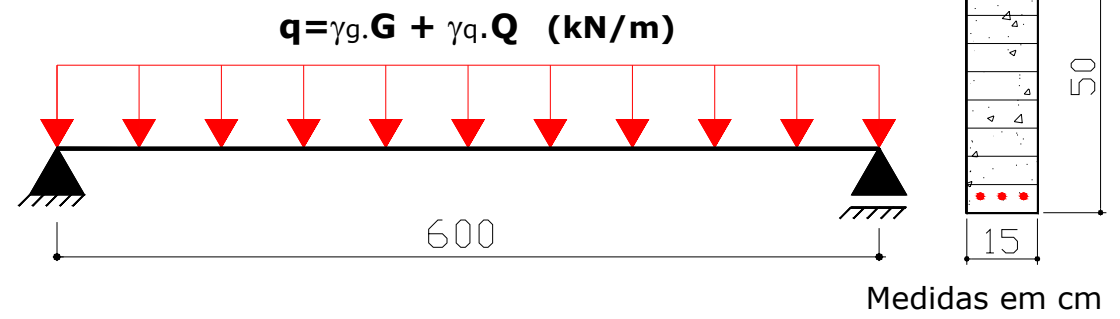

\section{Figura 4.13 - Viga biapoiada.}

A viga biapoiada foi dimensionada em regime elástico-linear atendendo ao ELU, utilizando programa elaborado pelo autor no software MathCad considerando o valor do carregamento distribuído expresso pela eq.(4.5). Os coeficientes ponderadores das resistências dos materiais foram $\gamma_{c}=1,4$ (concreto) e $\gamma_{s}=1,15$ (aço). Foram considerados os valores das resistências características do concreto à compressão de $30 \mathrm{MPa}$ e à tração para o aço de $500 \mathrm{MPa}$.

\section{a) Regime elástico-linear}

$$
\begin{aligned}
& M_{d}=189,00 \mathrm{kN} \cdot \mathrm{m} ; \mathrm{h}=50 \mathrm{~cm} \rightarrow d=47 \mathrm{~cm} \\
& \text { portanto, } A_{s}=11,59 \mathrm{~cm}^{2} \rightarrow \text { Domínio } 3
\end{aligned}
$$

A verificação da seção resistente e as análises não-lineares foram realizadas com as resistências médias, de referência e de cálculo dos materiais, expressas na Tabela 4.2. 
Tabela 4.2 -Resistência dos materiais.

\begin{tabular}{l|cccccc}
\hline \multirow{2}{*}{ Material } & \multicolumn{2}{|c}{ Média } & \multicolumn{2}{c}{ Referência } & \multicolumn{2}{c}{ Cálculo } \\
\cline { 2 - 7 } & Expressão & $\begin{array}{l}\text { Valor } \\
(\mathrm{MPa})\end{array}$ & Expressão & $\begin{array}{l}\text { Valor } \\
(\mathrm{MPa})\end{array}$ & Expressão & $\begin{array}{c}\text { Valor } \\
(\mathrm{MPa})\end{array}$ \\
\hline Concreto & $f_{c k}+1,65 \cdot s_{d}$ & 36,60 & $0,85 \cdot f_{c k}$ & 25,50 & $f_{c k} / 1,4$ & 21,43 \\
\multirow{2}{*}{ Aço } & $f_{y k}$ & 500,00 & $1,035 \cdot f_{y k}$ & 517,50 & $f_{y k} / 1,15$ & 434,78 \\
\hline
\end{tabular}

O coeficiente de segurança da seção transversal $\left(\gamma_{S T}=M_{u} / M_{d}\right)$ foi de $\gamma_{S T}=1,24$ considerando os valores médios e $\gamma_{S T}=1,19$ para os valores de referência.

\section{b) Regime não-linear}

Nesta análise foi considerada a armadura dimensionada com o regime elásticolinear, mostrado acima. A viga foi discretizada em 15 nós e 14 elementos, com maior densidade na região de momento máximo e seção transversal estratificada em 10 camadas, como mostra a Figura 4.14.

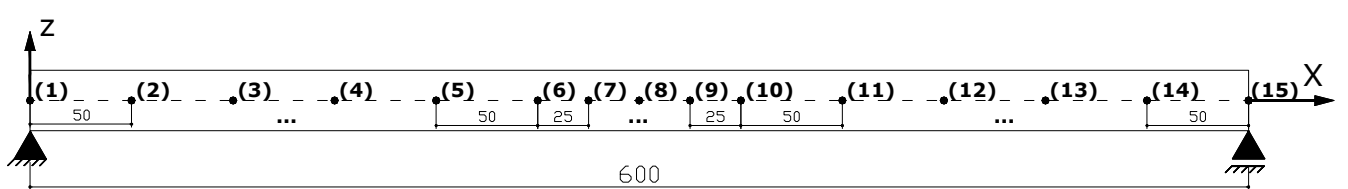

Medidas em $\mathrm{cm}$

Figura 4.14 - Discretização da viga biapoiada e estratificação da seção transversal.

Os resultados das análises são apresentados na Figura 4.15 considerando os valores médios, de referência das propriedades dos materiais e com a proposta de dimensionamento apresentada neste trabalho. Observe-se que $\lambda=1,0$ corresponde a $q=42,00 \mathrm{kN} / m$. No caso, a obtenção de $\lambda>1,0$ na análise não-linear indica a existência de uma reserva de segurança teórica. 


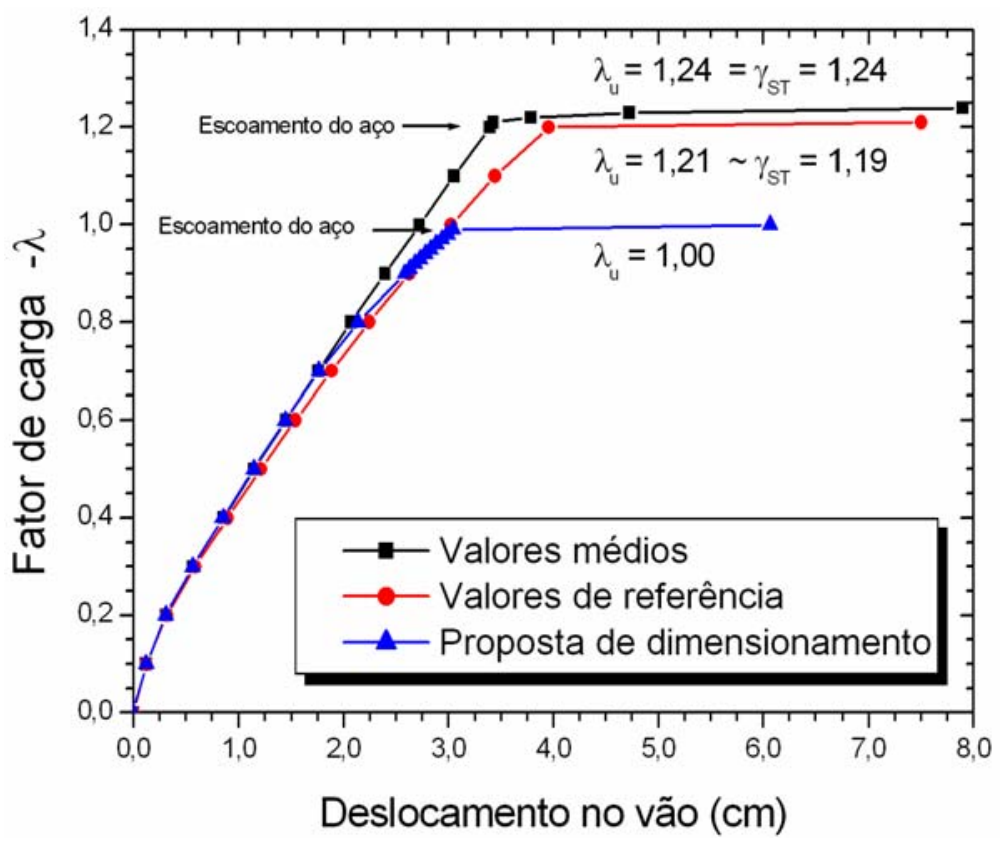

Figura 4.15 - Fator de carga vs. deslocamento no meio do vão da viga biapoiada.

A Figura 4.15 mostra as curvas do fator de carga $(\lambda \cdot q)$ versus deslocamento da viga biapoiada no meio do vão. $\mathrm{O}$ valor último do fator de carga, considerando os valores médios das resistência dos materiais, foi de $\lambda_{u}=1,24$, representando um acréscimo de $24 \%$ no valor do carregamento para o regime elástico-linear, enquanto para os valores de referência o fator de carga último foi de $\lambda_{u}=1,21$, suportando $21 \% \mathrm{a}$ mais da carga original. Observe-se que esses resultados são praticamente iguais aos valores das análises do coeficiente de segurança da seção transversal.

O fator último de carga considerando a proposta de dimensionamento deste trabalho - consideração dos valores médios da resistência dos materiais e limitando-os nos valores de projeto - foi de $\lambda_{u}=1,00$ satisfazendo ao ELU, Figura 4.15.

Percebe-se que o elemento estrutural, quando considerada a proposta de dimensionamento, representou a rigidez de forma adequada, ou seja, com valores praticamente iguais aos médios, o que é desejável. As pequenas alterações ocorrem nas proximidades do fim do carregamento, pois o modelo proposto atende às condições de dimensionamento, isto é, limita as tensões aos valores de projeto das resistências. Essa transição do valor médio ao valor de projeto se dá de forma suave e consistente. Assim, percebe-se que esta proposta contempla simultaneamente as verificações do ELU e do ELS em comportamento não-linear. 
Para confirmar que esta proposta de dimensionamento satisfaz também ao ELS foram verificados estes estados quanto a deformação excessiva e aberturas de fissuras.

A verificação das flechas para o ELS (combinação quase permanente - CQP), conforme valor da eq.(4.6), foi realizado no regime não-linear avaliando a proposta de dimensionamento feita neste trabalho e, de forma simplificada, como prescreve a NBR 6118:2003. Na análise não-linear física a flecha foi determinada tanto para o instante do carregamento quanto para o carregamento ao longo do tempo, considerando o efeito da fluência do concreto.

A flecha elástica máxima, segundo a Resistência dos Materiais para uma viga biapoiada, é expressa pela eq.(4.9). As expressões para o cálculo da rigidez equivalente, bem como da flecha diferida no tempo segundo a norma brasileira NBR 6118:2003 estão mostrados no capítulo 3 deste trabalho.

$$
a_{o}=\frac{5}{384} \cdot \frac{q \cdot L^{4}}{(E I)_{e q}}
$$

Os resultados das flechas imediatas e finais estão mostrados na Tabela 4.3.

Tabela 4.3 - Flechas da viga biapoiada.

\begin{tabular}{l|cc}
\hline \multirow{2}{*}{ Flecha } & \multicolumn{2}{|c}{ Valor (cm) } \\
\cline { 2 - 3 } & Análise não-linear & NBR 6118:2003 \\
\hline Imediata & 1,54 & 1,57 \\
Final & 2,32 & 3,58 \\
\hline
\end{tabular}

A flecha final é o somatório da flecha imediata (instante da aplicação do carregamento) e a flecha diferida no tempo. A flecha imediata na análise não-linear foi bastante próxima à calculada com os quesitos da NBR 6118:2003.

O valor da flecha final, considerando um tempo de recorrência para a avaliação da flecha diferida de 70 meses, calculada segundo a prescrição normalizada, não satisfez a flecha limite para aceitabilidade sensorial estabelecido pela NBR 6118:2003 para elementos estruturais de concreto armado $(L / 250=2,40 \mathrm{~cm})$. Assim os valores das dimensões da seção transversal ou armaduras longitudinais deveriam ser alterados ou poderiam ser utilizadas contra-flechas para satisfazer a este critério. 
$\mathrm{Na}$ análise não-linear, foi feito um novo processamento no programa ANPAV, considerando agora o valor do coeficiente de fluência de $\varphi_{(t, t o)}=1,84$ para o mesmo tempo de recorrência (70 meses), em que a flecha final resultou em 2,32, Tabela 4.3. Portanto, satisfazendo o limite de aceitabilidade sensorial estabelecido pela NBR 6118:2003.

A verificação da abertura característica de fissuras para o ELS (combinação freqüente - CF) foi realizada segundo as prescrições da NBR 6118:2003. As expressões e os limites de abertura máxima de fissuras foram mostrados no capítulo 3 deste trabalho. Foi desenvolvida uma rotina no software MathCad para verificação de aberturas de fissuras. Na análise numérica considerou-se $\phi=16,00 \mathrm{~mm}$ para as armaduras longitudinais tracionadas dispostas em duas camadas e classe de agressividade ambiental tipo I (CAA I); assim, a abertura máxima de fissuras no vão para a viga biapoiada foi de 0,11 $\mathrm{mm}$. A NBR 6118:2003 recomenda uma abertura máxima de fissuras de $0,40 \mathrm{~mm}$ para a classe de agressividade tipo I. Desta forma, a abertura máxima das fissuras encontradas para a viga biapoiada satisfez a prescrição normalizada $\left(w_{a p}=0,11 \leq w_{k}=0,40 \mathrm{~mm}\right)$.

\subsubsection{Viga apoiada-engastada}

A viga apoiada-engastada com seção transversal de $15 \mathrm{~cm}$ de largura e $50 \mathrm{~cm}$ de altura, submetida à carga uniformemente distribuída, é mostrada na Figura 4.16.

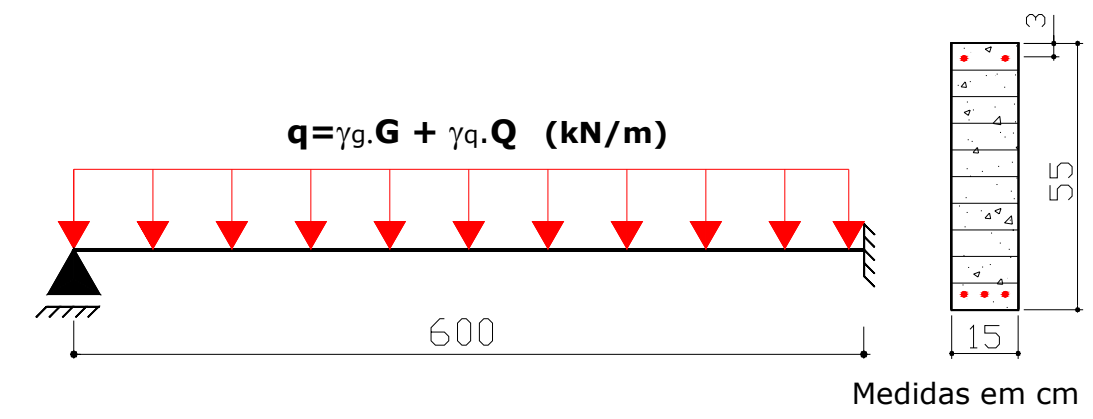

Figura 4.16 - Viga apoiada-engastada.

A viga foi dimensionada em regime elástico-linear atendendo ao ELU utilizando o programa no software MathCad considerando o valor do carregamento distribuído expresso pela eq.(4.5). Adotaram-se os valores das resistências 
características à compressão do concreto de $30 \mathrm{MPa}$ e resistência característico à tração do aço de $500 \mathrm{MPa}$.

\section{a) Regime elástico-linear sem redistribuição}

\section{a.1) Vão}

$M_{d}=106,30 \mathrm{kN} \cdot \mathrm{m} ; \mathrm{h}=55 \mathrm{~cm} \rightarrow d=51 \mathrm{~cm}$

portanto, $A_{s}=5,25 \mathrm{~cm}^{2} \rightarrow$ Domínio 2

\section{a.2) Engaste}

$$
M_{d}=189,00 \mathrm{kN} \cdot \mathrm{m} ; \mathrm{h}=55 \mathrm{~cm} \rightarrow d=51 \mathrm{~cm}
$$

portanto, $A_{s}=10,19 \mathrm{~cm}^{2} \rightarrow$ Domínio 3

As armaduras longitudinais principais foram arranjadas conforme a Figura 4.17, sendo a armadura da face inferior disposta na região de momento positivo e a armadura na face superior disposta na região de momento negativo junto ao engaste. Sob o ponto de vista prático, parte da armadura inferior deveria ser prolongada até o apoio. Isso não foi considerado no exemplo, por não modificar os conceitos envolvidos.

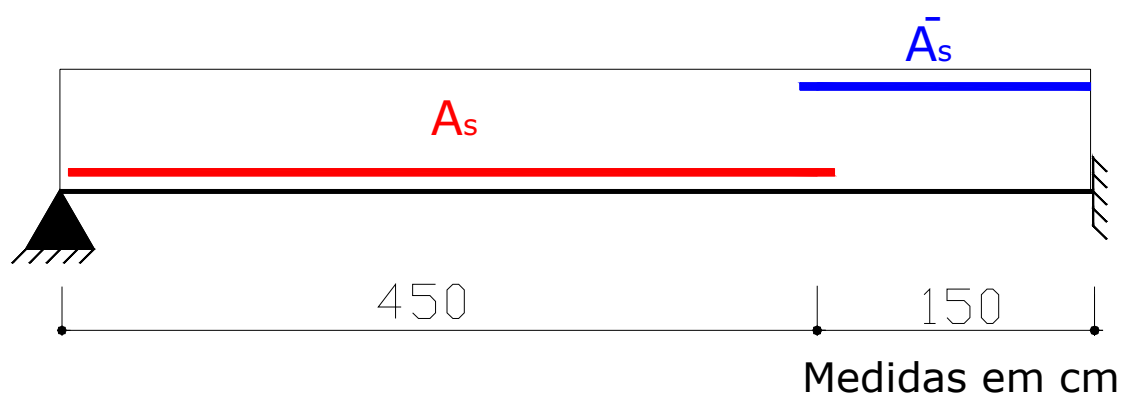

Figura 4.17 - Disposições das armaduras na viga apoiada-engastada.

Os coeficientes de segurança das seções transversais críticas (engaste e vão) e as análises não-lineares, foram realizadas com as resistências médias, de referência e de cálculo dos materiais, expressas na Tabela 4.2. A seção do engaste teve coeficiente de segurança da seção transversal de 1,22 (valores médios) e 1,19 (valores de referência), enquanto a seção crítica do vão de 1,18 (valores médios) e 1,19 (valores de referência). 


\section{b) Regime não-linear sem redistribuição}

Nas análises não-lineares a viga foi discretizada em 17 nós e 16 elementos, com maior discretização nas regiões de maiores momentos (vão e engaste), sendo a seção transversal estratificada em 10 camadas, Figura 4.18.

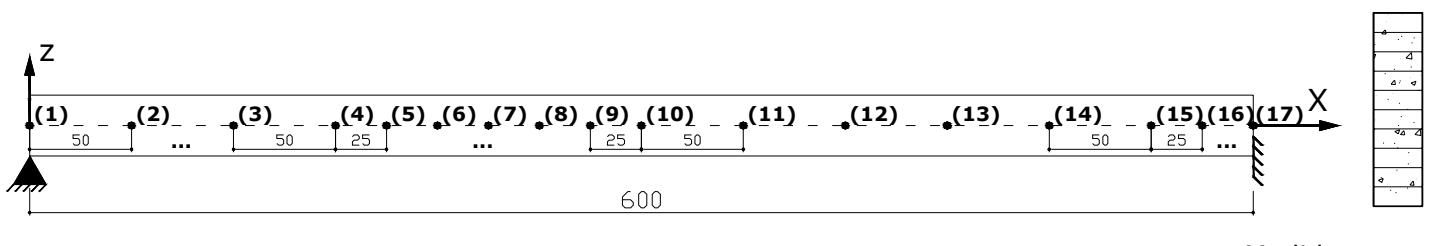

Medidas em $\mathrm{cm}$

Figura 4.18 - Discretização da viga apoiada-engastada e estratificação da seção transversal.

Os resultados das análises estão ilustrados na Figura 4.19 considerando os valores médios, de referência e a proposta de dimensionamento deste trabalho.

A Figura 4.19 mostra as curvas do fator de carga $(\lambda)$ versus deslocamento no vão da viga apoiada-engastada. $O$ fator de carga igual a 1,0 indica que a carga original, neste caso majorada $(q=42,00 \mathrm{kN} / \mathrm{m})$, foi totalmente aplicada à estrutura; caso este fator seja maior que 1,0, representa que a estrutura ainda tem reserva de capacidade resistente teórica, desse modo, absorvendo maiores cargas que a originalmente projetada.

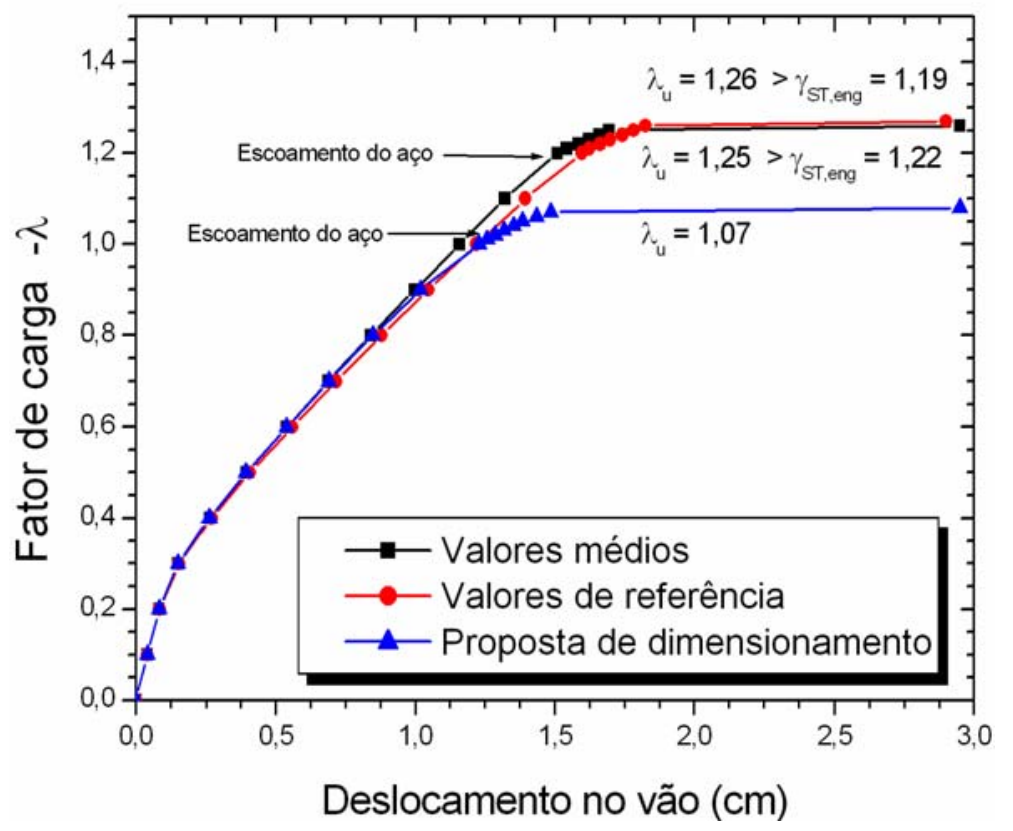

Figura 4.19 - Fator de carga vs. deslocamento no vão da viga apoiada-engastada sem redistribuição. 
Os fatores de carga foram maiores do que os coeficientes de segurança das seções transversais críticas tanto para os valores médios $\left(\lambda_{u}=1,26\right)$ quanto para os de referência $\left(\lambda_{u}=1,25\right)$ das resistências dos materiais. Como a viga apoiada-engastada é hiperestática já era esperada a diferença entre os coeficientes de segurança da seção transversal e da estrutura. Isto ocorre pelo fato das forças internas serem determinadas simultaneamente pelas condições de equilíbrio e de compatibilidade.

$\mathrm{O}$ fator de carga empregando a proposta de dimensionamento deste trabalho foi de $\lambda_{u}=1,07$, satisfazendo ao ELU. Percebe-se que o elemento estrutural, quando considerada a proposta de dimensionamento, representou a rigidez de forma adequada, ou seja, com valores praticamente iguais aos médios, o que é desejável. Com pequenas alterações nas proximidades do fim do carregamento, pois o modelo proposto atende às condições de dimensionamento. Neste caso, viga hiperestática, a proposta mostrou, mesmo que pequena (7\%), uma reserva de carregamento. Confirmando que esta proposta contempla simultaneamente as verificações do ELU e do ELS em comportamento não-linear.

Os esforços solicitantes das análises não-lineares com o programa ANPAV estão mostrados na Tabela 4.4 para as três verificações realizadas. Percebe-se que os momentos fletores foram todos maiores que os valores correspondentes ao regime elástico-linear.

Tabela 4.4 - Momentos fletores máximos na viga apoiada-engastada sem redistribuição para análise nãolinear.

\begin{tabular}{l|cc}
\hline \multirow{2}{*}{ Resistência dos materiais } & \multicolumn{2}{c}{ Momento fletor máximo $(\mathrm{kN} \cdot \mathrm{m})$} \\
\cline { 2 - 3 } & Vão & Engaste \\
\hline Regime elástico-linear & 106,30 & 189,00 \\
Valores médios & 126,30 & 243,00 \\
Valores de referência & 128,50 & 241,80 \\
Proposta de dimensionamento & 116,60 & 198,70 \\
\hline
\end{tabular}

Entretanto, devem ser verificados os ELS quanto à deformação excessiva da viga e aberturas de fissuras. A verificação das flechas para o ELS (combinação quase permanente - CQP), conforme valor da eq.(4.6), foi realizado no regime não-linear, 
avaliando-se a proposta de dimensionamento feita neste trabalho e de forma simplificada como prescreve a NBR 6118:2003.

A flecha elástica máxima, segundo a Resistência dos Materiais para a viga apoiada-engastada, é expressa pela eq.(4.10). As expressões para o cálculo da rigidez equivalente, bem como das flechas imediata e diferida no tempo segundo a norma brasileira estão mostradas no capítulo 3 deste trabalho.

$$
a_{o}=\frac{5}{72 \cdot \sqrt{3}} \cdot \frac{q \cdot L^{4}}{(E I)_{e q}}
$$

Os resultados das flechas imediatas e finais estão na Tabela 4.5.

Tabela 4.5 -Flechas da viga apoiada-engastada.

\begin{tabular}{l|cc}
\hline \multirow{2}{*}{ Flecha } & \multicolumn{2}{|c}{ Valor (cm) } \\
\cline { 2 - 3 } & Análise não-linear & NBR 6118:2003 \\
\hline Imediata & 0,59 & 1,20 \\
Final & 0,89 & 2,74 \\
\hline
\end{tabular}

A flecha imediata na análise não-linear foi bem menor, praticamente a metade do valor considerando a rigidez equivalente estabelecida por norma. $\mathrm{O}$ valor da flecha final, Tabela 4.5, considerando um tempo de recorrência de 70 meses para o cálculo da flecha diferida no tempo e do coeficiente de fluência $\left(\varphi_{(t, t o)}=1,84\right)$, não satisfez o limite de aceitabilidade sensorial estabelecido pela NBR 6118:2003 $(L / 250=2,40 \mathrm{~cm})$, quando verificado com as suas prescrições. No entanto, em um novo processamento para a análise não-linear com o programa ANPAV considerando o coeficiente de fluência $\left(\varphi_{(t, t o)}=1,84\right)$, este critério foi atendido.

A verificação da abertura máxima de fissuras para o ELS (combinação freqüente $-\mathrm{CF}$ ) foi realizada segundo as prescrições da NBR 6118:2003. Na análise numérica considerou-se $\phi=16,0 \mathrm{~mm}$ dispostas em duas camadas para as armaduras longitudinais tracionadas e classe de agressividade ambiental tipo I (CAA I). O valor da abertura máxima de fissuras foi de $0,21 \mathrm{~mm}$ no vão e $0,12 \mathrm{~mm}$ no engaste. A NBR 6118:2003 recomenda abertura máxima de fissuras de 0,40 $\mathrm{mm}$ para a classe de 
agressividade especificada. Desta forma, as aberturas máximas das fissuras encontradas para a viga apoiada-engatada com as respectivas armaduras transversais satisfizeram a prescrição normativa.

$\mathrm{Na}$ análise acima não foi considerada a redistribuição dos esforços solicitantes. Entretanto, a NBR 6118:2003 permite redução dos momentos fletores sobre os apoios em até $10 \%$ para estruturas de nós moveis e $25 \%$ para outros casos.

A NBR 6118:2003 indica, ainda, que no caso de reduzir-se o momento fletor de $M$ para $\delta \cdot M$ em uma determinada seção transversal, a razão entre o coeficiente de redistribuição $(\delta)$ e a profundidade da linha neutra na seção $(x / d)$ deve obedecer à seguinte expressão.

$$
\begin{aligned}
& \delta \geq 0,44+1,25 \cdot x / d \quad \text { para } f_{c k} \leq 35 M P a \\
& \delta \geq 0,56+1,25 \cdot x / d \quad \text { para } f_{c k}>35 M P a
\end{aligned}
$$

A norma brasileira recomenda, ainda, que a posição da linha neutra, no ELU, deve satisfazer os limites estabelecidos na eq.(4.12) para melhorar a ductilidade das estruturas nas regiões de apoio das vigas ou de ligações com outros elementos estruturais, mesmo quando não forem feitas redistribuições de esforços solicitantes.

$$
\begin{aligned}
& x / d \leq 0,50 \text { para } f_{c k} \leq 35 \mathrm{MPa} \\
& x / d \leq 0,40 \text { para } f_{c k}>35 \mathrm{MPa}
\end{aligned}
$$

Na seção do engaste, a profundidade da linha neutra foi de $20,03 \mathrm{~cm}$, ou seja, $x / d=0,39<0,50$ satisfazendo a condição da eq.(4.12). De acordo com a eq.(4.11) o coeficiente de redistribuição é de $\delta=0,93$, permitindo redistribuição dos esforços solicitantes, ocorrendo uma redução do momento negativo de $7 \%$.

A viga apoiada-engastada será dimensionada para os novos esforços solicitantes provenientes da redistribuição. 
c) Regime elástico-linear com redistribuição $(\delta=0,93)$

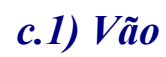

$M_{d}=111,33 \mathrm{kN} \cdot \mathrm{m} ; \mathrm{h}=55 \mathrm{~cm} \rightarrow d=51 \mathrm{~cm}$

portanto, $A_{s}=5,52 \mathrm{~cm}^{2} \rightarrow$ Domínio 2

\section{c.2) Engaste}

$M_{d}=175,77 \mathrm{kN} \cdot \mathrm{m} ; \mathrm{h}=55 \mathrm{~cm} \rightarrow d=51 \mathrm{~cm}$

portanto, $A_{s}=9,32 \mathrm{~cm}^{2} \rightarrow$ Domínio 3

d) Regime não-linear com redistribuição $(\delta=0,93)$

$\mathrm{Na}$ análise não-linear física, considerando a redistribuição dos esforços solicitantes, as armaduras longitudinais principais foram dispostas da mesma forma que no caso anterior, Figura 4.17, bem como a discretização da viga mostrada na Figura 4.18. Os resultados das análises estão ilustrados na Figura 4.20.

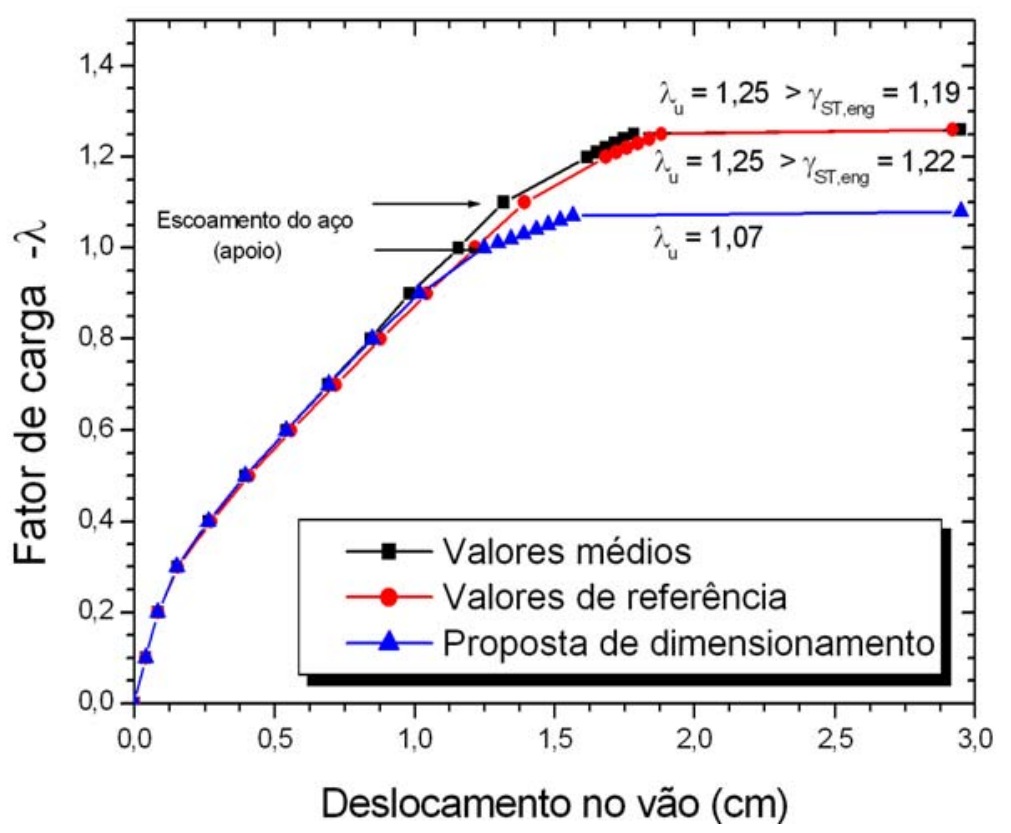

Figura 4.20 - Fator de carga vs. deslocamento no vão da viga apoiada-engastada com redistribuição.

$\mathrm{Na}$ Figura 4.20 percebe-se que os fatores de carga foram maiores que os coeficientes de segurança da seção transversal. Os fatores de carga, considerando a redistribuição dos esforços, foram iguais aos das análises sem redistribuição. Esperava- 
se redução da margem de segurança (fator de carga) da estrutura pelo fato de ter sido realizada a redistribuição dos esforços solicitantes; isto, porém, não aconteceu, provavelmente, em virtude da baixa redistribuição dos esforços, no caso apenas $7 \%$.

A Tabela 4.6 mostra os esforços solicitantes para as análises não-lineares considerando a redistribuição. Os momentos fletores obtidos no regime não-linear foram maiores que os calculados quando se utilizou a redistribuição dos esforços solicitantes; sendo maiores, também, para todas as análises, sem considerar a redistribuição - exceto para a proposta de dimensionamento de estados limites que fícou bastante próximo do valor elástico no engaste.

Tabela 4.6 - Momentos fletores máximos na viga apoiada-engastada com redistribuição para análise nãolinear.

\begin{tabular}{l|cc}
\hline \multirow{2}{*}{ Resistência dos materiais } & \multicolumn{2}{|c}{ Momento fletor máximo $(\mathrm{kN} \cdot \mathrm{m})$} \\
\cline { 2 - 3 } & Vão & Engaste \\
\hline Regime elástico-linear & 111,33 & 175,77 \\
Valores médios & 132,50 & 226,30 \\
Valores de referência & 133,00 & 225,10 \\
Proposta de dimensionamento & 116,80 & 185,10 \\
\hline
\end{tabular}

A flecha elástica máxima para uma viga apoiada-engastada é expressa pela eq(4.10). Os resultados das flechas imediatas e finais estão mostrados na Tabela 4.7.

Tabela 4.7 - Flechas da viga apoiada-engastada com redistribuição $(\delta=0,93)$.

\begin{tabular}{l|cc}
\hline \multirow{2}{*}{ Flecha } & \multicolumn{2}{|c}{ Valor (cm) } \\
\cline { 2 - 3 } & Análise não-linear & NBR 6118:2003 \\
\hline Imediata & 0,59 & 1,16 \\
Final & 0,89 & 2,66 \\
\hline
\end{tabular}

O valor da fecha na análise não-linear considerando a redistribuição dos esforços solicitantes, foi o mesmo para a análise sem considerar a redistribuição; não houve variação em virtude da pequena redistribuição, satisfazendo o critério de aceitabilidade sensorial estabelecido pela norma brasileira. 
Na verificação da flecha, segundo as prescrições normativas, ocorreu pequena variação, praticamente desprezível em relação à análise anterior. Nesta análise também foi ultrapassado o limite máximo estabelecido pela NBR 6118:2003.

Para a verificação de abertura máxima de fissuras, as armaduras longitudinais dispostas em duas camadas, com bitola das barras de $\phi=16,0 \mathrm{~mm}$, e classe de agressividade ambiental tipo I (CAA I) - o valor da abertura máxima de fissuras foi de $0,19 \mathrm{~mm}$ no vão e $0,14 \mathrm{~mm}$ no engaste. Os valores foram menores que os recomendados na NBR 6118:2003 que é de 0,40 $\mathrm{mm}$ para a classe de agressividade especificada. Assim, as aberturas máximas das fissuras encontradas para a viga apoiadaengatada, considerando redistribuição dos esforços solicitantes, satisfizeram a prescrição normativa.

Os resultados das análises considerando ou não a redistribuição dos esforços solicitantes estão mostrados na Tabela 4.8.

Tabela 4.8 - Resultados das análises com ou sem redistribuição dos esforços solicitantes da viga apoiadaengastada.

\begin{tabular}{c|ccccc}
\hline \multirow{2}{*}{ Caso } & \multicolumn{2}{c}{$\begin{array}{c}\text { Armaduras } \\
\left(\mathrm{cm}^{2}\right)\end{array}$} & $\begin{array}{c}\text { Abertura de fissuras } \\
w_{k}-(\mathrm{mm})\end{array}$ & $\gamma_{g l}$ \\
\cline { 2 - 5 } & $A_{s}$ & $A_{s}^{-}$ & Vão & Engaste & \\
\hline Sem redistribuição & 5,25 & 10,19 & 0,21 & 0,12 & 1,07 \\
Com redistribuição & 5,52 & 9,32 & 0,19 & 0,14 & 1,07 \\
\hline
\end{tabular}

Pelo fato da redistribuição dos esforços solicitantes ter sido pequena, apenas $7 \%$, as diferenças nas áreas das armaduras também foram insignificantes. Nos dois casos analisados, a estrutura mostrou-se segura e com reserva de carga, satisfazendo tanto o ELU como o ELS.

As aberturas de fissuras apresentaram valores diferentes para os dois casos. A situação mais desfavorável foi para o caso sem redistribuição dos esforços, com uma abertura de 0,21 no vão em virtude da menor taxa de armadura em relação às demais seções. 


\subsubsection{Viga biengastada}

A Figura 4.21 mostra a viga biengastada com seção transversal de $15 \mathrm{~cm}$ de largura, $40 \mathrm{~cm}$ de altura e $600 \mathrm{~cm}$ de comprimento submetida a carga uniformemente distribuída. Foi considerada altura inferior à do exemplo anterior objetivando estudar os efeitos de plastificação no apoio.
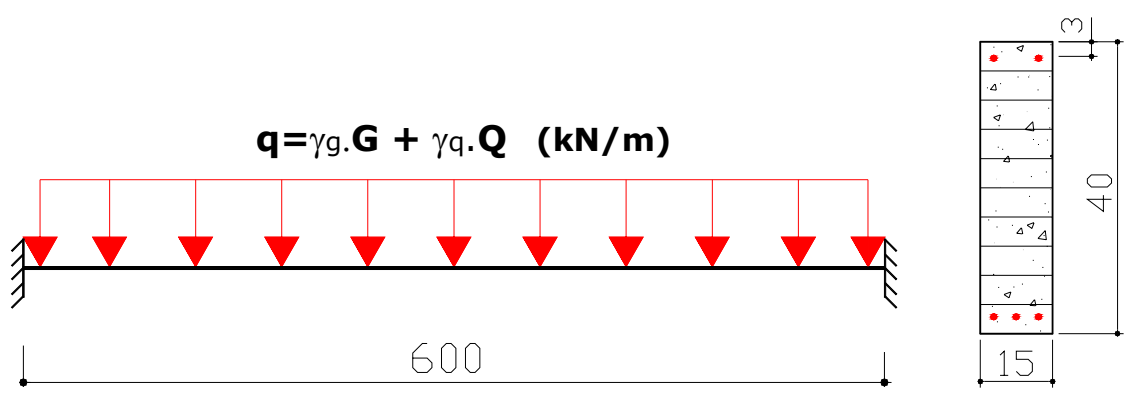

Medidas em $\mathrm{cm}$

Figura 4.21 - Viga biengastada.

Foram considerados os mesmos valores característicos da resistência dos materiais que os exemplos anteriores, com resistências características à compressão do concreto de $30 \mathrm{MPa}$ e à tração do aço de $500 \mathrm{MPa}$. O dimensionamento da viga no ELU considerando o valor do carregamento distribuído de $q=42,00 \mathrm{kN} / m$ sem considerar a redistribuição dos esforços solicitantes é mostrado a seguir.

\section{a) Regime elástico-linear sem redistribuição}

\section{a.1) Vão}

$M_{d}=63,00 \mathrm{kN} \cdot \mathrm{m} ; \mathrm{h}=40 \mathrm{~cm} \rightarrow d=37 \mathrm{~cm}$

portanto, $A_{s}=4,34 \mathrm{~cm}^{2} \rightarrow$ Domínio 2

\section{a.2) Engaste}

$M_{d}=126,00 \mathrm{kN} \cdot \mathrm{m} ; \mathrm{h}=40 \mathrm{~cm} \rightarrow d=37 \mathrm{~cm}$

portanto, $A_{s}=10,08 \mathrm{~cm}^{2} \rightarrow$ Domínio 3

A Figura 4.22 mostra a disposição das armaduras principais longitudinais da viga biengastada. As armaduras na face superior foram dispostas nas regiões dos apoios, e, conseqüentemente, as armaduras da face inferior nas regiões de momento positivo. 
Sob o ponto de vista prático, parte da armadura inferior deveria ser prolongada até o apoio. Isso não foi considerado no exemplo, por não modificar os conceitos envolvidos.

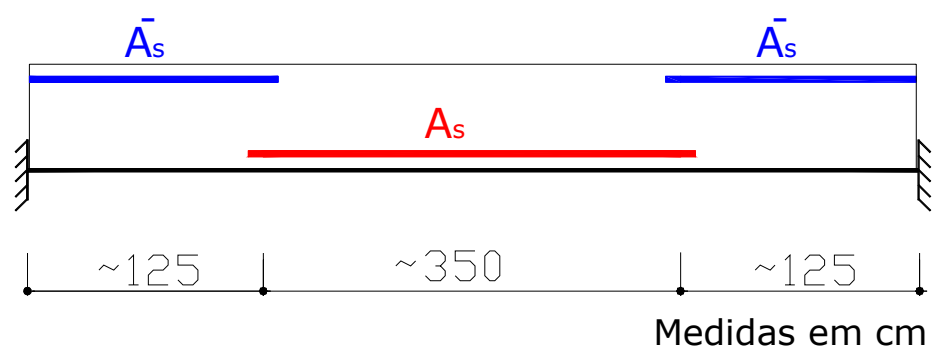

Figura 4.22 - Disposição das armaduras ao longo da viga biengastada.

Foram calculados os coeficientes de segurança das seções transversais críticas; neste caso, na seção do engaste e do vão. O coeficiente de segurança na seção do engaste foi de 1,26, considerando os valores médios da resistência dos materiais, e 1,19 para os valores de referência. Na seção crítica do vão, o valor foi de 1,19 tanto para os valores médios quanto para os valores de referência. As expressões e os respectivos valores das resistência médias e de referência dos materiais são as mesmas mostradas na Tabela 4.2.

\section{b) Regime não-linear sem redistribuição}

Nas análises não-lineares realizadas com o programa ANPAV, a viga foi discretizada em 25 nós e 24 elementos, cujos elementos foram considerados com comprimentos constantes de $25 \mathrm{~cm}$ cada, Figura 4.23. As seções transversais foram estratificadas em 10 camadas.

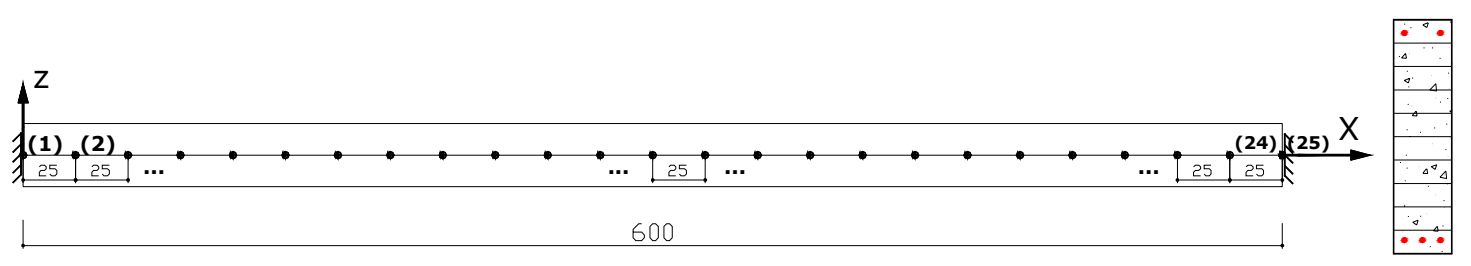

Medidas em $\mathrm{cm}$

Figura 4.23 - Discretização da viga biengastada e estratificação da seção transversal.

Na Figura 4.24 são mostrados os resultados das análises realizadas com as propostas alternativas para verificação da segurança das estruturas de concreto armado. 


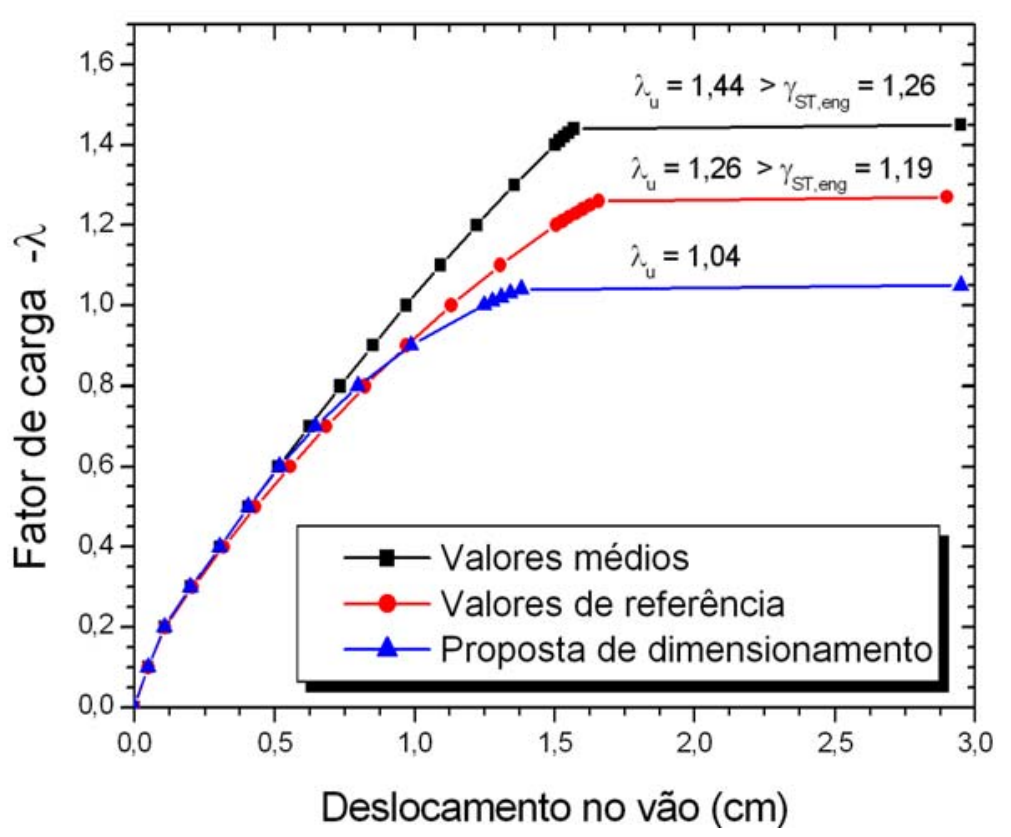

Figura 4.24 - Fator de carga vs. deslocamento no vão da viga biengastada sem redistribuição.

Percebe-se que para o ELU as propostas satisfizeram tal verificação. Os fatores de carga foram maiores que os coeficientes de segurança das seções transversais, tanto para os valores médios quanto para os valores de referência das propriedades dos materiais. Pelo fato da viga biengastada ser uma estrutura hiperestática, neste caso com dois graus de hiperasticidade, os valores dos fatores de carga foram superiores aos do coeficiente de segurança das seções críticas. Como explicado anteriormente, isto ocorre em virtude das estruturas hiperestáticas terem várias configurações de equilíbrio e, também, pelo fato das forças internas serem verificadas simultaneamente pelas equações de equilíbrio e de compatibilidade nas várias seções críticas.

$\mathrm{Na}$ proposta de dimensionamento, o fator de carga foi de $\lambda_{u}=1,04$, indicando que a estrutura suportou um acréscimo de 4\% além da carga original prevista, satisfazendo o ELU. Foram verificados, também, os estados limites de serviço para a deformação excessiva da viga e aberturas de fissuras.

Os esforços solicitantes das análises não-lineares estão mostrados na Tabela 4.4 para as três verificações realizadas. Nos casos analisados, os momentos fletores das seções críticas foram maiores que os do regime elástico-linear, menos na seção do apoio quando se considerou a proposta de dimensionamento, apesar desta diferença ter sido pequena, apenas $1,90 \%$. 
Tabela 4.9 - Momentos fletores máximos na viga biengastada sem redistribuição para análise não-linear.

\begin{tabular}{l|cc}
\hline \multirow{2}{*}{ Resistência dos materiais } & \multicolumn{2}{|c}{ Momento fletor máximo $(\mathrm{kN} \cdot \mathrm{m})$} \\
\cline { 2 - 3 } & Vão & Engaste \\
\hline Regime elástico-linear & 63,00 & 126,00 \\
Valores médios & 86,20 & 176,40 \\
Valores de referência & 75,93 & 153,80 \\
Proposta de dimensionamento & 66,60 & 123,60 \\
\hline
\end{tabular}

Para a verificação dos ELS procedeu-se do mesmo modo que nos casos anteriormente estudados. A combinação utilizada é a quase permanente - CQP com o valor do carregamento descrito apresentado na eq.(4.6). As verificações foram feitas com a proposta de dimensionamento e de forma simplificada como prescreve a NBR 6118:2003.

De acordo com a Resistência dos Materiais a flecha elástica máxima para uma viga biengastada é expressa pela eq.(4.13). As expressões para o cálculo da rigidez equivalente e da flecha diferida no tempo prescrito pela NBR 6118:2003 já foram apresentadas no capítulo 3.

$$
a_{o}=\frac{1}{384} \cdot \frac{q \cdot L^{4}}{(E I)_{e q}}
$$

Os resultados das flechas imediatas e finais estão na Tabela 4.10.

Tabela 4.10 - Flechas da viga biengastada.

\begin{tabular}{l|cc}
\hline \multirow{2}{*}{ Flecha } & \multicolumn{2}{|c}{ Valor (cm) } \\
\cline { 2 - 3 } & Análise não-linear & NBR 6118:2003 \\
\hline Imediata & 0,55 & 1,08 \\
Final & 1,03 & 2,45 \\
\hline
\end{tabular}

A flecha imediata na análise não-linear foi bem menor, praticamente a metade do valor calculado com as prescrições estabelecidas pela norma brasileira. $\mathrm{O}$ valor da flecha final, Tabela 4.10, com tempo de recorrência de 70 meses que resulta no 
coeficiente de fluência de $1,84\left(\varphi_{(t, t o)}=1,84\right)$, não satisfez o limite estabelecido pela NBR 6118:2003 $(L / 250=2,40 \mathrm{~cm})$ quando verificada com as suas prescrições. No entanto, em um novo processamento para a análise não-linear com o programa ANPAV considerando o coeficiente de fluência $\left(\varphi_{(t, t o)}=1,84\right)$, este critério foi satisfeito.

A verificação de abertura máxima de fissuras, combinação freqüente $(\mathrm{CF})$, foi realizada segundo as prescrições da NBR 6118:2003 e considerada a mesma bitola $(\phi=16,0 \mathrm{~mm})$ e classe de agressividade ambiental (CAA I) dos exemplos anteriores. $\mathrm{O}$ valor da abertura máxima de fissuras foi de $0,21 \mathrm{~mm}$ no vão e $0,11 \mathrm{~mm}$ no engaste, satisfazendo a prescrição da NBR 6118:2003 que é de 0,40 $\mathrm{mm}$ para abertura máxima de fissuras para a classe de agressividade considerada.

Nas análises referidas acima não foi considerada a redistribuição dos esforços solicitantes. Entretanto, nas verificações seguintes foi introduzida a redistribuição dos esforços.

Nos apoios, a profundidade da linha neutra foi de $19,81 \mathrm{~cm}$; com isso $x / d=0,54>0,50$ não satisfaz a condição da eq.(4.12) e, assim, não permite a análise linear com redistribuição, pois $\delta=1,12$, conforme eq.(4.11).

Entretanto, a NBR 6118:2003 refere-se que pode ser adotada redistribuição fora dos limites por ela estabelecidos, desde que a estrutura seja verificada mediante o emprego de análise não-linear ou de análise plástica, com averiguação explícita da capacidade de rotação de rótulas plásticas.

No exemplo da viga biengastada foram estipuladas diminuições dos momentos fletores nos apoios de $12 \%$ e $25 \%$,ou seja, os coeficientes de redistribuição foram $\delta=0,88$ e $\delta=0,75$.

\section{c) Regime elástico-linear}

Os momentos e armaduras provenientes da redução dos momentos são mostrados na Tabela 4.11. As disposições das armaduras e discretização dos elementos foram as mesmas consideradas no caso sem redistribuição, Figura 4.22 e Figura 4.23, respectivamente. 
Tabela 4.11 - Momentos fletores e armaduras da viga biengastada com redistribuição.

\begin{tabular}{c|cccc}
\hline \multirow{2}{*}{$\begin{array}{c}\text { Coeficiente } \\
\text { de }\end{array}$} & \multicolumn{2}{|c}{ Apoios } & \multicolumn{3}{c}{ Vão } \\
\cline { 2 - 5 } redistribuição & $\begin{array}{c}\text { Momento fletor } \\
(\mathrm{kN} \cdot \mathrm{m})\end{array}$ & $\begin{array}{c}\text { As } \\
\left(\mathrm{cm}^{2}\right)\end{array}$ & $\begin{array}{c}\text { Momento fletor } \\
(\mathrm{kN} \cdot \mathrm{m})\end{array}$ & $\begin{array}{c}\text { As } \\
\left(\mathrm{cm}^{2}\right)\end{array}$ \\
\hline$\delta=1,00$ & 126,00 & 10,08 & 63,00 & 4,34 \\
$\delta=0,88$ & 110,88 & 8,48 & 78,12 & 5,53 \\
$\delta=0,75$ & 94,50 & 6,94 & 94,50 & 6,94 \\
\hline
\end{tabular}

\section{d) Regime não-linear com redistribuição}

Para as análises não-lineares considerou-se a mesma discretização e estratificação da seção transversal do caso sem redistribuição, Figura 4.23. Os resultados das análises são mostrados na Figura 4.25.

Nas análises com redução de $12 \%$ nos momentos dos apoios $(\delta=0,88)$ as três verificações satisfizeram o ELU da estrutura, apesar de proporcionar uma diminuição nos fatores de carga e, portanto, uma diminuição em sua margem de segurança, Figura 4.25(a). Verifica-se que a proposta de dimensionamento resultou em um coeficiente igual a 1,00, indicando que a carga inicialmente projetada foi absorvida pela estrutura.

Considerando um coeficiente de redistribuição de 0,75, Figura 4.25(b), as propostas satisfizeram ao ELU, com exceção da proposta de dimensionamento que resultou em um fator de carga de 0,93. Desse modo, para essa proposta podem ser absorvidos apenas $93 \%$ da carga original. 


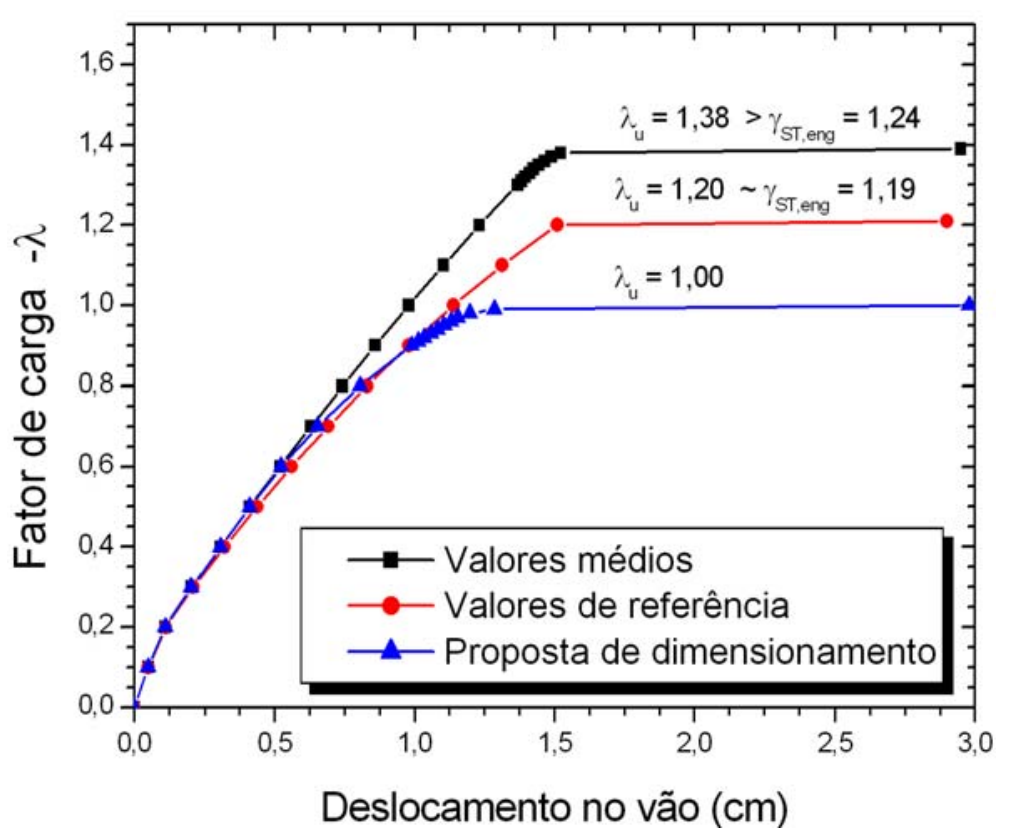

(a)

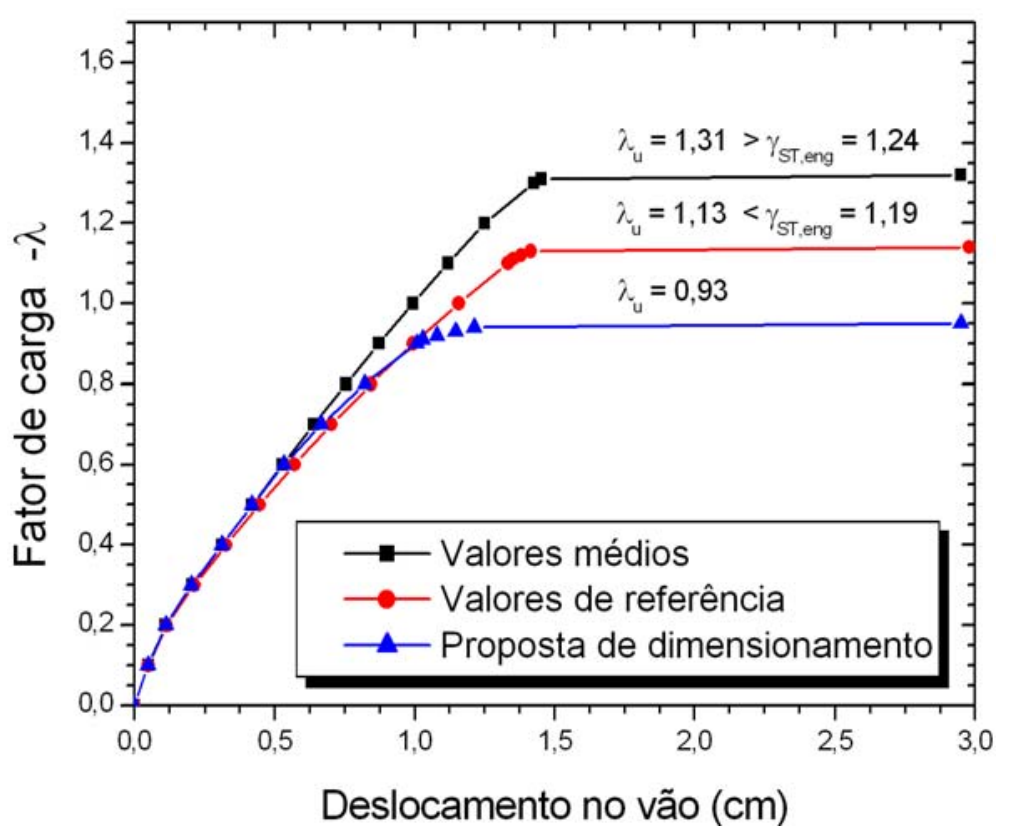

(b)

Figura 4.25 - Fator de carga $v s$. deslocamento no vão da viga biengastada: a) com redistribuição de $\delta=0,88$ e b) com redistribuição de $\delta=0,75$.

Nota-se que o comportamento da viga biengastada, quando considerada a proposta de dimensionamento, representou a rigidez de forma adequada, ou seja, com valores praticamente iguais aos médios até próximo a $70 \%$ da carga para as duas análises, com coeficientes de redistribuição de $\delta=0,88$ e $\delta=0,75$, o que é desejável. As pequenas alterações ocorrem nas proximidades do fim do carregamento, pois o 
modelo proposto atende às condições de dimensionamento, isto é, limita as tensões aos valores de projeto das resistências.

Em vista das análises apresentadas foi possível concluir-se que a segurança da estrutura depende do coeficiente de redistribuição: quanto maior a redistribuição dos esforços solicitantes, menor o fator de segurança, como esperado.

Como comentando anteriormente, é obrigatória a verificação das rotações nas rótulas plásticas, correspondentes aos mecanismos adotados, que não podem superar a capacidade de rotação plástica das seções nos apoios. O limite estabelecido pela NBR 6118:2003 em função da profundidade da linha neutra da seção para o momento fletor considerado na rótula, deve ser determinado através da Figura 4.26, para razão $a / d$ igual a 6 . Para outras relações de $a / d$, deve-se multiplicar os valores obtidos na Figura 4.26 por $\sqrt{(a / d) / 6}$. Onde $a$ é a distância entre pontos de momento nulo da região que contém a seção plastificada, neste caso junto aos engastes.

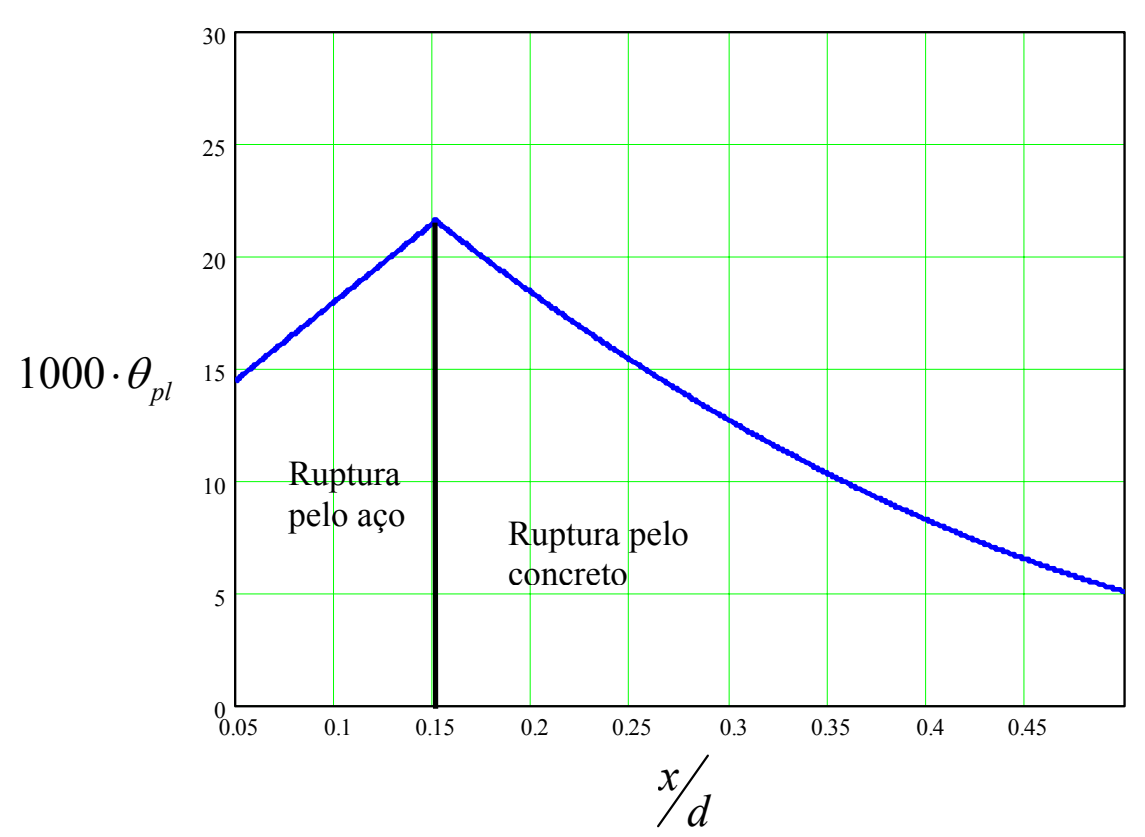

Figura 4.26 - Capacidade de rotação de rótulas plásticas, NBR 6118:2003 [adaptada].

Os limites da capacidade de rotação das rótulas plásticas, estabelecidos pela NBR 6118:2003, estão mostrados na Tabela 4.12 para os dois casos de redistribuição dos esforços solicitantes. 
Tabela 4.12 - Limite da capacidade de rotação da rótula plástica para os apoios.

\begin{tabular}{ccc}
\hline $\begin{array}{c}\text { Coeficiente de } \\
\text { redistribuição }\end{array}$ & $\begin{array}{c}\text { Posição da linha } \\
\text { neutra }(x / d)\end{array}$ & $\begin{array}{c}\theta_{p l, \text { lim }} \\
\left(10^{-3}\right)\end{array}$ \\
\hline$\delta=0,88$ & 0,45 & 6,70 \\
$\delta=0,75$ & 0,37 & 9,60 \\
\hline
\end{tabular}

As rotações da rótula plástica para as análises considerando a não-linearidade, estão mostradas na Tabela 4.13. Nesta verificação considerou-se o carregamento elástico original, isto é, de fator de carga igual a 1,0. Nota-se que nas análises as rotações foram menores que os limites estabelecidos pela NBR 6118:2003, satisfazendo a verificação dos ELU.

Tabela 4.13 - Rotações das rótulas plásticas para as análises não-lineares.

\begin{tabular}{c|ccc}
\hline \multirow{2}{*}{$\begin{array}{c}\text { Coeficiente de } \\
\text { redistribuição }\end{array}$} & \multicolumn{3}{|c}{ Rotações plásticas $-\theta_{p l}\left(10^{-3}\right)$} \\
\cline { 2 - 4 } & Valores médios & $\begin{array}{c}\text { Valores de } \\
\text { referência }\end{array}$ & $\begin{array}{c}\text { Proposta de } \\
\text { dimensionamento }\end{array}$ \\
\hline$\delta=0,88$ & 4,72 & 5,40 & 6,00 \\
$\delta=0,75$ & 4,80 & 5,70 & 5,60 \\
\hline
\end{tabular}

No ELS a verificação de abertura máxima de fissuras, para combinação freqüente (CF), foi realizada de acordo com as prescrições da NBR 6118:2003, considerada a mesma bitola $(\phi=16,0 \mathrm{~mm})$ e classe de agressividade ambiental (CAA I) dos exemplos anteriores. O valor das aberturas de fissuras para as três situações analisadas, com ou sem redistribuição dos esforços solicitantes, constam da Tabela 4.14. 
Tabela 4.14 - Aberturas de fissuras na viga biengastada.

\begin{tabular}{c|cccc}
\hline \multirow{2}{*}{$\begin{array}{c}\text { Coeficiente de } \\
\text { redistribuição }\end{array}$} & \multicolumn{2}{|c}{$\begin{array}{c}\text { Armaduras } \\
\left(\mathrm{cm}^{2}\right)\end{array}$} & $\begin{array}{c}\text { Abertura de fissuras } \\
w_{k}-(\mathrm{mm})\end{array}$ \\
\cline { 2 - 5 } & $A_{s}$ & $A_{s}^{-}$ & Vão & Engaste \\
\hline$\delta=1,00$ & 4,34 & 10,08 & 0,22 & 0,11 \\
$\delta=0,88$ & 5,53 & 8,48 & 0,14 & 0,15 \\
$\delta=0,75$ & 6,94 & 6,94 & 0,09 & 0,21 \\
\hline
\end{tabular}

Como pode ser observado, as maiores aberturas das fissuras $(0,22 \mathrm{~mm})$ aconteceram no vão sem a consideração de redistribuição dos esforços e no engaste de $(0,21 \mathrm{~mm})$ com a consideração do coeficiente de redistribuição de 0,75. Essas aberturas ocorreram em virtude da pequena taxa de armadura existente nas respectivas seções. As aberturas de fissuras foram praticamente iguais na consideração do coeficiente de redistribuição de 0,88 , com menores valores de aberturas quer no vão quer no engaste ao se comparar com os outros dois casos de redistribuição.

A proposta de dimensionamento, no qual o valor médio na relação tensãodeformação teve as propriedades dos materiais limitadas ao valor de projeto, proporcionou resultados bastante satisfatórios na verificação dos estados limites últimos e estados limites de serviços, para os elementos submetidos à flexão analisados neste trabalho. Percebe-se que o modelo proposto representa bem ao valor médio das propriedades dos materiais em serviço e atende aos valores de projeto, para efeitos de dimensionamento, além de permitir uma verificação explícita da capacidade de rotação das rótulas plásticas, estando a favor da segurança em suas estimativas. 


\section{CONCLUSÃO E SUGESTÃO}

\subsection{Sobre o trabalho}

Nas análises realizadas para o dimensionamento e verificação da capacidade resistente das estruturas de concreto armado, essencialmente submetidas à flexão pura, considera-se que os objetivos inicialmente propostos neste trabalho foram plenamente atingidos.

Sabe-se que a necessidade de considerar valores médios para as propriedades dos materiais na representação da rigidez e de valores reduzidos de projeto no dimensionamento de peças de concreto armado, leva naturalmente a uma inconsistência, ao se considerar a evolução do carregamento. Buscando superar o problema, foram analisadas algumas alternativas de modelos para melhor representar o comportamento das estruturas de concreto armado, que pudessem atender simultaneamente aos ELU e ELS.

As alternativas analisadas consideraram os valores médios para a relação tensão-deformação e para as resistências dos materiais, valores de referência que permitem a composição de coeficientes globais de segurança independentemente da ruptura ser provocada pelo esgotamento da capacidade resistente do aço ou do concreto e uma terceira, em que se consideraram os valores médios para a relação tensãodeformação até que as tensões atingissem os valores reduzidos de projeto, o que ocorre nas etapas finais do carregamento. Esta última alternativa mostrou-se a mais adequada 
em todos os casos analisados, constituindo-se na posposta estabelecida pelo presente trabalho.

Em estruturas isostáticas, em que a configuração de equilíbrio é única, o método dos coeficientes globais, em que se consideram os valores de referência para as propriedades dos materiais, não produz inconsistências, pois há apenas uma seção crítica a ser verificada. Nas estruturas hiperestáticas, em que há várias configurações alternativas de equilíbrio, em virtude das possíveis redistribuições dos esforços solicitantes, pode-se chegar a vários coeficientes globais de segurança, desse modo não estabelecendo qual o valor a ser considerado. Entretanto, não se descarta seu emprego para avaliação da segurança das estruturas, por ser uma metodologia que contempla um único coeficiente global para toda a estrutura, independentemente da ruptura ser causada pelo aço ou pelo concreto, o que constitui uma grande qualidade.

Com base nas análises realizadas, a proposta mais adequada para o dimensionamento e verificação da segurança de peças de concreto por ter atendido simultaneamente às verificações dos estados limites últimos e do estados limites de serviço é a que considera os valores médios para a relação tensão-deformação dos materiais, limitando as tensões atuantes aos valores reduzidos de resistência de projeto. Neste trabalho ela foi denominada simplificadamente de proposta de dimensionamento. No estudo de vigas isostáticas esta proposta mostrou-se satisfatória para a verificação de ELU e ELS. No caso de estruturas hiperestáticas, em que se considera a redistribuição dos esforços solicitantes há a necessidade de verificação explícita da capacidade de rotação das rótulas plásticas, o que não inviabiliza a sua utilização. No presente trabalho essa verificação foi feita posteriormente, com base nos resultados produzidos pelas análises realizadas, embora pudesse ser embutida no modelo proposto.

\subsection{Sugestão para trabalho futuros}

Estender o presente estudo às lajes de concreto armado e às barras submetidas à flexão composta.

Com o modelo estendido, estudar o comportamento de pavimentos de edifícios de concreto armado, avaliando-se simultaneamente os ELU e ELS.

Estudar pórticos planos com introdução destas propostas para avaliar o comportamento dos elementos quanto ao efeito de segunda ordem e sua influência na capacidade de rotação de rótulas plásticas. 


\section{REFERÊNCIAS}

ABDEL-SAYED, S.I.; GARDER, N.J. (1975). Design of symmetric square slender reinforced concrete columns under biaxially eccentric loads. ACI Symposium, Detroit, p.149-164.

AHNER, C. (1999). Results of deterministic investigations of reinforced concrete structures for the safety of non-linear calculations. (Leipzig Annual Civil Engineering Report, 4). Disponível em: $<$ http://www.unileipzig.de/ massivb/institut/lacer/lacer04/104_37.pdf>. Acesso em: 5 May 2004.

. (2000). Reliability of slender columns. (Leipzig Annual Civil Engineering Report, 5). Disponível em: $<$ http://www.unileipzig.de/ massivb/institut/lacer/lacer05/105 35.pdf>. Acesso em: 5 May 2004.

AHNER, C.; TUE, N.V. (1997). A new safety format for the design of reinforced concrete structures with non-linear behaviour of materials. (Leipzig Annual Civil Engineering Report, 2). Disponível em: $<$ http://www.unileipzig.de/ massivb/institut/lacer/lacer02/102_30.pdf>. Acesso em: 10 Apr. 2004.

ANG, A.H-S.; TANG, W.H. (1984). Probability concepts in engineering planning and design. New York: John Wiley.

ASSAN, A.E. (1994). Análise não-linear de arcos de concreto armado. In: CONGRESSO IBERO LATINO-AMERICANO SOBRE MÉTODOS COMPUTACIONAIS PARA ENGENHARIA, 15., 1994, Belo Horizonte. Anais... Belo Horizonte: CILAMCE. v.2, p.1386-1394. 
ASSOCIAÇÃO BRASILEIRA DE NORMAS TÉCNICAS (1996). NBR 12655: Concreto - preparo, controle e recebimento. Rio de Janeiro.

. (2003). NBR 6118: Projeto de estruturas de concreto - procedimento. Rio de Janeiro.

. (2003a). NBR 8661: Ações e segurança nas estruturas - procedimento. Rio de Janeiro.

BALLAROTI, C. (1981). Análise elastoplástica de pórticos planos retangulares. Dissertação (Mestrado) - Escola de Engenharia de São Carlos, Universidade de São Paulo, São Carlos. 1981.

BAZANT, Z.P.; BHAT, P. (1976). Endochronic theory of inelasticity and failure of concrete. Journal of Engineering Mechanics Division, New York, v.102, n.4, p.701722, Aug.

BERNARDO, T.R.R. (1999). Contribuição à análise da confiabilidade em pavimentos de edifícios de concreto armado. Dissertação (Mestrado) - Escola de Engenharia de São Carlos, Universidade de São Paulo, São Carlos. 1999.

BRANSON, D.E. (1968). Design procedures for computing deflections. ACI Structural Journal, Detroit, v.65, p.730-742, Sept.

CAMARA, J.; VINAGRE, J.; PINTO, A. (1994). Metodologia para verificação da segurança em análises não-lineares. In: ENCONTRO NACIONAL BETÃO ESTRUTURAL, 1994, Porto. Anais... Porto: FEUP. p.373-383.

CARVALHO, R.C.; FIGUEIREDO FILHO, J.R. (2004). Cálculo e detalhamento de estruturas usuais de concreto armado. 2.ed. São Carlos: EdUFSCar.

CASTRO, L.A.; MALITE, M.; SÁLES, J.J. (1997). Introdução da segurança no projeto de estruturas: método dos estados limites. In: JORNADAS SUL-AMERICANAS DE ENGENHARIA ESTRUTURAL, 28., 1997, São Carlos. Anais... São Carlos: Departamento de Engenharia de Estruturas/EESC/USP; Associação Sulamericana de Engenharia Estrutural. v.3, p.1217-1226. 
CHAVES, I.A. (2004). Otimização de pilares de concreto armado mediante uniformização do índice de confiabilidade. Dissertação (Mestrado) - Escola de Engenharia de São Carlos, Universidade de São Paulo, São Carlos. 2004.

CHEN, A.C.T.; CHEN, W.F. (1975). Constitutive equations and puch-indentation of concrete. Journal of the Engineering Mechanics Division, New York, v.101, n.6, p.889-906, Dec.

CEB BULLETIN D’INFORMATION (1990). Lausanne, n.203/204, July.

CEB BULLETIN D’INFORMATION (1995). Lausanne, n.227, Aug.

CEB BULLETIN D’INFORMATION (1995). Lausanne, n.229, Aug.

CEB BULLETIN D’INFORMATION (1997). Lausanne, n.239, Aug.

CORRÊA, M.R.S. (1991). Aperfeiçoamento de modelos usualmente empregados no projeto de sistemas estruturais de edifícios. Tese (Doutorado) - Escola de Engenharia de São Carlos, Universidade de São Paulo, São Carlos. 1991.

CRANSTON, W.R. (1982). Analysis of slender biaxially loaded restrained columns. Cement and Concrete Association, Research report, London.

DRYSDALE, R.G.;HUGGINS, M.W. (1971). Sustained biaxial load on slender concrete columns, ASCE, ST5, p.1423-1443.

EIBL, J.; SCHMIDT-HURTIENNE, B. (1995). General outline of a new safety format. CEB Bulletin d'Information, Lausanne, n.229, p.33-48, Aug..

ELIGEHAUSEN, R.; FABRITIUS, E. (1991). Steel quality and static analysis. In: COLlOQUIUM ON THE CEB-FIB MC90, 1991, Rio de Janeiro. Proceedings... Rio de Janeiro: COPPE/UFRJ, p. 61-102.

EL-METWALLY, S.E.; EL-SHAHHAT, A.M.; CHEN, W.F. (1990). 3-D nonlinear analysis of R/C slender columns. Computers \& Structures, New York, v.37, n.5, p.863-872. 
FIGUEIRAS, J.A. et al. (1983). Ultimate load analysis of anisotropic and reinforced concrete plates and shells. Swansea. Ph.D. Thesis, Depart. Of Civil Engeneering, University College of Swansea.

FIGUEIRAS, J.A. et al. (1994). A consistent procedure for the design of concrete shell structures. In: INTERNATIONAL CONFERENCE COMPUTER MODELLING OF CONCRETE STRUCTURES, 1994, Innsbruck. Proceedings... Mumbles: Pineridge. v.2, p.955-963.

FUSCO, P.B. (1976). Introdução ao projeto estrutural. São Paulo: McGraw-Hill do Brasil.

. (1985). Estruturas de concreto - introdução ao projeto estrutural. São Paulo: Escola Politécnica/USP.

GOYAL, B.B.; JACKSON, N. (1975). Slender concrete columns under sustained load. ASCE, ST11, p. 2751-2750.

GIONGO, J.S. (1990). Argamassa armada: dimensionamento de perfis submetidos à flexão. Fundamentos e experimentação. Tese (Doutorado) - Escola de Engenharia de São Carlos, Universidade de São Paulo, São Carlos. 1990.

GRAUBNER, C.-A.; SIX, M. (1999). Consistent safety format for non-linear analysis of concrete structures. In: EUROPEAN CONFERENCE ON COMPUTATIONAL MODELING, 1999, Munich. Proceedings... Munich: ECCM. 1 CD-ROM.

HENRIQUES, A.A.R. (1991). Análise não-linear de estruturas planas de betão préesforçado. Dissertação (Mestrado) - Faculdade de Engenharia, Universidade do Porto, Porto. 1992.

(1998). Aplicação de novos conceitos de segurança no dimensionamento do betão estrutural. Tese (Doutorado) - Faculdade de Engenharia, Universidade do Porto, Porto. 1998.

HENRIQUES, A.A.R.; CALHEIROS, F.; FIGUEIRAS, J.A. (1994). A structural safety approach applied to non-linear methods of analysis. In: INTERNATIONAL 
CONFERENCE COMPUTER MODELLING OF CONCRETE STRUCTURES, 1994, Innsbruck. Proceedings... Mumbles: Pineridge. v.2, p.975-986.

. (2002). Safety format for the design for concrete frames. Engineering Computations, Swansea, v.19, n.3, p.246-363.

KIM, J.K.; LEE, T.G. (1992). Nonlinear analysis of reinforced concrete beams with softening. Computers \& Structures, New York, v.44, n.3, p.567-573, July.

KÖNIG, G.; TUE, N.V.; AHNER, C. (1997). Consistent safety format. CEB Bulletin d'Information, Lausanne, n.239, p.1-16, May.

KWARK, H.G.; FILIPPOU, F.C. (1997). Nonlinear fe analysis of R/C structures under monotonic loads. Computers \& Structures, New York, v.65, n.1, p.1-16, Oct.

LABBANE, M.; NRIPENDRA, K.S.; TING, E.C. (1993). Yield criterion and loading function for concrete plasticity. International Journal Solids Structures, New York, v.30, n.9, p.1269-1288.

LAGGERINI, M.R.C.; CAMPOS FILHO, A. (2004). Estado limite de serviço de aberturas de fissuras em seções de concreto armado submetida à flexão simples. In: JORNADAS SUDAMERICANAS DE INGENIERÍA ESTRUTURA1, 31., 2004, Mendonza. Anais... Mendonza: IMERIS/Universidade de Cuyo/ASAEE. 1 CDROOM.

LOPATIC, J.; SAJE, F. (1994). Modelling of elasto-plastic response of concrete structures. In: INTERNATIONAL CONFERENCE COMPUTER MODELLING OF CONCRETE STRUCTURES, 1994, Innsbruck. Proceedings... Mumbles: Pineridge. v.2, p.765-774.

LOURENÇO, P.B.; PÓVOAS, R.H.C.F.; FIGUEIRAS, J.A. (1992). Compared study of non-linear finite element analysis and the strut-and-tie model for concrete strutctures: a designer perspective. In: INTERNATIONAL CONFERENCE ON EDUCATION, PRACTICE AND PROMOTION OF COMPUTATIONAL METHODS IN ENGINEERING USING SMALL COMPUTERS, 4., 1992, Dalian. Proceedings... Dalian: Dalian University of Technology Press. p.660-667. 
MACCHI, G. (1995). Non-linear analysis. CEB Bulletin d'Information, Lausanne, n.229, p.7-12, Aug.

MACHADO, E.R.; FREITAS, M.S.R.; DINIZ, S.M.C. (2001). Avaliação da segurança de vigas projetadas segundo a NBR 6118. In: CONGRESSO BRASILEIRO DO CONCRETO, 43., 2001, Foz do Iguaçu. Anais... Foz do Iguaçu: IBRACON. 1 CDROM.

MALITE, M.; GIONGO, J.S. (1999). Segurança nas estruturas em concreto armado. In: SANCHEZ FILHO, E.S. (Org.). Normalização brasileira para o concreto estrutural. Rio de Janeiro: Interciência. Cap.5, p.71-101

MOLLICA JÚNIOR, S. (1986). O uso da tela soldada no combate à fissuração. São Paulo: IBTS.

NEVES, R.A. (2004). Desenvolvimento de modelos mecânico - probabilísticos para estruturas de pavimentos de edifícios. Tese (Doutorado) - Escola de Engenharia de São Carlos, Universidade de São Paulo, São Carlos. 2004.

NGO, D.; SCORDELIS, A.C. (1967). Finite element analysis of reinforced concrete beams. ACI Structural Journal, Detroit, v.64, n.3, p.152-163, Mar.

NILSON, A.H. (1968). Nonlinear analysis of reinforced concrete by the finite element method. ACI Structural Journal, Detroit, v.65, n.9, p.757-766, Sept.

NOVOTNY, A.A. et al. (1994). Análise comparativa entre alguns procedimentos de integração na espessura para problemas elastoplásticos em placas semi-espessas. In: CONGRESSO IBERO LATINO-AMERICANO SOBRE MÉTODOS COMPUTACIONAIS PARA ENGENHARIA, 15., 1994, Belo Horizonte. Anais... Belo Horizonte: CILAMCE. v.2, p.1569-1579.

OLIVEIRA, R.S. (1997). Análise de pavimentos de edifícios de concreto armado com a consideração da não-linearidade física. Dissertação (Mestrado) - Escola de Engenharia de São Carlos, Universidade de São Paulo, São Carlos. 1997.

. (2001). Análise de pavimentos de edifícios de concreto armado com a consideração da não-linearidade física - modelagem e metodologia de aplicação a 
projetos. Tese (Doutorado) - Escola de Engenharia de São Carlos, Universidade de São Paulo, São Carlos. 2001.

OLIVEIRA, W.L.A. (2004). Análise teórica e experimental de pilares de concreto armado sob a ação de força centrada com resistência média à compressão do concreto de 40 MPa. Dissertação (Mestrado) - Escola de Engenharia de São Carlos, Universidade de São Paulo, São Carlos. 2004.

OWEN, D.R.J.; HINTON, E. (1980). Finite elements in plasticity: theory and practice. Swansea: Pineridge Press.

PINTO, R.S. (2002). Análise não-linear das estruturas de contraventamento de edifícios em concreto armado. Tese (Doutorado) - Escola de Engenharia de São Carlos, Universidade de São Paulo, São Carlos. 2002.

PINTO, R.S.; RAMALHO, M.A.; CORRÊA, M.R.S. (1999). Consideração simplificada da não-linearidade física no projeto de edifícios de concreto armado. In: CONGRESSO BRASILEIRO DO CONCRETO, 41., 1999, Salvador. Anais... Salvador: IBRACON.

PRADO, J.F.M.A.; GIONGO, J.S.S. (1997). Redistribuição de momentos fletores em vigas de edifícios. In: JORNADAS SUL-AMERERICANAS DE ENGENHARIA ESTRUTURAL, 28., 1997, São Carlos. Anais... São Carlos: Departamento de Engenharia de Estruturas/EESC/USP; Associação Sulamericana de Engenharia Estrutural. v.4, p.1555-1563.

PROENÇA, S.P.B. (1988). Sobre modelos matemáticos do comportamento não linear do concreto: análise crítica e contribuições. Dissertação (Mestrado) - Escola de Engenharia de São Carlos, Universidade de São Paulo, São Carlos. 1988.

RAMALHO, M.A. (1990). Sistema para análise de estruturas considerando interação com o meio elástico. Tese (Doutorado) - Escola de Engenharia de São Carlos, Universidade de São Paulo, São Carlos. 1990.

SAENZ, L.P. et al. (1964). Discussion of "equation for the stress-strain curve of concrete" paper by P.Desayi; S.Krishnan. Journal of the american Concrete Institute, Detroit, v.1, n.3/9, Mar./Sept. 
SANCHES JÚNIOR, F. (1998). Cálculo de esforços e deslocamentos em pavimentos de edifícios considerando-se modelos próprios para o concreto armado. Dissertação (Mestrado) - Escola de Engenharia de São Carlos, Universidade de São Paulo, São Carlos. 1998.

SANTOS, L.M. (1983). Cálculo de concreto armado: segundo a nova NB-1 e o CEB. 2.ed. São Paulo: LMS. v.1.

SATHURAPPAN, G.; RAJAGOPALAN, N.; KRISHNAMOORTHY, C.S. (1992). Nonlinear finite element analysis of reinforced and prestressed concrete slabs with reinforcement (inclusive of prestressing steel) modelled as discrete integral components. Computers \& Structures, New York, v.44, n.3, p.575-584, July.

TUE, N.V. (1996). Relationship between the bearing capacity of cross section and the bearing capacity of whole structure. (Leipzig Annual Civil Engineering Report, 1). Disponível em: $<$ http://www.unileipzig.de/ massivb/institut/lacer/lacer01/101_21.pdf>. Acesso em: 5 May 2004.

WITTEK, U.; MEISWINKEL, R. (2000). Ultimate load design concept of RC structures considerering cross-sectional safeties. In: ASCE SPECIALTY CONFERENCE ON PROBABILISTIC MECHANICS AND STRUTURAL RELIABILITY, 8., 2000. $\quad$ Proceedings... $\quad$ Disponível em: $<$ http://www.usc.edu/dept/civil_eng/johnsone/pmc2000/sessions/papers/p039.pdf $>$. Acesso em: 10 June 2004.

WONG, K.W.; WARNER, R.F. (1999). Non-linear design of reinforced concrete structures: safety considerations. In: EUROPEAN CONFERENCE ON COMPUTATIONAL MECHANICS, 1999, Munich. Proceedings... Munich: ECCM. 1 CD-ROM.

ZAGOTIS, D. (1974). A introdução da segurança no projeto estrutural. Construção Pesada, São Paulo, ano 4, n.36, p.22-25, jan.

ZIENCKIEWICZ, O.C.; VALLIAPAN, S.; KING, I.P. (1969). Elasto-plastic solutions on engineering problems - 'initial stress' finite element approach. International Journal for Numerical Methods in Engineering, London, v.1, n.1, p.75-100. 


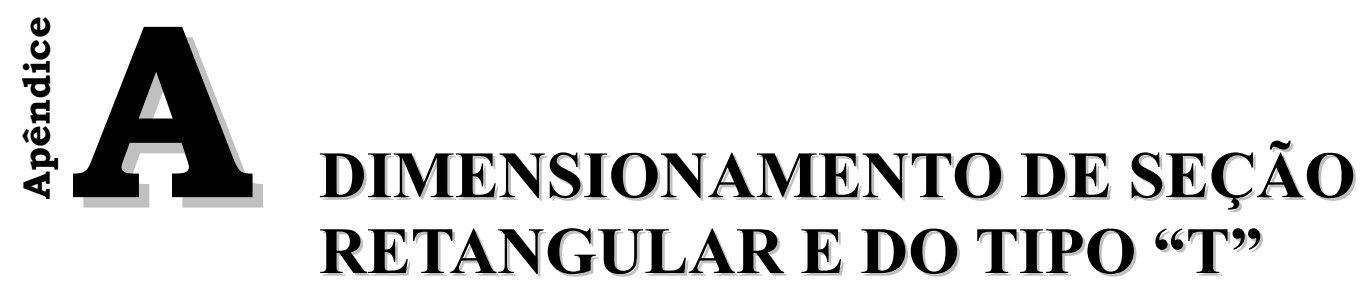

\section{A.1 Considerações gerais}

Neste apêndice estão expressas as equações empregadas no dimensionamento de peças de concreto armado submetidas a esforços de flexão normal simples utilizadas para implementar o programa computacional no software MathCad.

No dimensionamento, como o nome sugere, dados os esforços internos solicitantes, procuram-se as dimensões da seção transversal e a armadura necessária. Todo dimensionamento baseia-se em três tipos de equações: equações de equilíbrio, de compatibilidade e constitutivas.

A seção encontra-se equilibrada quando os esforços resistentes contrapõem-se aos esforços internos solicitantes, de modo tal que o conjunto forme um sistema equivalente a zero. As equações de compatibilidade, no caso de estruturas de concreto armado, baseiam-se na hipótese de NAVIER-BERNOULLI, afirmando que as deformações são compatíveis entre si quando se distribuem linearmente ao longo da altura da seção. Por fim, as equações constitutivas relacionam as tensões com as deformações ou vice-versa, de acordo com os diagramas $\sigma-\varepsilon$ dos materiais que compõem a seção. 
No dimensionamento das seções retangulares e do tipo " $T$ " considerou-se a hipótese de distribuição parábola-retângulo de tensões de compressão para o concreto e para o aço um diagrama bilinear com patamar de escoamento, Figura A.1.

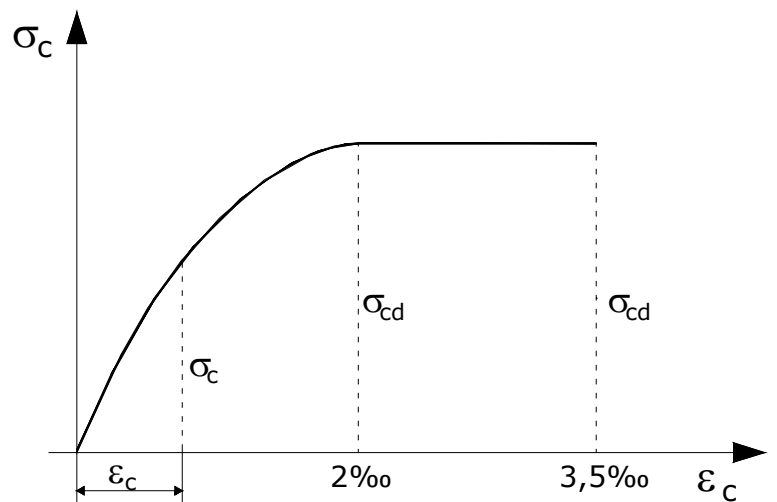

(a)

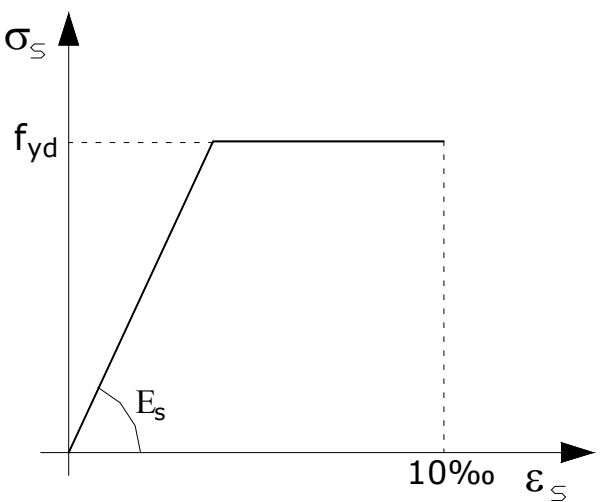

(b)

Figura A.1 - Diagramas tensão-deformação: a) concreto à compressão e b) aço.

Até o valor de deformação de $\varepsilon_{c}=2 \%$, a tensão no concreto $\left(\sigma_{c}\right)$ varia segundo uma parábola do $2^{\circ}$ grau, conforme eq. (A.1).

$\sigma_{c}=\sigma_{c d} \cdot\left(\varepsilon_{c}-\frac{\varepsilon_{c}^{2}}{4}\right)$

onde $\varepsilon_{c}$ é dado em $\%$, e $\sigma_{c d}$ é expresso pela eq.(A.2).

$\sigma_{c d}=0,85 \cdot f_{c d}$

Para $\varepsilon_{c} \geq 2 \%$ até o encurtamento convencional de ruptura $\varepsilon_{c}=3,5 \%, \sigma_{c}$ permanece constante e igual a $\sigma_{c d}$.

O programa de dimensionamento desenvolvido no software MathCad permite que a seção retangular ou do tipo " $T$ " possua ou não armadura dupla.

As figuras deste apêndice com as necessárias adaptações são SANTOS (1983). 


\section{A.2 Dimensionamento de seção retangular}

A seção transversal, o diagrama de deformações e o diagrama de tensõs são mostrados na Figura A.2.

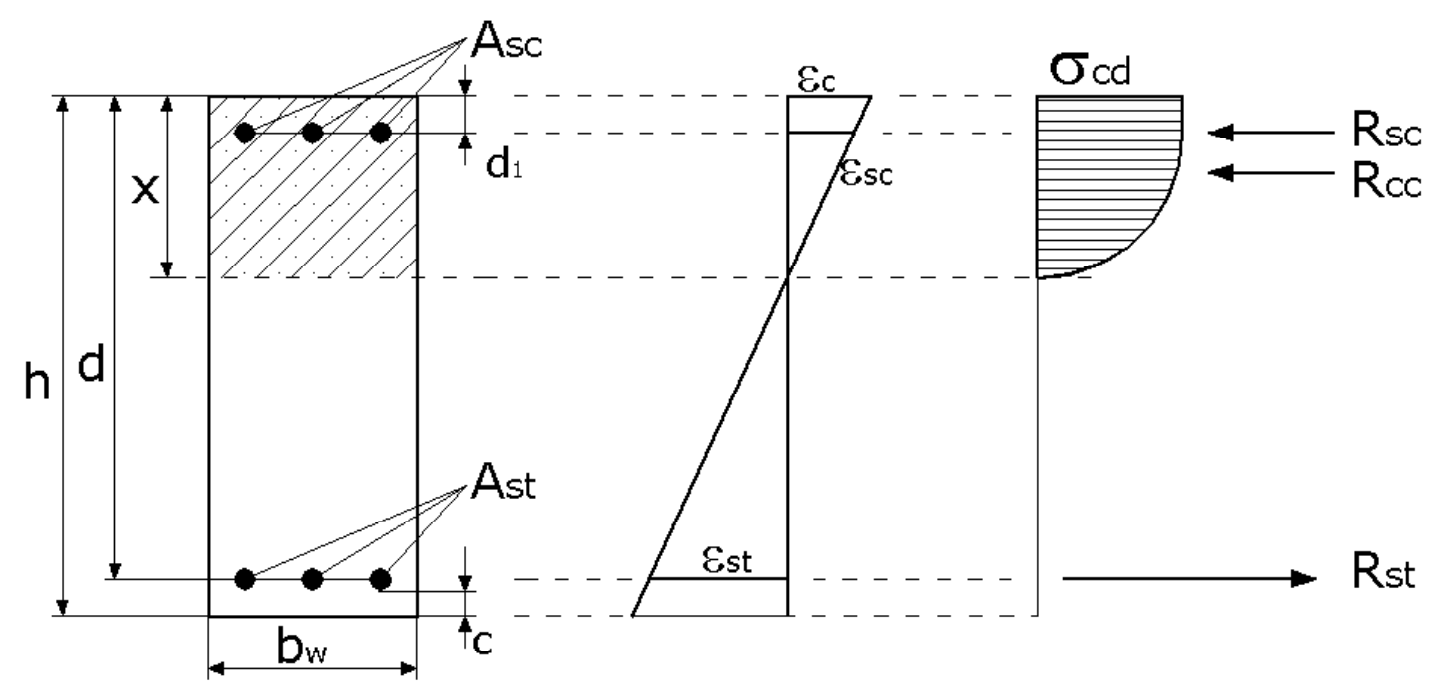

Figura A.2 - Seção retangular, diagrama de deformações e tensões de compressão no concreto.

A distribuição de tensões na zona comprimida de concreto pode ter um diagrama exclusivamente parabólico ou parábola-retângulo. Desse modo, tem-se dois casos para efeito de estabelecer o equacionamento para o dimensionamento. Para tanto, foram necessário considerar três casos:

$1^{\mathrm{o}}$ caso: correspondente ao sub-domínio $2 \mathrm{a}$;

$2^{\circ}$ caso: correspondente ao sub-domínio $2 \mathrm{~b}$;

$3^{\circ}$ caso: correspondente aos domínios 3 e 4.

As expressões que governam estes casos são mostradas a seguir.

\section{A.2.1 Cálculo da resultante interna de compressão do concreto e seu centro de gravidade}

\section{A.2.1.1 Sub-domínio 2a}

O diagrama de tensões de compressão do concreto é parabólico. Esta situação ocorre quando $\varepsilon_{c} \leq 2 \%$ simultaneamente com $\varepsilon_{s t}=10 \%$, estado limite último de deformação plástica excessiva. Seja $x$ a profundidade da linha neutra real e $v$ a 
distância a ela de uma fibra genérica, onde atua a tensão $\sigma_{c}^{\prime}$, como mostra a Figura A.3.

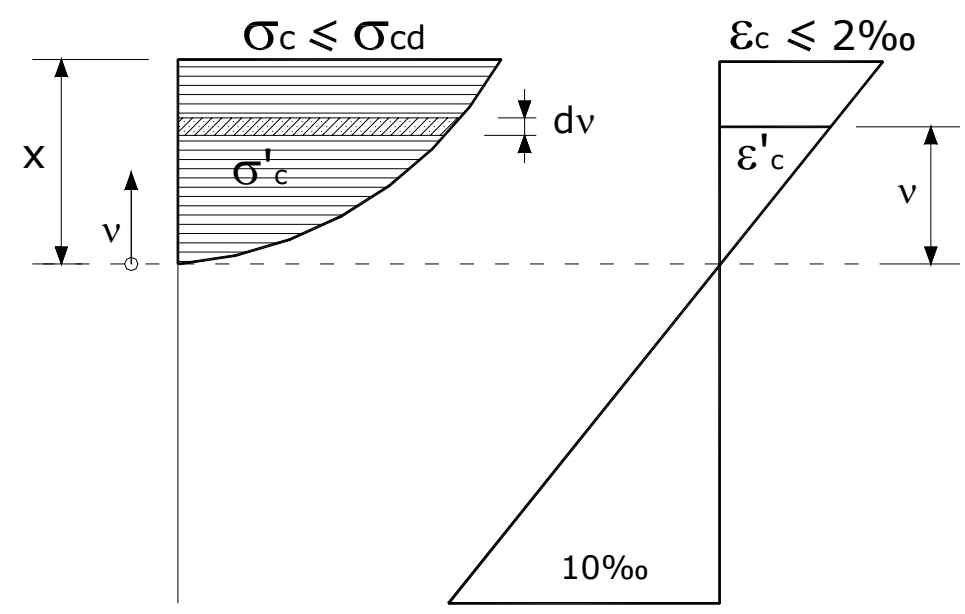

Figura A.3 - Diagrama de tensão e deformação do concreto no sub-domínio 2a.

As relações que governam tal comportamento são mostradas a seguir:

$$
\begin{aligned}
& \varepsilon_{c}^{\prime}=\varepsilon_{c} \cdot \frac{v}{x} \\
& \sigma_{c}^{\prime}=\sigma_{c d} \cdot\left(\varepsilon_{c}^{\prime}-\frac{\varepsilon_{c}^{\prime 2}}{4}\right) \\
& R_{c c}=b_{w} \cdot \int_{0}^{x} \sigma_{c}^{\prime} \cdot d v
\end{aligned}
$$

Substituindo as expressões acima e integrando, decorre o valor da resultante interna de compressão do concreto em:

$$
R_{c c}=\frac{5 \cdot b_{w} \cdot \sigma_{c d} \cdot x^{2} \cdot(3 \cdot d-8 \cdot x)}{3 \cdot(d-x)^{2}}
$$

Verificando agora o centro de gravidade da área hachurada de modo a localizar a posição de $R_{c c}$ em relação à profundidade da linha neutra, Figura A.4. 


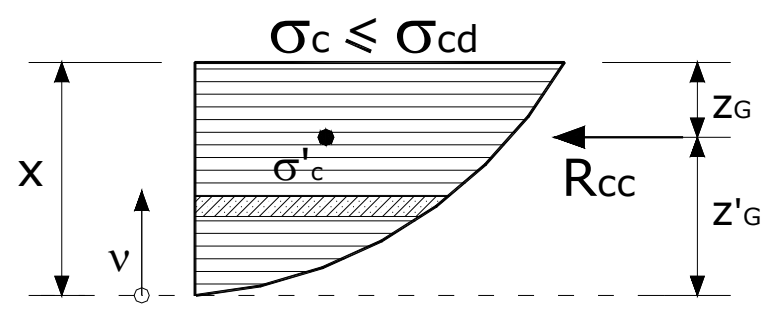

Figura A.4 - Centro de gravidade da força $R_{c c}$ : sub-domínio $2 \mathrm{a}$.

As expressões para determinar a área hachurada e, conseqüentemente, o centróide são mostrados a seguir:

$$
\begin{aligned}
& A_{\text {hachurada }}=\frac{5 \cdot \sigma_{c d} \cdot x^{2} \cdot(3 \cdot d-8 \cdot x)}{3 \cdot(d-x)^{2}} \\
& z_{G}^{\prime}=\frac{\int_{0}^{x} \sigma_{c d}^{\prime} \cdot v \cdot d v}{A_{\text {rachurada }}}
\end{aligned}
$$

Considerando as relações anteriores, na eq.(A.6) resulta o valor de $z_{G}^{\prime}$. Assim, o centro de gravidade da resultante das forças internas do concreto à compressão é expressa pela eq.(A.7).

$$
\begin{aligned}
& z_{G}^{\prime}=\frac{x \cdot(8 \cdot d-23 \cdot x)}{4 \cdot(3 \cdot d-8 \cdot x)} \\
& z_{G}=x-z^{\prime}{ }_{G}
\end{aligned}
$$

\section{A.2.1.2 Sub-domínio 2b}

O diagrama das tensões de compressão do concreto torna-se paráboloretângulo. Neste sub-domínio, o encurtamento do concreto $\left(\varepsilon_{c}\right)$ varia entre $2 \% \mathrm{e}$ $3,5 \%$, Figura A.5. A profundidade da linha neutra no domínio $2 \mathrm{~b}$ torna-se:

$x=a+x^{\prime}$ 


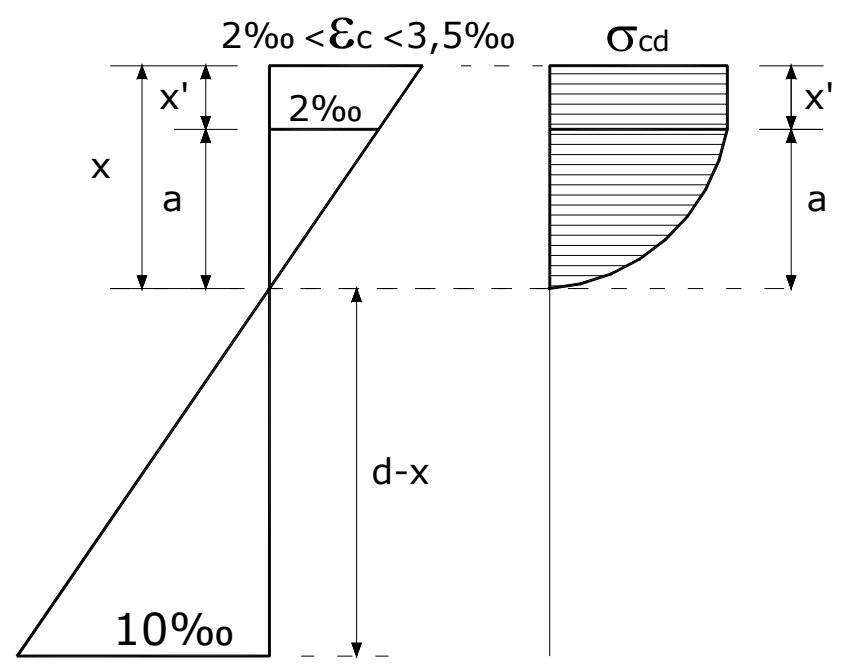

Figura A.5 - Diagrama de tensão e deformação do concreto no sub-domínio $2 b$.

Do diagrama de deformações, Figura A.5, as seguintes relações podem ser realizadas:

$$
\begin{aligned}
& \frac{2}{10}=\frac{a}{d-x} \\
& a=\frac{d-x}{5}
\end{aligned}
$$

O valor da profundidade da linha neutra será:

$$
\begin{aligned}
& x=\frac{5 \cdot x^{\prime}+d}{6} \\
& x^{\prime}=\frac{6 \cdot x-d}{5}
\end{aligned}
$$

Dessa forma, a resultante da força interna do concreto à compressão é expressa abaixo.

$$
\begin{aligned}
& R_{c c}=b_{w} \cdot \sigma_{c d} \cdot\left(\frac{6 \cdot x-d}{5}\right)+b \cdot \frac{2}{3} \cdot \sigma_{c d} \cdot\left(\frac{d-x}{5}\right) \\
& R_{c c}=\frac{b_{w} \cdot \sigma_{c d}}{15} \cdot(16 \cdot x-d)
\end{aligned}
$$


Verificando o centro de gravidade da área hachurada, de modo a encontrar o ponto de atuação da força interna de compressão do concreto, Figura A.6, a posição do centro de gravidade da área hachurada, Figura A.6, é determinado pela expressão:

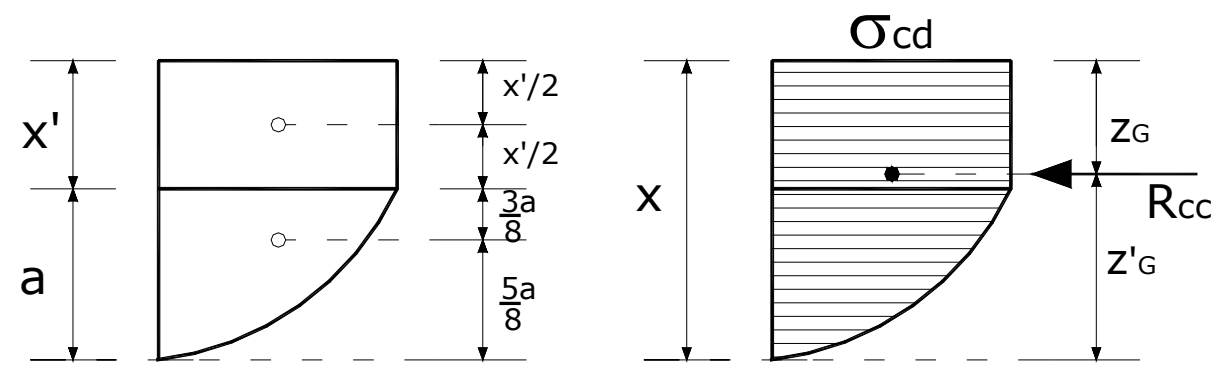

Figura A.6 - Centro de gravidade da força $R_{c c}$ : sub-domínio $2 \mathrm{~b}$.

$R_{c c} \cdot z_{G}=b_{w} \cdot \sigma_{c d} \cdot \frac{x^{\prime 2}}{2}+b_{w} \cdot \sigma_{c d} \cdot \frac{2}{3} \cdot a \cdot\left(\frac{3}{8} \cdot a+x^{\prime}\right)$

O centro de gravidade é expresso pela eq.(A.13).

$z_{G}=\frac{\frac{3}{10} \cdot(6 \cdot x-d)^{2}+\frac{1}{4} \cdot(d-x) \cdot(9 \cdot x-d)}{16 \cdot x-d}$

$z_{G}^{\prime}=x-z_{G}$

\section{A.2.1.3 Domínios 3 e 4}

Nestes domínios a deformação do concreto é constante e igual a 3,5\%0 $\left(\varepsilon_{c d}=3,5 \%=c t e\right)$. Assim, decorrem da Figura A.7 as seguintes relações:

$$
\begin{aligned}
& \frac{2}{a}=\frac{3,5}{x} \\
& a+x^{\prime}=x \\
& a=\frac{4}{7} \cdot x \\
& x^{\prime}=\frac{3}{7} \cdot x
\end{aligned}
$$




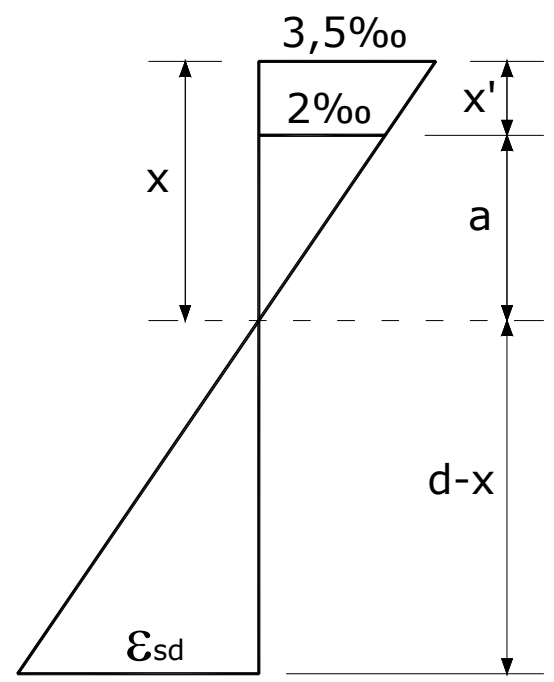

Figura A.7 - Diagrama de deformação do concreto nos domínios 3 e 4.

A resultante interna das forças de compressão do concreto, substituindo as expressões anteriores, torna-se igual a eq.(A.16).

$R_{c c}=b_{w} \cdot \sigma_{c d} \cdot x^{\prime}+b \cdot \frac{2}{3} \cdot \sigma_{c d} \cdot a$

$R_{c c}=\frac{17}{21} \cdot b_{w} \cdot \sigma_{c d} \cdot x$

A posição do centro de gravidade da força $R_{c c}$ é determinada conforme a Figura A.6 e a eq.(A.12). Levando em conta os valore de $x^{\prime}$ e de $a$, mostrados na eq.(A.15), têm se:

$$
\begin{aligned}
& R_{c c} \cdot z_{G}=\frac{33}{98} \cdot b_{w} \cdot \sigma_{c d} \\
& \mathrm{z}_{\mathrm{G}}=\frac{33 \cdot b_{w} \cdot \sigma_{c d} \cdot x^{2}}{98 \cdot R_{c c}} \\
& \mathrm{z}_{\mathrm{G}}=\frac{99}{238} \cdot x^{2} \\
& \mathrm{z}_{\mathrm{G}}=x-z_{G}
\end{aligned}
$$




\section{A.2.2 Equações de equilíbrio}

São duas as equações de equilíbrio. Uma exprime as forças internas resultantes, tanto do concreto quanto do aço; a outra os momentos dessas forças em relação a profundidade da linha neutra e o momento externo atuante na seção transversal.

$$
\begin{aligned}
& \sum N=0 \quad \rightarrow \quad R_{s t}=R_{c c}+R_{s c} \\
& \sum M^{L N}=0 \rightarrow M=R_{s t} \cdot(d-x)+R_{s c}\left(x-d^{\prime}\right)+R_{c c} \cdot z_{G}^{\prime}
\end{aligned}
$$

sendo:

$$
\begin{array}{ll}
R_{s t}=A_{s} \cdot \sigma_{s t} & \text { força resistente da armadura tracionada; } \\
R_{s c}=A_{s}^{\prime} \cdot \sigma_{s c} & \text { força resistente da armadura comprimida; } \\
\sigma_{s t}=E_{s} \cdot \varepsilon_{s t} & \text { tensão na armadura tracionada; } \\
\sigma_{s c}=E_{s} \cdot \varepsilon_{s c} & \text { tensão na armadura comprimida; } \\
M & \text { momento externo atuante na seção transversal. }
\end{array}
$$

\section{A.2.3 Programa no software MathCad}

Com as expressões aqui mostradas, foi desenvolvido o programa para dimensionamento de seção retangular no software MathCad para facilitar as análises, o qual ficará disponível no Departamento de Engenharia de Estruturas da EESC/USP. O programa é mostrado a seguir.

\section{Rotina de dimensionamento - FLEXÃO SIMPLES}

\section{SEÇÃO TRANSVERSAL RETANGULAR}

Rotina de dimensionamento de seção retangular de concreto armado submetida a flexão simples.

Foi considerado diagrama parábolo-retângulo para o concreto e diagrama bilinear para o aço.

Domínios de verificação 2 - 3 - 4 .

Obs: Os valores que estão destacados em verdesão atribuidos ao dimensionamento e em amarelo os calculados.

Autor: Geilson Márcio Albuquerque de Vasconcelos Engenheiro Civil Mestrando em Engenharia de Estruturas Escola de Engenharia de São Carlos - EESC Universidade de São Paulo - USP 
Orientador: Márcio Roberto Silva Corrêa

Data: Junho de 2004

\section{Dados de entrada}

Transformação de unidades

Resistência característica à compressão do concreto

fck $:=30 \mathrm{MPa}$

Resistência característica do aço

fyk $:=500 \mathrm{MPa}$

Altura da seção transversal retangular

$\mathrm{h}:=50 \mathrm{~cm}$

Altura útil da seção transversal retangular

$\mathrm{d}:=47 \mathrm{~cm}$

Largura da seção transversal retangular

bw $:=15 \mathrm{~cm}$

Distância do centróide da armadura comprimida

à face da região comprimida

$\mathrm{d} 1:=3 \mathrm{~cm}$

Cobrimento da armadura

$\mathrm{c}:=2.5 \mathrm{~cm}$

Módulo de Elasticidade do aço

Es $:=210000 \mathrm{MPa}$

- $\quad$ Armadura comprimida (porta estribos)

Número de barras da armadura comprimida

Nsc $:=0$

Diâmetro da barra da armadura comprimida

Dsc $:=6.3 \mathrm{~mm}$

- Momento atuante

Momento atuante na seção transversal

$\mathrm{M}:=189.00 \mathrm{kN} \cdot \mathrm{m}$

Dálculo da área da armadura

Área da armadura comprimida (porta estribo)

Aspe $=0 \mathrm{~cm}^{2}$

\section{Dimensionamento da armadura}

- Coeficientes ponderadores das resistências $\left(\gamma_{c}\right.$ e $\gamma_{s}$ ou $\gamma_{c R}$ e $\left.\gamma_{s R}\right)$

Concreto

Aço

Dropriedades dos Materiais

Dquacionamento $\gamma c:=1.40$

$\gamma_{S}:=1.15$ 


\section{Estimativa Inicial}

$\mathrm{x}:=1 \mathrm{~cm} \quad$ As $:=1 \mathrm{~cm}^{2}$

Resolução do sistema

$$
\text { As }=11.583 \mathrm{~cm}^{2} \quad \mathrm{x}=22.77 \mathrm{~cm}
$$

Dimites dos domínios

Dominio = "Dominio 3 - Seção subarmada"

Ruptura = "Ruptura do concreto e escoamento do aço"

- Deformação nos materiais

Concreto

Armadura tracionada

Armadura comprimida

Deformação na tensão de escoamento da armadura tracionada

$$
\operatorname{ccc}(\mathrm{x})=3.5 \times 10^{-3}
$$$$
\varepsilon s t(x)=3.724 \times 10^{-3}
$$

$$
\csc (\mathrm{x})=0
$$

Eyd $=2.07 \times 10^{-3}$

\section{A.3 Dimensionamento de seção do tipo " $T$ "}

A seção do tipo "T" é caso freqüente em concreto armado, particularmente nas

estruturas de edifícios, em virtude da colaboração prestada pela laje à viga. É claro que, se o momento atuante for negativo, isto é, se comprimir a nervura e não a mesa, a viga é considerada como viga retangular. Ainda que o momento seja positivo, se a profundidade da linha neutra for menor que a altura da mesa, tratar-se-á também como seção retangular.

A seção transversal e as respectivas notações são mostradas na Figura A.8. 


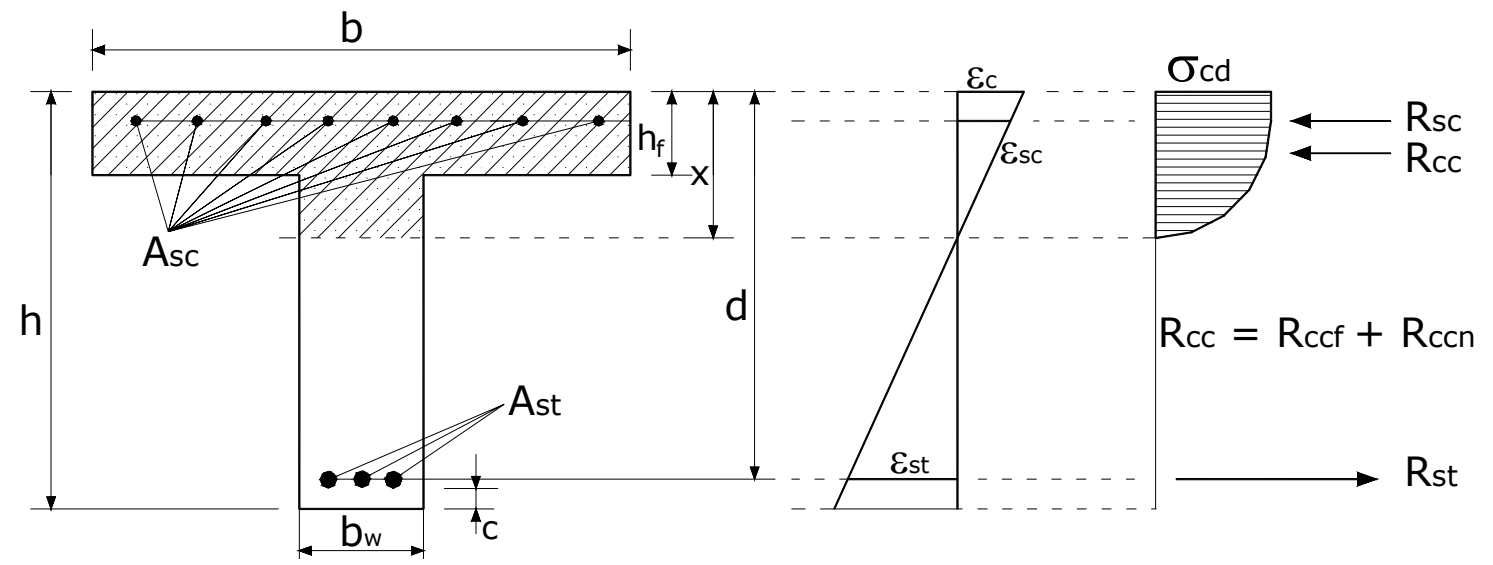

Figura A.8 - Seção do tipo "T", diagrama de deformações e tensões de compressão no concreto.

O processo de cálculo consiste em subdividir a seção do tipo "T" em duas seções retangulares, como mostra a Figura A.9.
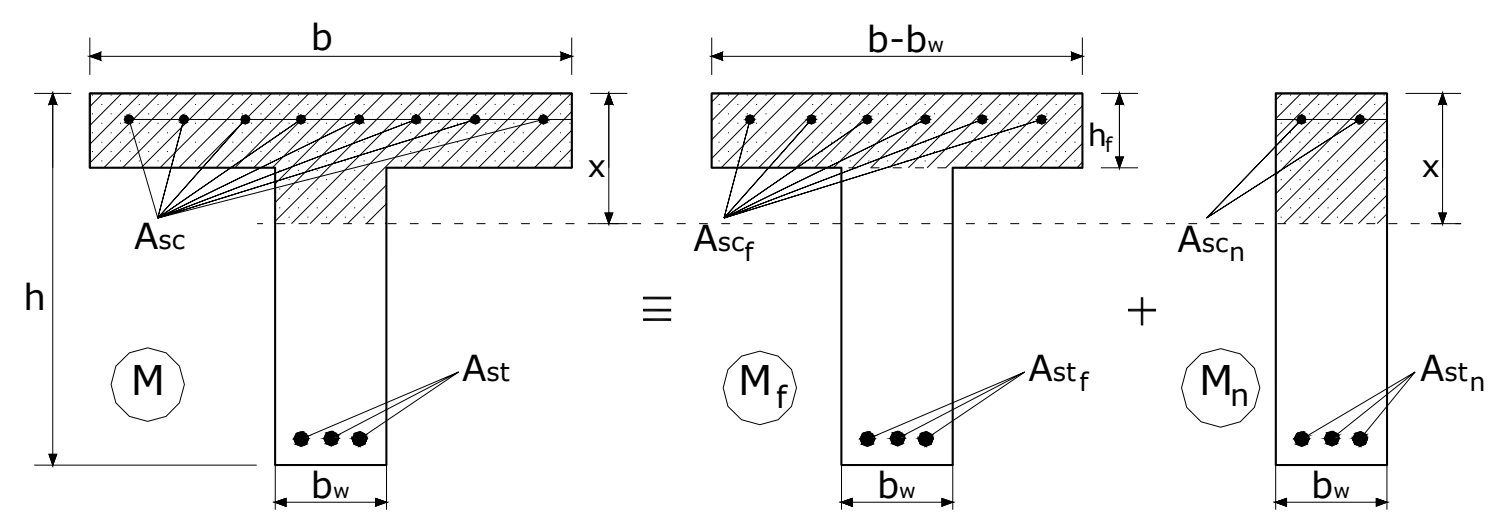

Figura A.9 - Subdivisão da seção do tipo “T”.

Percebe-se que o momento resistente total $M$ é dividido em duas parcelas, uma referente à contribuição da mesa $\left(M_{f}\right)$ e outra referente à contribuição da nervura $\left(M_{n}\right)$, conforme:

$M=M_{f}+M_{n}$

Para efeito do cálculo algébrico, pode-se pensar em três casos para o dimensionamento, sendo eles:

$1^{\circ}$ Caso: O diagrama das tensões de compressão na mesa é parabólico;

$2^{\circ}$ Caso: O diagrama das tensões de compressão na mesa é parábolo-retângulo;

$3^{\circ}$ Caso: $\mathrm{O}$ diagrama das tensões de compressão na mesa é retangular. 
As expressões mostradas a seguir são referentes apenas à contribuição da mesa na resistência da seção, visto que, a contribuição da nervura é tratada como viga retangular, mostrada anteriormente.

\section{A.3.1 Cálculo da resultante interna de compressão do concreto e seu centro de gravidade}

\section{A.3.1.1 $1^{\circ}$ Caso}

O diagrama das tensões de compressão na mesa é parabólico, Figura A.10. Desse modo, a deformação é $\varepsilon_{c 2} \leq 2 \%$ e a tensão de compressão $\sigma_{c 2} \leq \sigma_{c d}$.

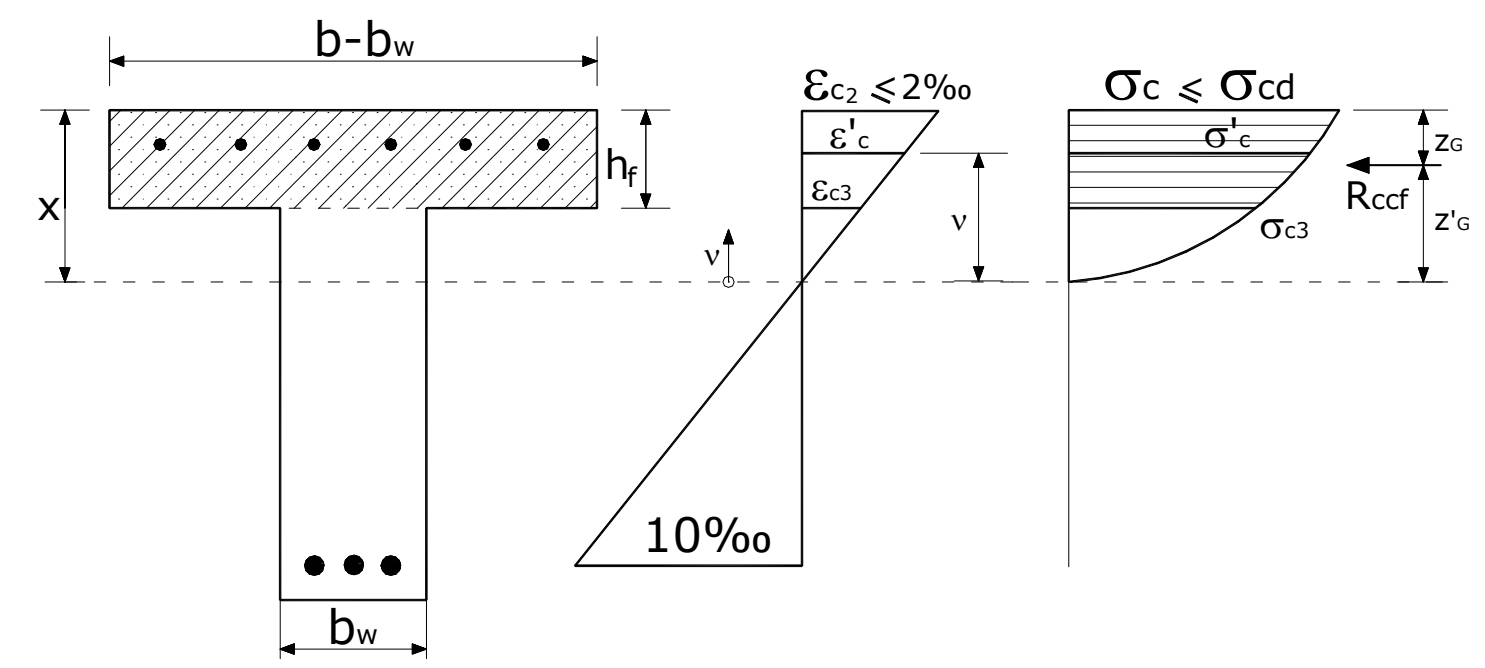

Figura A.10 - Diagrama das tensões de compressão na mesa parabólico.

Este caso ocorre sempre que a condição abaixo for satisfeita.

$h_{f}<x \leq \frac{d}{6}$

Seja $v$ a distância à linha neutra de uma fibra genérica da mesa, com deformação $\varepsilon_{c}^{\prime}$ e tensão de compressão $\sigma^{\prime}{ }_{c}$. A tensão $\sigma_{c}{ }_{c}$ está em função da deformação $\varepsilon_{c}^{\prime}$ por meio da eq.(A.3). Do diagrama de deformação, Figura A.10, decorrem as relações mostradas na eq.(A.23) e eq.(A.24). 
$\varepsilon^{\prime}{ }_{c}=\varepsilon_{c 2} \frac{\nu}{x}$

$\varepsilon_{c 2}=\frac{10 \cdot x}{d-x} \quad(\%)$

A largura a ser considerada é a diferença entre a largura da mesa e da nervura $\left(b-b_{w}\right)$. Assim, a resultante de compressão do concreto na mesa $\left(R_{c c f}\right)$ é dada por:

$R_{c c f}=\left(b-b_{w}\right) \cdot \int_{x-h_{f}}^{x} \sigma_{c}^{\prime} \cdot d v$

Substituindo a eq.(A.23) e a eq.(A.24) na eq.(A.3) e o valor resultante de $\sigma_{c}^{\prime}$ na eq.(A.25) e integrando, o valor resultante das forças internas de compressão do concreto atuante na mesa é expresso pela eq.(A.26). A posição de $R_{c c f}$ é determinada pela eq.(A.27),

$$
\begin{aligned}
& R_{c c f}=\frac{5 \cdot \sigma_{c d} \cdot\left(b-b_{w}\right) \cdot h_{f}}{d-x} \cdot\left[\left(2 \cdot x-h_{f}\right)-\frac{5}{3 \cdot(d-x)} \cdot\left(3 \cdot x^{2}-3 \cdot x \cdot h_{f}+h_{f}^{2}\right)\right] \\
& R_{c c f} \cdot z_{G f}^{\prime}=\left(b-b_{w}\right) \cdot \int_{x-h_{f}}^{x} \sigma_{c}^{\prime} \cdot v \cdot d v
\end{aligned}
$$

Desenvolvida a integral e considerando as relações anteriores, chega-se à seguinte expressão:

$$
z_{G f}^{\prime}=\frac{\frac{2}{3} \cdot\left(3 \cdot x^{2}-3 \cdot x \cdot h_{f}+h_{f}^{2}\right)-\frac{5}{4 \cdot(d-x)} \cdot\left(4 \cdot x^{3}-6 \cdot x^{2} \cdot h_{f}+4 \cdot x \cdot h_{f}^{2}-h_{f}^{3}\right)}{2 \cdot x-h_{f}-\frac{5}{3 \cdot(d-x)} \cdot\left(3 \cdot x^{2}-3 \cdot x \cdot h_{f}+h_{f}^{2}\right)}
$$

O centro de gravidade $R_{c c f}$ em relação a fibra mais comprimida é expresso pela eq.(A.29).

$$
z_{G f}=x-z_{G f}^{\prime}
$$




\section{A.3.1.2 $2^{\circ}$ Caso}

O diagrama das tensões de compressão na mesa é parábolo-retângulo, Figura A.11.

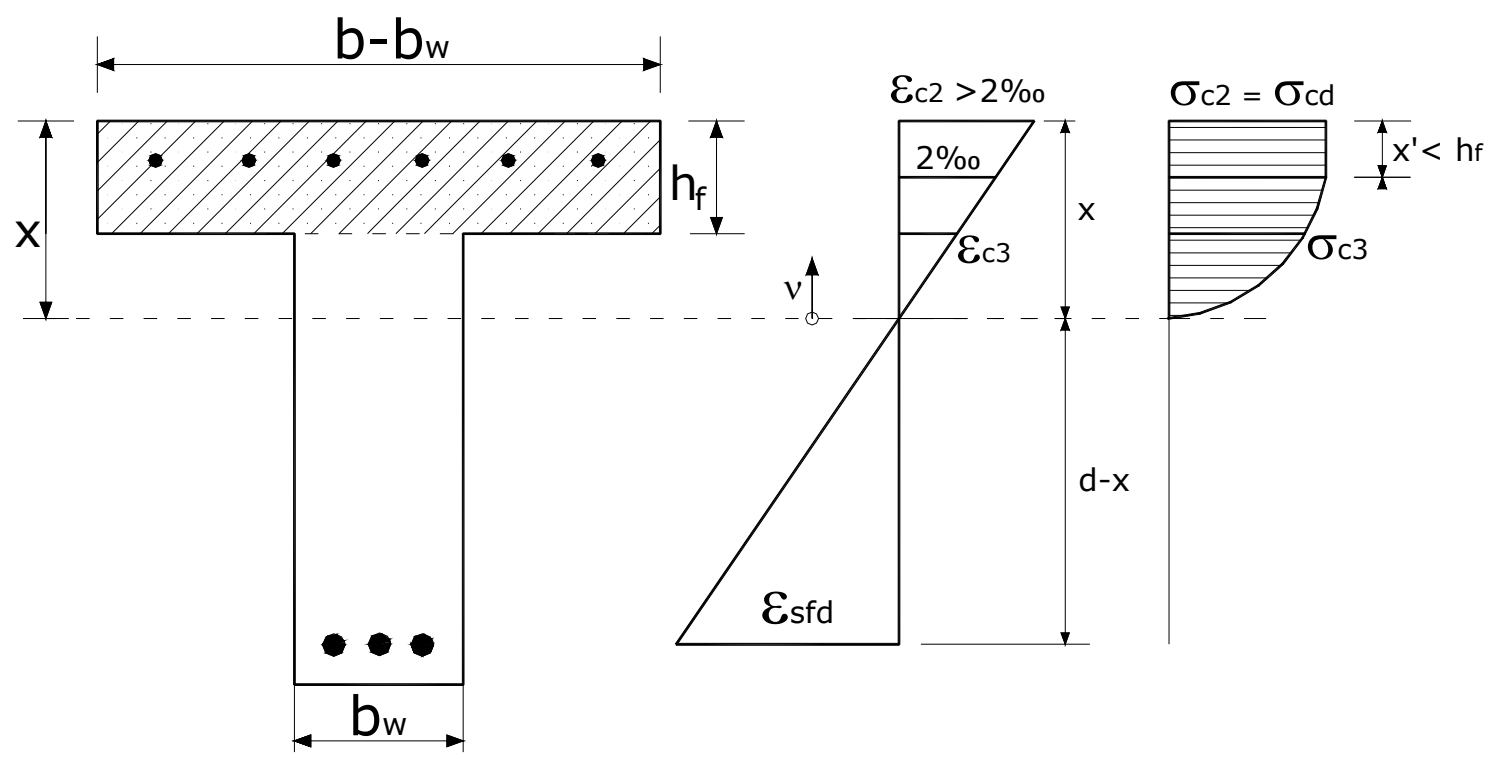

Figura A.11 - Diagrama das tensões de compressão na mesa parábolo-retângulo.

Este caso será sub-dividido em dois outros.

$2^{o}$ Caso a: Se $x$ estiver no intervalo $\frac{d}{6}<x<0,259 \cdot d$, a deformação no aço $\varepsilon_{s t}$ continuará valendo $10 \%$. Considerando $x^{\prime}$ a altura parcial da mesa onde a distribuição das tensões se tornou retangular, Figura A.11, do diagrama de deformações resulta a seguinte relação:

$\frac{x-x^{\prime}}{2}=\frac{d-x}{10}$
$x^{\prime}=\frac{6 \cdot x-d}{5}$

No limite com o $3^{\circ}$ caso (diagrama de tensões retangular na mesa), tem-se $x^{\prime}=h_{f}$ de modo que os limites do caso 2 serão dados pelas desigualdades mostradas na eq.(A.31).

$\frac{d}{6}<x<\frac{d}{6}+0,833 \cdot h_{f}$ 
Conforme a Figura A.11 e supondo que se atenda à eq.(A.31), as relações da eq.(A.30) e eq.(A.24) são válidas. Deste modo, a resultante $R_{c c f}$ é expressa por:

$$
R_{c c f}=\left(b-b_{w}\right) \cdot \int_{x-h_{f}}^{x-x^{\prime}} \sigma_{c}^{\prime} \cdot d v+\left(b-b_{w}\right) \sigma_{c d} \cdot x^{\prime}
$$

Integrando a equação acima, onde $\sigma_{c}^{\prime}$ é dado pela eq.(A.3), $\varepsilon^{\prime}{ }_{c}$ pela eq.(A.23) e $\varepsilon_{c 2}$ eq.(A.24), o valor de $R_{c c f}$ resulta em:

$$
R_{c c f}=\left(b-b_{w}\right) \cdot \sigma_{c d} \cdot\left\{\begin{array}{l}
x^{\prime}+\frac{5}{d-x} \cdot\left[x^{\prime 2}+2 x \cdot\left(h_{f}-x^{\prime}\right)-h_{f}^{2}\right]- \\
-\frac{25}{3 \cdot(d-x)^{2}} \cdot\left[h_{f}^{3}-x^{\prime 3}+3 x \cdot\left(x^{\prime 2}-h_{f}^{2}\right)+3 x^{2} \cdot\left(h_{f}-x^{\prime}\right)\right]
\end{array}\right\}
$$

Para a determinação da posição de $R_{c c f}$, tomando os momentos em relação à posição da linha neutra, tem-se:

$$
R_{c c f} \cdot z_{G f}^{\prime}=\left(b-b_{w}\right) \cdot \int_{x-h_{f}}^{x-x^{\prime}} \sigma_{c}^{\prime} \cdot v \cdot d v+\left(b-b_{w}\right) \cdot \sigma_{c d} \cdot x^{\prime} \cdot\left(x-\frac{x^{\prime}}{2}\right)
$$

Desenvolvendo a eq.(A.34), encontra-se a distância $z_{G f}^{\prime}$ que é expressa por:

$$
\begin{aligned}
z_{G f}^{\prime}= & \left\{\begin{array}{l}
x^{\prime}\left(x-\frac{x^{\prime}}{2}\right)+\frac{10}{3(d-x)}\left[3 x^{2}\left(h_{f}-x^{\prime}\right)+3 x\left(x^{2}-h_{f}{ }^{2}\right)+h_{f}{ }^{3}-x^{\prime 3}\right]- \\
-\frac{25}{4(d-x)^{2}}\left[4 x^{3}\left(h_{f}-x^{\prime}\right)+6 x^{2}\left(x^{\prime 2}-h_{f}{ }^{2}\right)+4 x\left(h_{f}{ }^{3}-x^{\prime 3}\right)+x^{\prime 4}-h_{f}{ }^{4}\right]
\end{array}\right\} \div \\
& \div\left\{x^{\prime}+\frac{5}{d-x}\left[x^{\prime 2}+2 x\left(h_{f}-x^{\prime}\right)-h_{f}{ }^{2}\right]-\frac{25}{3(d-x)^{2}}\left[\begin{array}{l}
h_{f}{ }^{3}-x^{\prime 3}+3 x\left(x^{\prime 2}-h_{f}{ }^{2}\right)+ \\
3 x^{2}\left(h_{f}-x^{\prime}\right)
\end{array}\right]\right\}
\end{aligned}
$$

$2^{o}$ Caso b: Se $x \geq 0,259 \cdot d$, a deformação $\varepsilon_{s t}$ será menor que $10 \%$, mas $\varepsilon_{c 2}$ tornar-se-á constante e igual a 3,5\%, Figura A.11. Resulta do diagrama de deformações a relação expressa a seguir: 
$\frac{x-x^{\prime}}{2}=\frac{x}{3,5}$
$x^{\prime}=\frac{3}{7} \cdot x$

No limite com o $3^{\circ}$ caso, $x^{\prime}=h_{f}$, virá: $x=\frac{7}{3} \cdot h_{f}$. Portanto, estará também no caso 2 quando a eq.(A.37) for satisfeita.

$0,259 \cdot d \leq x<\frac{7}{3} \cdot h_{f}$

Conforme Figura A.11, supondo que se atenda à eq.(A.37), são válidas as relações da eq.(A.36), uma vez que $\varepsilon_{c 2}=c t e=3,5 \%$. No trecho parabólico $\sigma_{c}{ }_{c}$ é dado pela eq.(A.3). A resultante $R_{c c f}$ é dada pela eq.(A.32) e sua posição pela eq.(A.34), levando em conta a eq.(A.38) os valores de $R_{c c f}$ e $z_{G f}^{\prime}$ são mostrados a seguir:

$\varepsilon^{\prime}{ }_{c}=\varepsilon_{c 2} \cdot \frac{v}{x}=3,5 \cdot \frac{v}{x} \quad(\% 0)$

$R_{c c f}=\left(b-b_{w}\right) \cdot \sigma_{c d} \cdot\left\{\begin{array}{l}x^{\prime}+\frac{3,5}{2 x} \cdot\left[x^{\prime 2}+2 x \cdot\left(h_{f}-x^{\prime}\right)-h_{f}{ }^{2}\right]- \\ -\frac{3,5^{2}}{12 x^{2}} \cdot\left[h_{f}{ }^{3}-x^{\prime 3}+3 x \cdot\left(x^{\prime 2}-h_{f}{ }^{2}\right)+3 x^{2} \cdot\left(h_{f}-x^{\prime}\right)\right]\end{array}\right\}$

$\begin{aligned} z_{G f}^{\prime} & =\left\{\begin{array}{l}x^{\prime}\left(x-\frac{x^{\prime}}{2}\right)+\frac{3,5}{3 x}\left[3 x^{2}\left(h_{f}-x^{\prime}\right)+3 x\left(x^{2}-h_{f}^{2}\right)+h_{f}^{3}-x^{\prime 3}\right]- \\ -\frac{3,5^{3}}{16 x^{2}}\left[4 x^{3}\left(h_{f}-x^{\prime}\right)+6 x^{2}\left(x^{\prime 2}-h_{f}{ }^{2}\right)+4 x\left(h_{f}^{3}-x^{\prime 3}\right)+x^{\prime 4}-h_{f}{ }^{4}\right.\end{array}\right\} \div \\ & \div\left\{x^{\prime}+\frac{3,5}{2 x}\left[x^{\prime 2}+2 x\left(h_{f}-x^{\prime}\right)-h_{f}^{2}\right]-\frac{3,5}{12 x^{2}}\left[\begin{array}{l}h_{f}{ }^{3}-x^{\prime 3}+3 x\left(x^{\prime 2}-h_{f}{ }^{2}\right)+ \\ 3 x^{2}\left(h_{f}-x^{\prime}\right)\end{array}\right]\right\}\end{aligned}$

\section{A.3.1.3 $3^{\circ}$ Caso}

O diagrama das tensões de compressão na mesa é retangular. 


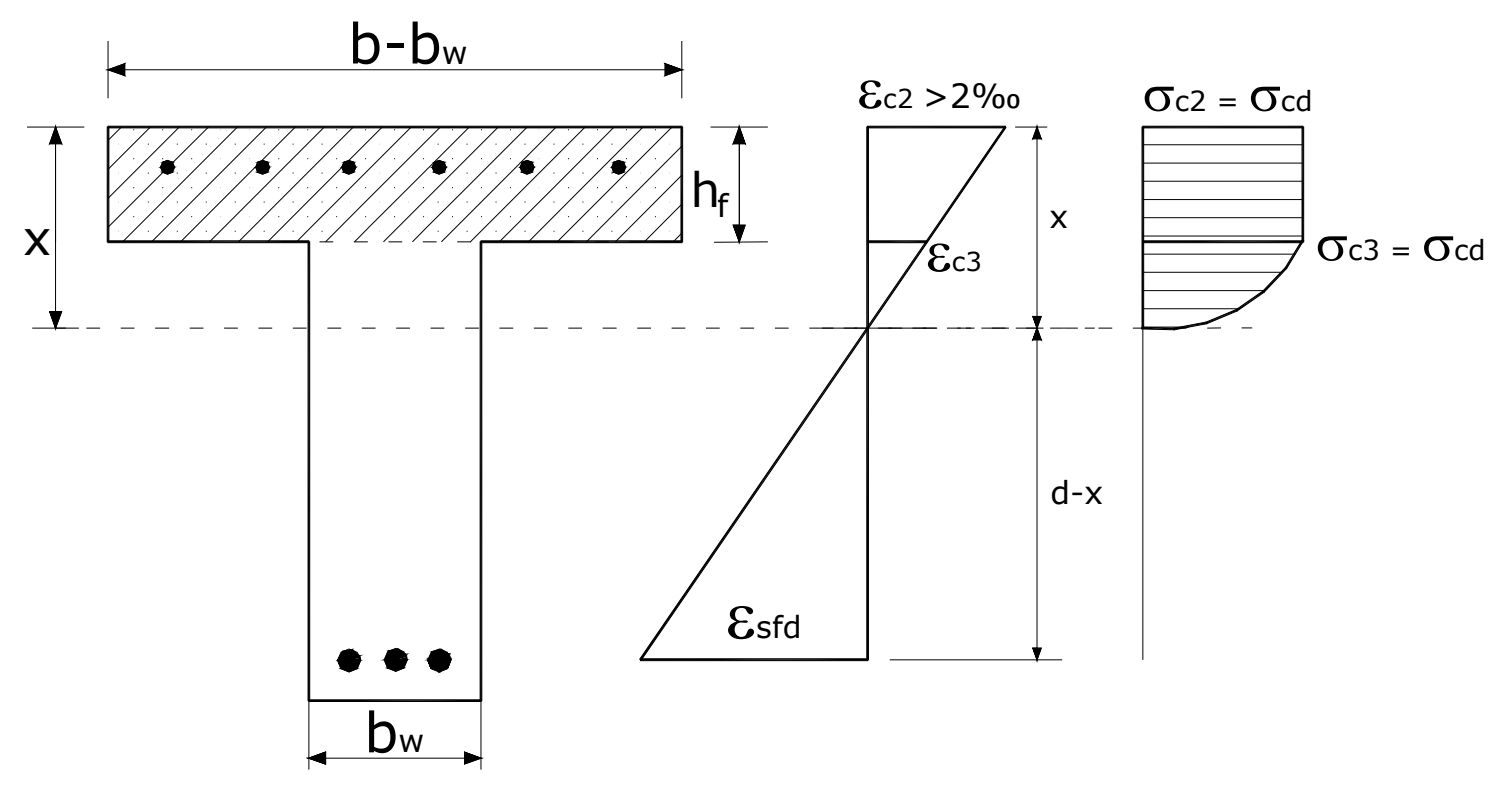

Figura A.12 - Diagrama das tensões de compressão na mesa retangular.

De acordo com o exposto, este caso ocorre quando a eq.(A.41) é satisfeita.

$\frac{d}{6}+0,833 \cdot h_{f}<x<0,259 \cdot d$

A resultante $R_{c c f}$ e sua respectiva posição são dadas pelas seguintes expressões:

$R_{c c f}=\left(b-b_{w}\right) \cdot \sigma_{c d} \cdot h_{f}$

$z_{G f}^{\prime}=x-\frac{h_{f}}{2}$

\section{A.3.2 Equações de equilíbrio}

São duas as equações de equilíbrio, uma referente às forças internas solicitantes e a outra aos momentos dessas forças em relação a profundidade da linha neutra. As forças internas atuantes na seção do tipo "T", Figura A.8, com a respectiva ação externa atuante; neste caso, momento fletor, resultam nas seguintes equações de equilíbrio. 


$$
\begin{aligned}
& \sum N=0 \quad \rightarrow \quad R_{s t}=R_{c c f}+R_{c c n}+R_{s c} \\
& \sum M^{L N}=0 \rightarrow M=R_{s t} \cdot(d-x)+R_{s c}\left(x-d^{\prime}\right)+R_{c c f} \cdot z^{\prime}{ }_{G f}+R_{c c n} \cdot z^{\prime}{ }_{G}
\end{aligned}
$$

sendo:

$$
\begin{aligned}
& R_{c c f} \text { força resistente à compressão do concreto proveniente da contribuição } \\
& \text { da mesa; } \\
& \text { força resistente à compressão do concreto proveniente da contribuição } \\
& \text { da nervura, calculada conforme a seção retangular; }
\end{aligned}
$$

\section{A.3.3 Programa no software MathCad}

Com as expressões mostradas acima foi desenvolvido o programa para dimensionamento de seção "T" no software MathCad, mostrado a seguir.

\section{Rotina de dimensionamento - FLEXÃO SIMPLES \\ SEÇÃO T} simples.

Rotina de dimensionamento de seção T de concreto armado submetida a flexão

Foi considerado diagrama parábolo-retângulo para o concreto e diagrama bilinear para o aço.

Domínios de verificação 2 - 3 - 4.

Obs: Os valores que estão destacados em verdesão atribuidos ao dimensionamento e em amarelo os calculados.
Autor: Geilson Márcio Albuquerque de Vasconcelos Engenheiro Civil Mestrando em Engenharia de Estruturas Escola de Engenharia de São Carlos - EESC Universidade de São Paulo - USP

Orientador: Márcio Roberto Silva Corrêa

Data: Junho de 2004

\section{Dados de entrada}

Transformação de unidades

Resistência característica à compressão do concreto fck $:=30 \mathrm{MPa}$

Resistência característica do aço fyk $:=500 \mathrm{MPa}$

Altura da seção transversal "T" 
Altura da mesa da seção transversal "T"

Altura do útil da seção transversal "T"

Largura da mesa da seção transversal "T"

Largura da nervura (alma) da seção transversal "T"

Distância do centróide da armadura comprimida à face da região comprimida

Módulo de Elasticidade do aço

$$
\mathrm{hf}:=12 \mathrm{~cm}
$$$$
\mathrm{d}:=47 \mathrm{~cm}
$$$$
\mathrm{b}:=100 \mathrm{~cm}
$$$$
\mathrm{bw}:=15 \mathrm{~cm}
$$$$
\mathrm{d} 1:=3 \mathrm{~cm}
$$

Es $:=210000 \mathrm{MPa}$

OBS: Para o progrma fazer uma análise como seção retangular deve-se considerar:

- Largura da mesa do elemento estrutural (b) igual a largura da nervura (bw) $->b=b w$.

- Armadura comprimida (porta estribos)

Número de barras da armadura comprimida

$\mathrm{Nsc}:=4$

Diâmetro da barra da armadura comprimida

Dsc $:=6.3 \mathrm{~mm}$

- Momento atuante

Momento atuante na seção transversal

$\mathrm{M}:=189.00 \mathrm{kN} \cdot \mathrm{m}$

- Cálculo da área de armadura

Armadura comprimida (porta estribo)

Aspe $=1.247 \mathrm{~cm}^{2}$

\section{Dimensionamento da armadura}

- Coeficientes ponderadores das resistências $\left(\gamma_{c}, \gamma_{s}\right.$ ou $\gamma_{c R}$ e $\left.\gamma_{s R}\right)$

Concreto

Aço

- Características Mecânicas

Dquacionamento

\section{Estimativa Inicial}

$\mathrm{x}:=1 \mathrm{~cm} \quad$ As $:=1 \mathrm{~cm}^{2}$

Resolução do sistema

$$
\text { As }=9.604 \mathrm{~cm}^{2} \quad \mathrm{x}=4.821 \mathrm{~cm}
$$

Dimites dos domínios

$$
\text { Dominio = "Dominio 2" }
$$




\section{Ruptura = "Ruptura do aço sem ruptura à compressão do concreto"}

- Deformação nos materiais

\section{Concreto}

\section{Armadura tracionada}

Armadura comprimida

Deformação na tensão de escoamento da armadura tracionada

$$
\operatorname{ccc}(\mathrm{x})=1.143 \times 10^{-3}
$$

$$
\varepsilon s t(\mathrm{x})=0.01
$$

$$
\operatorname{Esc}(\mathrm{x})=4.318 \times 10^{-4}
$$

$$
\text { Eyd }=2.07 \times 10^{-3}
$$




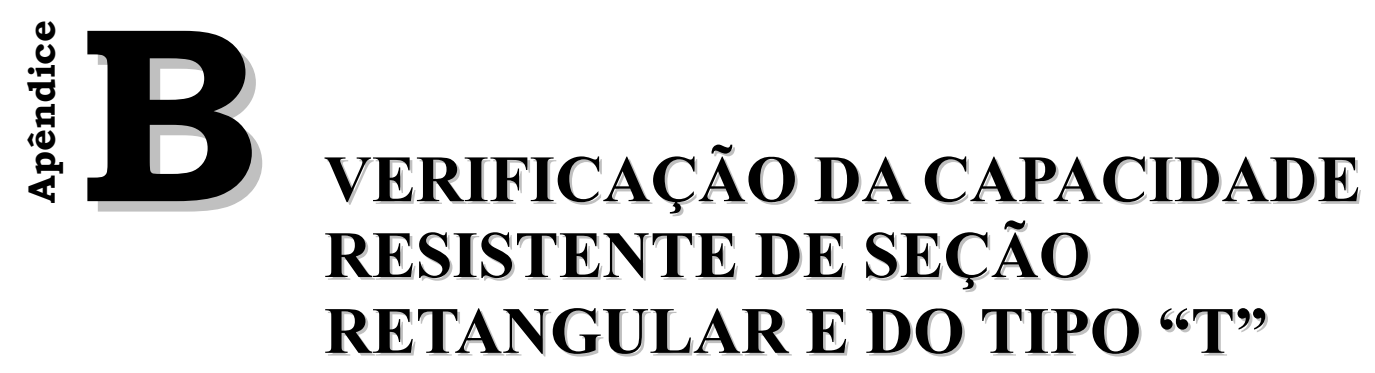

\section{B.1 Considerações gerais}

Neste apêndice são mostrados os programas que verificam a capacidade resistente de seção retangular e seção do tipo " $\mathrm{T}$ " de peças de concreto armado. O equacionamento, as hipóteses e considerações empregadas para o seu desenvolvimento são as mesmas que o apêndice de dimensionamento (Apêndice A), portanto, não foram mostradas. Assim, o programa desenvolvido no software MathCad para verificação da capacidade resistente de peças de concreto armado submetidas a esforços de flexão normal simples é apresentado sem muitos comentários.

No dimensionamento, como comentado anteriormente, dados os esforços internos solicitantes, procuram-se as dimensões da seção transversal e a armadura necessária. $\mathrm{Na}$ verificação resistente, ao contrário, tanto as armaduras como as dimensões da seção são conhecidas, procurando-se os esforços internos solicitantes últimos ou admissíveis. 


\section{B.2 Verificação da capacidade resistente de seção retangular}

A nomenclatura utilizada foi a mesma que no apêndice de dimensionamento. $\mathrm{O}$ programa desenvolvido no software MathCad de verificação da capacidade resistente para seção retangular é mostrada a seguir. O programa é apresentado de forma explicativa, de modo que, não proporcione dúvidas ao usuário.

\section{Rotina de verficação da capacidade resistente - FLEXÃO SIMPLES \\ SEÇÃO RETANGULAR}

Rotina de cálculo que determina o valor do momento resistente de seção retangular de concreto armado submetida a flexão simples.

Foi considerado diagrama parábolo-retângulo para o concreto e diagrama bilinear para o aço.

Domínios de verificação 2 - 3 - 4 .

Obs: Os valores que estão destacados em verdesão atribuidos ao dimensionamento e em amarelo os calculados.

\section{Autor: Geilson Márcio Albuquerque de Vasconcelos Engenheiro Civil Mestrando em Engenharia de Estruturas \\ Escola de Engenharia de São Carlos - EESC \\ Universidade de São Paulo - USP}

Orientador: Márcio Roberto Silva Corrêa

Data: Junho de 2004

\section{Dados de entrada}

Transformação de unidades

Resistência característica à compressão do concreto

fck $:=30.0 \mathrm{MPa}$

Resistência característica do aço

fyk $:=500 \mathrm{MPa}$

Altura da seção transversal retangular

$\mathrm{h}:=50 \mathrm{~cm}$

Altura do útil da seção transversal retangular

$\mathrm{d}:=47 \mathrm{~cm}$

Largura da seção transversal retangular

Distância do centróide da armadura comprimida

à face da região comprimida

Módulo de Elasticidade do aço bw := $15 \mathrm{~cm}$

$\mathrm{d} 1:=3.0 \mathrm{~cm}$

Es $:=210000 \mathrm{MPa}$ 
- Armadura tracionada (arm. principal)

Número de barras da armadura tracionada

Nst $:=4.0$

Diâmetro da barra da armadura tracionada

Dst $:=19.150 \mathrm{~mm}$

- Armadura comprimida (porta estribos)

Número de barras da armadura comprimida

Nsc $:=2$

Diâmetro da barra da armadura comprimida

Dsc $:=6.3 \mathrm{~mm}$

Dálculo das áreas das armaduras

Armadura tracionada (arm. principal)

As $=11.521 \mathrm{~cm}^{2}$

Armadura comprimida (porta estribo)

Aspe $=0.623 \mathrm{~cm}^{2}$

\section{Verificação do Momento Resistente}

- Coeficientes ponderadores das resistências $\left(\gamma_{c}, \gamma_{s}\right.$ ou $\gamma_{c R}$ e $\left.\gamma_{s R}\right)$

Concreto

$\gamma \mathrm{c}:=1.00$

Aço

$\gamma \mathrm{s}:=1.00$

Propriedades Mecânicas

Equacionamento

\section{Estimativa Inicial}

$$
\mathrm{x}:=1 \mathrm{~cm} \quad \mathrm{M}:=1 \mathrm{kN} \cdot \mathrm{m}
$$

- Resolução do sistema

$$
\mathrm{M}=229.923 \mathrm{kN} \cdot \mathrm{m} \quad \mathrm{x}=17.597 \mathrm{~cm}
$$

DLimites dos domínios

Dominio = "Dominio 3 - Seção subarmada"

Ruptura = "Ruptura do concreto e escoamento do aço"

- Deformação dos materiais

Concreto

Armadura tracionada

Armadura comprimida

Deformação na tensão de escoamento da armadura tracionada

$$
\operatorname{ccc}(\mathrm{x})=3.5 \times 10^{-3}
$$$$
\operatorname{sst}(\mathrm{x})=5.848 \times 10^{-3}
$$$$
\operatorname{Esc}(x)=2.903 \times 10^{-3}
$$

Eyd $=2.381 \times 10^{-3}$ 


\section{B.3 Verificação da capacidade resistente de seção " $T$ "}

O programa de verificação da capacidade resistente de seção do tipo "T" é mostrado a seguir. Este programa permite também que se analise uma seção retangular. Para isso, a largura da mesa deve ser igual a largura da nervura.

\section{Rotina de verficação da capacidade resistente - FLEXÃO SIMPLES}

\section{SEÇÃO T}

Rotina de cálculo que determina o valor do momento resistente de seção T de concreto armado submetida a flexão simples.

Foi considerado diagrama parábolo-retângulo para o concreto e diagrama bilinear para o aço.

Domínios de verificação 2 - 3 - 4 .

Obs: Os valores que estão destacados em verdesão atribuidos ao dimensionamento e em amarelo os calculados.

Autor: Geilson Márcio Albuquerque de Vasconcelos Engenheiro Civil Mestrando em Engenharia de Estruturas Escola de Engenharia de São Carlos - EESC Universidade de São Paulo - USP

Orientador: Márcio Roberto Silva Corrêa

Data: Junho de 2004

\section{Dados de entrada}

Dransformação de unidades

Resistência característica à compressão do concreto

fck $:=30 \mathrm{MPa}$

Resistência característica do aço

fyk $:=500 \mathrm{MPa}$

Altura da seção transversal "T"

$\mathrm{h}:=50 \mathrm{~cm}$

Altura da mesa da seção transversal "T"

$\mathrm{hf}:=12 \mathrm{~cm}$

Altura do útil da seção transversal "T"

$\mathrm{d}:=47 \mathrm{~cm}$

Largura da mesa da seção transversal "T"

$\mathrm{b}:=100 \mathrm{~cm}$

Largura da nervura (alma) da seção transversal "T"

bw $:=15 \mathrm{~cm}$

Distância do centróide da armadura comprimida

à face da região comprimida

$\mathrm{d} 1:=3 \mathrm{~cm}$

Módulo de Elasticidade do aço

Es $:=210000 \mathrm{MPa}$ 
OBS: Para o progrma fazer uma análise como seção retangular deve considerar: - Largura da mesa do elemento estrutural (b) igual a largura da nervura (bw) -> b = bw.

- Armadura tracionada (arm. principal)

Número de barras da armadura tracionada

Diâmetro da barra da armadura tracionada

$$
\text { Dst }:=16.0 \mathrm{~mm}
$$

- Armadura comprimida (porta estribos)

Número de barras da armadura comprimida

$$
\text { Nsc }:=2
$$

Diâmetro da barra da armadura comprimida

Dsc $:=6.3 \mathrm{~mm}$

- Cálculo das áreas das armaduras

Armadura tracionada (arm. principal)

$$
\text { As }=12.064 \mathrm{~cm}^{2}
$$

Armadura comprimida (porta estribo)

$$
\text { Aspe }=0.623 \mathrm{~cm}^{2}
$$

\section{Veficação do momento resistente}

- Coeficientes ponderadores das resistências $\left(\gamma_{c}, \gamma_{s}\right.$ ou $\gamma_{c R}$ e $\left.\gamma_{s R}\right)$

Concreto

Aço

$$
\gamma \mathrm{c}:=1.40
$$

$\gamma \mathrm{s}:=1.15$

Dropriedades Mecânicas

Equacionamento

\section{Estimativa Inicial}

$$
\mathrm{x}:=1 \mathrm{~cm} \quad \mathrm{M}:=1 \mathrm{kN} \cdot \mathrm{m}
$$

Resolução do sistema

$$
\mathrm{M}=236.147 \mathrm{kN} \cdot \mathrm{m} \quad \mathrm{x}=5.497 \mathrm{~cm}
$$

DLimites dos domínios

Dominio = "Dominio 2"

LN = "Linha Neutra na MESA"

Ruptura = "Ruptura do aço sem ruptura à compressão do concreto" 
- Deformação nos materiais

Concreto

\section{Armadura tracionada}

Armadura comprimida

Deformação na tensão de escoamento da armadura tracionada $\operatorname{scc}(\mathrm{x})=1.324 \times 10^{-3}$

$\operatorname{Est}(\mathrm{x})=0.01$

$\operatorname{ssc}(\mathrm{x})=6.016 \times 10^{-4}$

Eyd $=2.07 \times 10^{-3}$ 